STONE CENTER ON SOCIO-ECONOMIC INEQUALITY

WORKING PAPER SERIES

No. 44

Rising Top-Income Persistence in Australia:

Evidence from Income Tax Data

\author{
Nicolas Hérault \\ Dean Hyslop \\ Stephen P. Jenkins \\ Roger Wilkins
}

September 2021

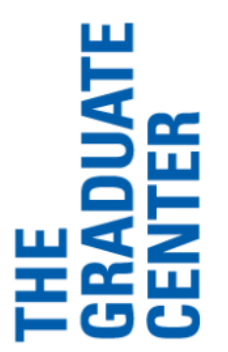




\title{
Rising top-income persistence in Australia: evidence from income tax data
}

\author{
Nicolas Hérault \\ (University of Melbourne, nherault@unimelb.edu.au) \\ Dean Hyslop \\ (Motu Research, dean.hyslop@motu.org.nz) \\ Stephen P. Jenkins \\ (LSE and IZA, s.jenkins@1se.ac.uk) \\ Roger Wilkins \\ (University of Melbourne and IZA, r.wilkins@unimelb.edu.au)
}

2 September 2021

\begin{abstract}
We use a new Australian longitudinal income tax dataset, Alife, covering 1991-2017, to examine levels and trends in the persistence in top-income group membership, focussing on the top $1 \%$. We summarize persistence in multiple ways, documenting levels and trends in rates of remaining in top-income groups; re-entry to the top; the income changes associated with top-income transitions; and we also compare top-income persistence rates for annual and 'permanent' incomes. Regardless of the perspective taken, top-income persistence increased markedly over the period, with most of the increase occurring in the mid-2000s and early 2010s. In the mid- to late-2010s, Australian top-income persistence rates appear to have been near the top of the range of tax-data estimates for other countries. Using univariate breakdowns and multivariate regression, we show that the rise in top-income persistence in Australia was experienced by many population subgroups.
\end{abstract}

Keywords: top incomes, income mobility, top-income persistence JEL classification codes: D31, I31, C81

Acknowledgements

We thank Andrew Leigh and participants at the Tax and Transfer Policy Institute's ALife Conference in March 2021 for comments on an earlier version of this paper. 


\section{Introduction}

There is continuing interest in top incomes, especially in information about levels and trends of the share of total income received by the top $1 \%$ or other top-income groups such as the top $0.1 \%$. Long time-series of estimates of top income shares now exist for many countries: see the WID.World portal (https://wid.world/) for an extensive collection from around the world. However, much less is known about intertemporal persistence in top-income group membership. This is a notable gap because how we judge estimates of yearly top income shares depends on how much turnover there is at the top. We are more likely to tolerate a top $1 \%$ income share of $10 \%$ if different individuals form the top $1 \%$ each year than if the same people are always at the top. The greater mobility in the former case means greater equality in the opportunity to reach the top of the income distribution than the latter case. The latter case signals an entrenched elite and greater inequality of permanent income. In this paper, we present new evidence about top-income persistence levels and trends using high-quality personal income tax data for Australia.

The advantages of using income tax data for studying top-income mobility are the same as the advantages for studying income inequality in yearly cross-sections. By comparison with household survey data, the tax data suffer much less from top-income undercoverage (whether arising from unit- or item-nonresponse) and provide significantly larger sample sizes, meaning that top-income group membership can be characterised more accurately. The longitudinal data we use in this paper, from the Australian Longitudinal Information files ('Alife') produced by the Australian Tax Office (ATO), have these desirable qualities. Alife also contains information about the characteristics of individuals, and so we are able to examine differences in top-income persistence between different population subgroups.

We make four contributions. First, compared to the majority of top-income mobility studies based on tax data, our analysis is more closely linked to the mainstream literature about top-income shares. That literature refers to income shares held by different groups among the population of all adults, whereas many prominent studies of top-income mobility have instead used data about tax filers - a subset of all adults (mostly individuals who are liable for income taxation). Table 1 (overleaf) demonstrates our point. 
Table 1. Studies of top-income persistence based on personal income tax administrative record data

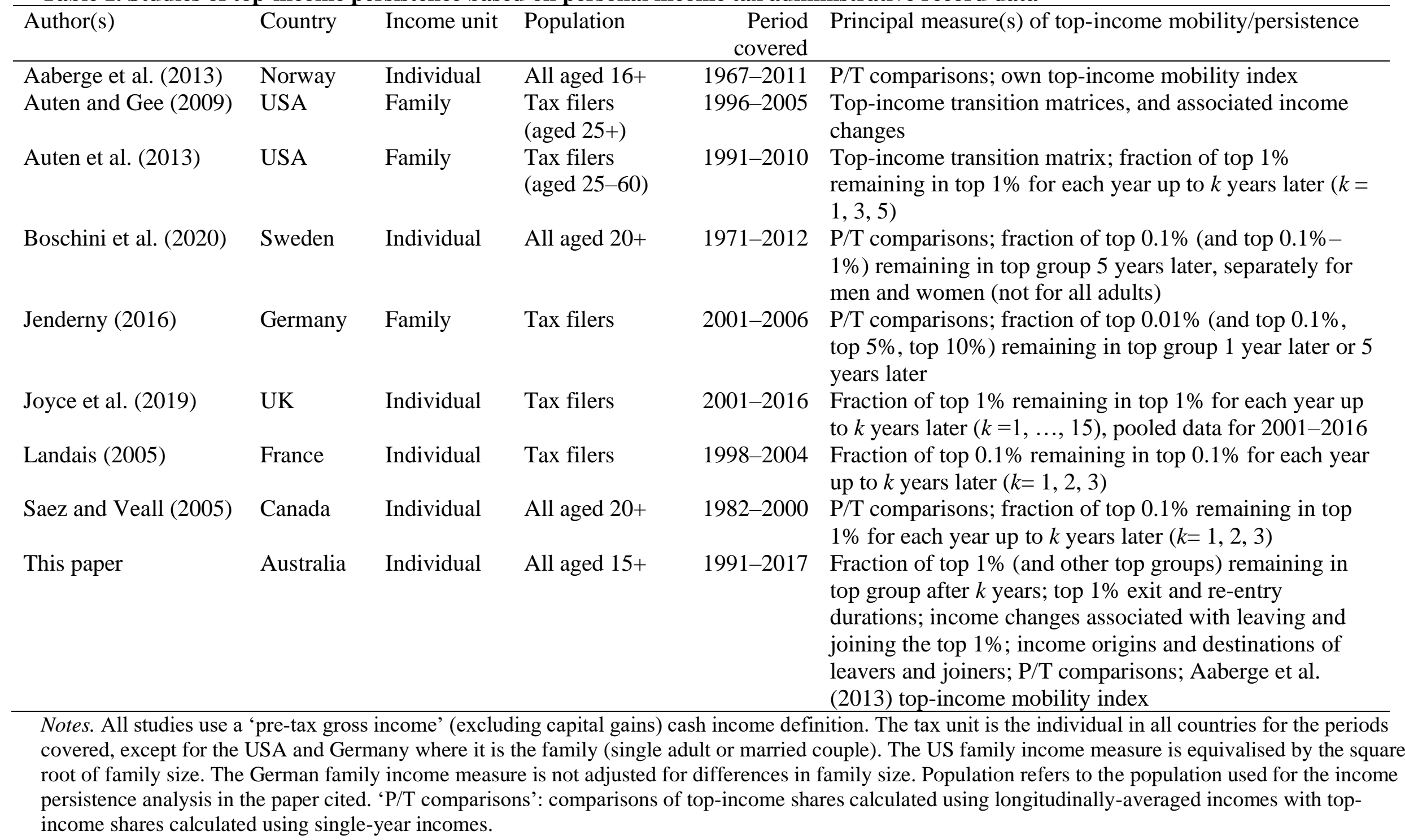


Table 1 summarises the key features of eight earlier studies of top-income persistence and contrasts the current study with them. We restrict attention to studies based on administrative record data (typically income tax records) rather than survey data for the reasons given earlier. ${ }^{1}$ Only three earlier studies - Aaberge et al. (2013) for Norway, Boschini et al. (2020) for Sweden, and Saez and Veall (2005) for Canada - have defined top income groups with reference to the total adult population, albeit with a range of lower age-cut offs to define that population.

Our second contribution is to provide a more detailed description of the top-income mobility process than earlier tax-data-based studies. Previous work has taken two main approaches to summarizing persistence, as the far-right-hand column of Table 1 indicates. The first and most common approach, exemplified by, for example, Auten et al. (2013) for the USA, is to take the individuals who belong to the top-income group of interest in a specific year and calculate the fraction of these individuals who remain in the same top-income group in subsequent years. That is, the focus is on top-income survival rates and their trends over time. This approach ignores the fact that turnover in top-income group membership also arises because non-top-income individuals join the top-income group. Therefore, distinctively, we also document top-income re-entry rates. In addition, following Auten and Gee (2009) and Auten et al. (2013), we provide information about the income group destinations of topincome leavers, and the origins of top-income joiners, using graphical summaries of transition matrices, supplementing these pictures with discussion of the income changes that accompany the top-income mobility. In each case, we document how patterns have changed over time.

The second approach in previous literature to summarizing top-income persistence is to take a window $T$ years long and to compare the top-income shares of incomes longitudinally-averaged over the $T$ years ('permanent' shares) with (averaged) yearly topincome shares ('transitory' shares). The greater the ratio of the former to the latter, the more top-income persistence there is. This is an application of Shorrocks' (1978) approach to income immobility in which a top-income share is used as the inequality index rather than the Gini coefficient or other indices based on all incomes. Aaberge et al.'s (2013) top-income mobility index encapsulates this idea. Three earlier studies based on tax data have taken the permanent/transitory approach: see the citations to ' $\mathrm{P} / \mathrm{T}$ comparisons' in Table 1 . We apply

\footnotetext{
${ }^{1}$ Table 1 cites the leading studies on top-income mobility but is not comprehensive. In particular, we do not consider studies of mobility in labour earnings (see, e.g., Kopczuk et al. 2010 or Martinez 2017). Some other earlier research about top-income mobility is cited by the studies listed in Table 1.
} 
this approach to our Australian data, using moving windows to describe levels and trends in top-income persistence.

Our third contribution arises from the nature of the specific application - to Australia and covering the 25-year period from 1991 through 2017. The long time span means that we can study trends in persistence as well as levels, and through to a year well after the Global Financial Crisis. The data used by four of the studies cited in Table 1 cover only up to the mid-2000s or earlier. Joyce et al. (2019), for the UK have data covering 2001-2016 but their analysis of top-income persistence is relatively brief (using only one approach) and they examine tax filers rather than all adults. The studies by Aaberge et al. (2013) for Norway, and Boschini et al. (2020) for Sweden, are more comparable to ours because they use data for all adults as we do, and the data span around 40 years in each case though end in the early 2010s. Our analysis uses data covering a long period too but, unlike the two Nordic studies, we employ multiple approaches to the measurement of top-income persistence in a single study. At the same time, by looking at Australia, we provide a new Anglo country comparison to these two Nordic countries. In all three nations, the share of total income held by the top $1 \%$ was declining prior to the mid- to late-1970s but increased thereafter, albeit at different rates. In around 1980, the 1\% share was around 5\% in Australia, Norway, and Sweden but, by the mid-2000s, was around 7\% to $8 \%$ in Australia and Sweden and around $11 \%$ to $12 \%$ in Norway. By comparison, the US top $1 \%$ share was around $17 \%$ at that time. (See Atkinson et al. 2011, Figures 8 and 10.) Although cross-national comparisons of top-income persistence are difficult to make because the various studies use different measures and cover different time periods, we are able to provide some new (but broad-brush) information about how trends in Australia compare with trends for a range of other countries.

Our fourth contribution is analysis of differences in top-income persistence across population subgroups. We provide not only breakdowns by principal income source and sex, but also regression-based analysis of the probabilities of remaining in the top $1 \%$ from one year to the next, and of entering the top $1 \%$, in which coefficients on the explanatory variables (e.g., age, principal income source, and federal state of residence) each vary by sex and time period.

We show that top-income persistence in Australia increased between 1991 and 2017, with most of the increase occurring in the mid-2000s and early 2010s. This picture arises whichever approach to assessing persistence we employ. By 2017, top-income persistence rates were similar for men and women, but women's rates were much lower at the start of the 1990s; their increase has therefore been greater. Also, the increase in top-income persistence 
is slightly larger if the principal income source is labour income rather than non-labour income. Our regression analysis indicates that rising top-income persistence among women helps account for the overall rise after adjusting for differences in other characteristics, but rising persistence among individuals aged 55+ years appears more clearly to contribute to the rise in overall persistence. Subject to caveats about comparability of measures and differences in time periods, top-income persistence levels in Australia in the mid- to late-2010s are towards the top of the range of estimates provided by the studies for other countries cited in Table 1. Comparability issues also bedevil cross-national comparisons of trends in persistence rates. However, despite differences in trends in yearly top-income shares, Australia and Norway both experienced marked increases in top-income persistence in the mid-2000s whereas Sweden - with similar top-income share trends to Australia - did not.

Our paper proceeds as follows. The Alife dataset is described in Section II. Section III documents levels and trends in top-income persistence using a range of perspectives. We focus on the top $1 \%$ as the top income group, but report robustness of estimates to various other 'top income' definitions ranging from top $10 \%$ to top $0.1 \%$. We examine turnover in the top $1 \%$ in more detail in Section IV, noting that changes in top $1 \%$ membership arise because people not in the top $1 \%$ experience an income rise sufficient to move their incomes above the $99^{\text {th }}$ percentile $(p 99)$ threshold or people in the top $1 \%$ experience an income fall sufficient to move them below the $p 99$ threshold. However, the effect on top income group membership also depends on the location of the top-income threshold relative to the incomes defining other income groups. How much top income mobility there is depends on how far apart the 'rungs of the ladder' are (where the rungs are the incomes demarcating income group boundaries). For someone outside the top $1 \%$, located at $p 95$ (say), an increase in real income of $\$ 10,000$ is more likely to lead to top income group membership if the gap between $p 95$ and $p 99$ is small rather than large. We provide information about the extent to which the top income rungs have been moving closer together or further apart, and about the income changes per se for those within the top income group and those on its fringes.

Section V investigates how top-income persistence differs across population subgroups. Our dataset allows us to look at the extent to which top-income group membership probabilities are related to sex, main source of income (labour income versus non-labour income), state of residence, and whether an individual has any self-employment income. In our regression analysis, we examine both the probabilities of remaining in the top $1 \%$ for an additional year (for those currently in top $1 \%$ ) and the probabilities of joining the top $1 \%$ (for 
individuals currently outside the group). Section VI contains a summary and conclusions. We provide additional estimates in Appendices A-F.

\section{Data}

We use the Alife longitudinal unit record dataset produced by the Australian Taxation Office (ATO), made available to researchers through a secure remote access facility. Alife is based on a $10 \%$ random sample of all tax filers observed by the ATO for tax years 1991 through 2017 and contains all the income tax records for these individuals over this period. ${ }^{2}$

In addition to detailed information on income components, deductions, rebates, offsets, and tax liabilities, ALife contains information on year of birth, sex, residential location and, for employed persons, occupation. The tax unit in Australia is the individual, and very little information is available about a tax filer's spouse (if present). For years in which an Alife-sampled individual did not file a tax return, Alife records the individual's information for those years as missing. ${ }^{3}$

Income totals and income components are not top coded, with one exception: in each year, the 24 largest 'employment termination' (redundancy) payments in the entire tax filer population are set equal to the level of the $25^{\text {th }}$-largest payment value. Between 1991 and 2017 , this represents an adjustment of between $\$ 8$ million and $\$ 57$ million in total and affected between 0 and 7 individuals in ALife each year (see Appendix A). All these individuals continue to belong to the top $0.5 \%$ of income recipients after this top coding, which means that the top coding does not affect estimates of transitions into and out of the top $1 \%$.

Our approach to examining top incomes using tax return data follows earlier work for Australia, notably Burkhauser et al. (2018), who in turn build on the work of Atkinson and Leigh (2007), and is consistent with approaches taken for many other countries (see, for

\footnotetext{
${ }^{2}$ We use the 2017 release of Alife, compiled in October 2019, by which time tax returns had been finalised for almost all people required to file a tax return for the 2017 tax year. (The Australian tax year runs from 1 July to 30 June. We refer to tax years according to the calendar year in which the tax year ended. For example, 1991 refers to the tax year running from 1 July 1990 to 30 June 1991.) Filing is compulsory for those with taxable income above the tax-free threshold. Many who earn less than the tax-free threshold also lodge a return to claim back tax withheld by their employer. The tax-free threshold was \$5,249 in 1991, \$5,400 from 1992 to 2000 , $\$ 6,000$ from 2001 to 2012 and \$18,200 from 2013 onwards. The ALife sample also includes people who never file a tax return that the ATO becomes aware of because of other contact with the government, for example through receipt of government benefits.

${ }^{3}$ Full details about ALife, including the variables available, are available at https://alife-research.app/.
} 
example, Morelli et al. 2015). The main income measure is annual gross taxable income exclusive of realised capital gains. Gross taxable income refers to taxable income before deductions, such as for work expenses and concessional superannuation contributions, and also before addition of tax credits such as dividend imputation credits. ${ }^{4} \mathrm{We}$ exclude taxable realised capital gains from the main analysis for reasons that are explained in detail by Burkhauser et al. (2015). Key among these reasons is that realised capital gains on assets held more than one year (excluding the family home) only became taxable from 1 July 1986, and only on assets acquired after 19 September 1985. This resulted in a steady rise in the share of realised capital gains entering the tax base from 1986, which would lead to spurious measured increases in top incomes if realised taxable capital gains were included. ${ }^{5}$

Australia has a system of individual-level taxation rather than the family-level taxation that exists in some countries (e.g., the USA and Germany). Analyses using Australian income tax data are therefore of the distribution of individual gross taxable income among individuals. Furthermore, since almost all tax filers are aged 15 or over, we examine distributions among individuals aged 15 and over. Consequently, we define top-income groups with reference to the total resident population aged 15 and over. ${ }^{6}$ Following Burkhauser et al. (2018), we derive top-income shares using income control totals from the household income account of the National Accounts rather than from ALife. ${ }^{7}$

Most of our analysis focuses on the top $1 \%$ of individuals aged $15+$, corresponding to the top 13,499 tax filers in ALife in 1991 and the top 20,290 tax filers in ALife in 2017. We also examine the top $0.1 \%$ and top $10 \%$, with most estimates for these groups reported in Appendices E and F respectively.

We begin by providing information about yearly top-income shares to provide a reference point for our analysis of top-income persistence. Figure 1 shows our Alife-based

\footnotetext{
${ }^{4}$ Since 1 July 1987 , Australia has had a system of dividend imputation allowing dividend recipients to claim tax credits for the imputed company tax paid on those dividends.

${ }^{5}$ Inclusion of taxable realised capital gains is problematic even absent changes over time in the share of capital gains that are taxed. Realised capital gains typically relate to a period longer than the annual time-frame over which other income sources are measured. In principle, it is all capital gains accrued over the year that should be included, not the taxable capital gains that happened to be realised in that year. Moreover, capital gains are not measured in the National Accounts, which are used to estimate the income 'control total'.

${ }^{6}$ We derive population control totals from ABS Catalogue No. 3101.0 (Australian Demographic Statistics), Table 59.

${ }^{7}$ We derive income control totals from the December 2019 release of the National Accounts. A given year's control total is equal to: Gross mixed income + Compensation of employees + Interest + Dividends + Workers' compensation + Social assistance benefits - Interest payable by unincorporated enterprises - Consumption of fixed capital - Employers' social contributions.
} 
estimates of the income shares of the top $0.1 \%$, top $1 \%$, and top $10 \%$ income groups by year over the period 1991-2017.

Figure 1 shows that the top $1 \%$ income share increased from $6.4 \%$ in 1991 to $9.5 \%$ in 2017. The increase largely occurred over the 1990 s, with the income share of the top $1 \%$ in 2017 approximately the same as in $2001 .^{8}$ The trends are broadly similar for the top $0.1 \%$ and top $10 \%$. The top $0.1 \%$ share rose from approximately $1.8 \%$ to $3 \%$ over the period but there was little change after 2001 . The top $10 \%$ share rose from approximately $28 \%$ to $35 \%$ but, in contrast to the top $1 \%$ and top $0.1 \%$ share, the top $10 \%$ share rose after the mid-2000s. ${ }^{9}$

Figure 1. Shares of total income held by the top 0.1\%, 1\%, and 10\%, 1991-2017

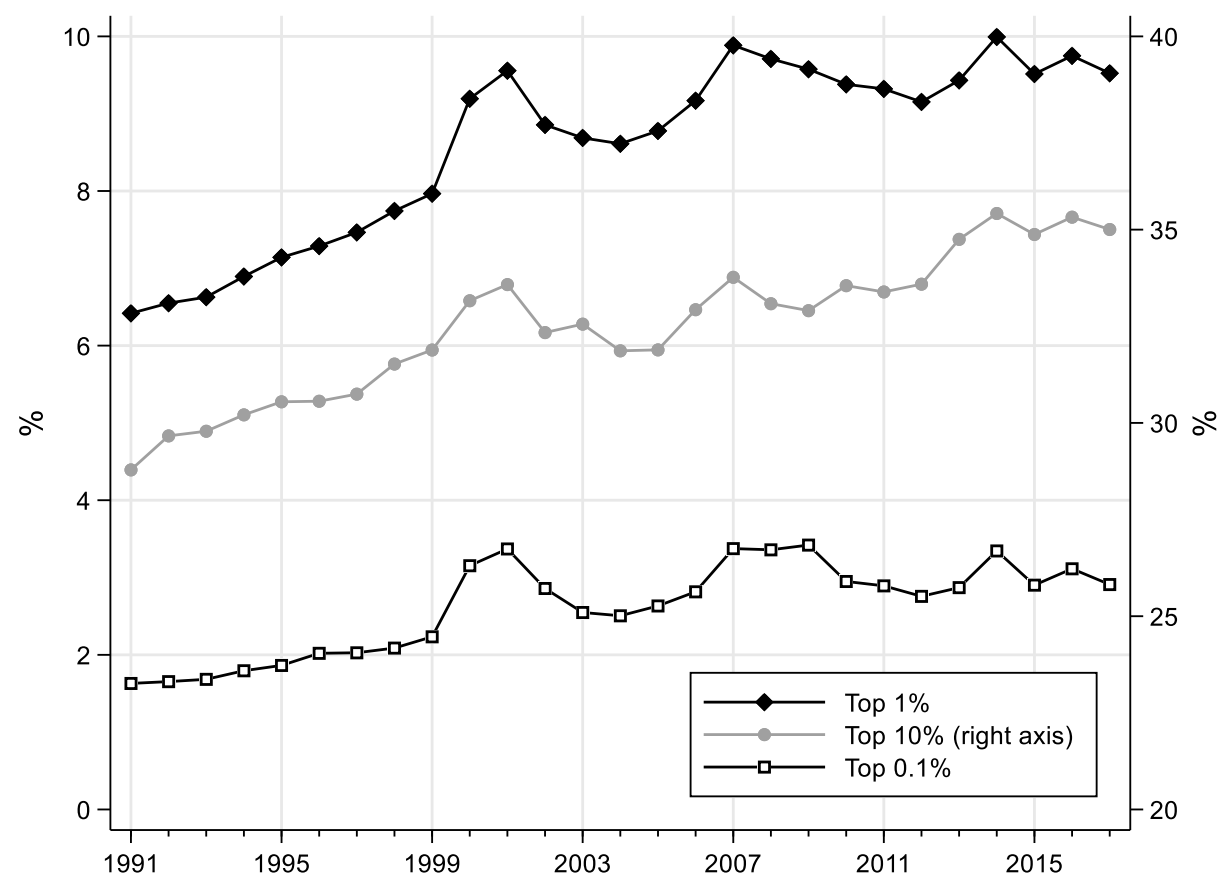

Notes: The individual is the unit of analysis. Estimates are based on the adult population (aged 15 or above). Source: Authors' calculations based on ALife data, ABS population estimates and ABS National Accounts data. Stata figure topcombosh

\footnotetext{
${ }^{8}$ Our estimates are consistent with estimates for the 2004-2014 period reported by Burkhauser et al. (2018): see Appendix B.

${ }^{9}$ Appendix $\mathrm{C}$ shows the composition of the top $1 \%$ income group in terms of main source of income, sex, selfemployment status, sex, age, and state of residence. Between 1991 and 2017, the female share of the top 1\% has increased, the proportion aged 55-64 has increased, the proportion aged under 35 has decreased, and the proportion residing in Western Australia has increased but, otherwise, no clear trends are evident.
} 


\section{Top income persistence - multiple perspectives}

\section{Estimates of top-income persistence}

We first consider top income persistence using the approach of Auten et al. (2013), showing the proportion of those in the top $1 \%$ in base year $t$ who remain in the top $1 \%$ in every subsequent year over three time frames: one year, three years, and five years. See Figure 2. As expected, survival rates in the top $1 \%$ decrease the longer the time frame considered: the 5year estimates lie below the 3-year estimates and, in turn, the 1-year estimates lie below the 3year estimates.

There is a clear rise in persistence according to all three measures over the period as a whole. The one-year survival rate fell from $64 \%$ in 1991 to $61 \%$ in 1994 but then rose to reach a peak of 73\% in 2011 and remained at approximately that level thereafter. Similarly, the three-year persistence rate rose from $40 \%$ in 1991 to $51 \%$ in 2011 and the five-year persistence rate increased from $29 \%$ in 1991 to $38 \%$ to reach peaks in 2011, with both measures remaining at these levels thereafter.

Figure 2. Persistence rates for the top 1\% income group, 1991-2017

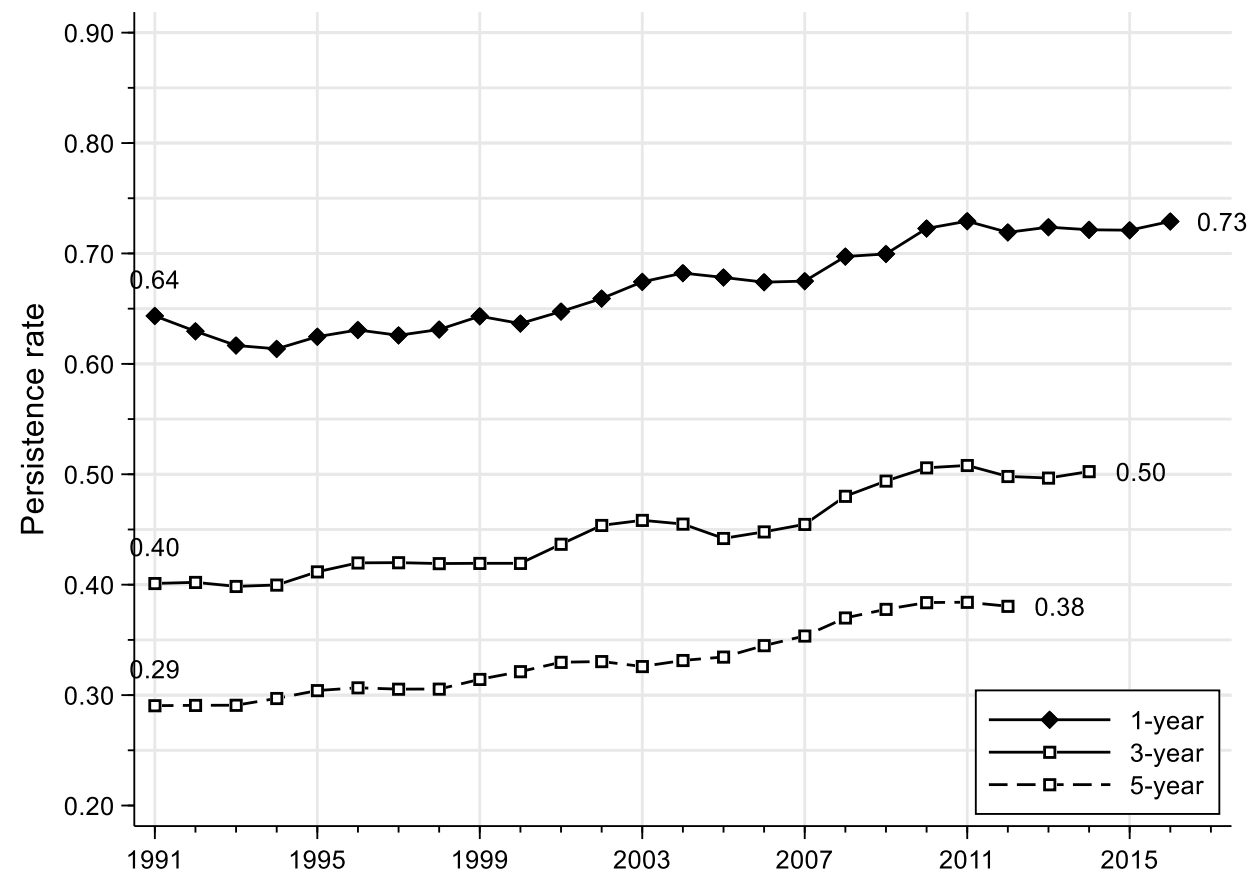

Notes: The persistence rate is the share of individuals in the top $1 \%$ in the base year who belong to the top $1 \%$ in each of the subsequent 1,3 , or 5 years.

Stata figure persist5_Oto99_topl_totinc_noKg 
Figure 3, focusing on one-year persistence rates, shows that the rise in top-income persistence also holds when we use narrower and broader definitions of the top-income group. ${ }^{10}$ However, it is also evident that the rise in persistence is greater the more narrowly defined is the top-income group. The one-year persistence rate rose from 0.77 to 0.81 between 1991 and 2017 for the top $10 \%$ (a 5\% increase), from 0.64 to 0.73 for the top $1 \%$ (14\%), and from 0.56 to 0.67 for the top $0.1 \%(20 \%) .^{11}$

Figure 3. One-year persistence rates: top 0.1\%, 1\%, and 10\%, 1991-2017

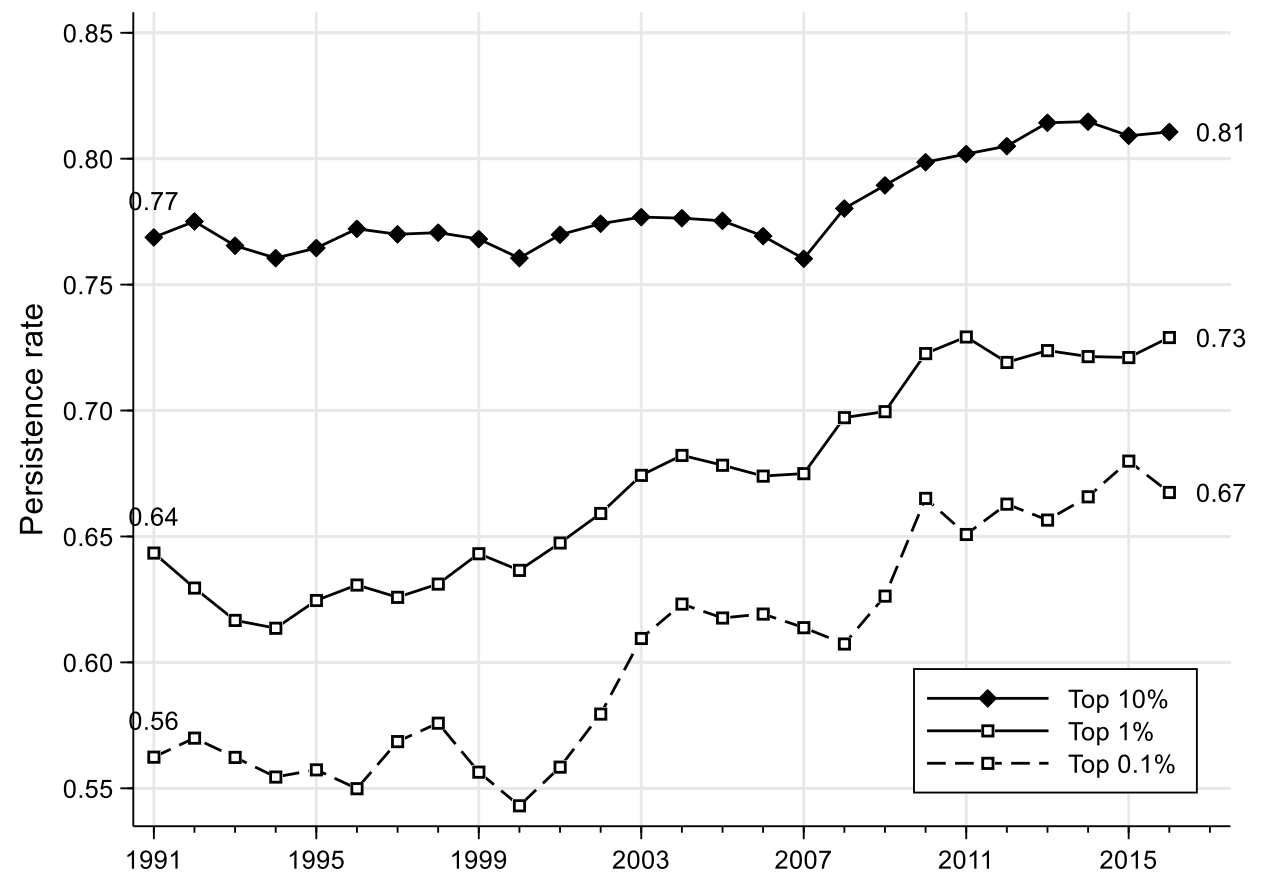

Notes: The persistence rate is the share of individuals in the top-income group in the base year who remain in the same top-income group in the following year.

Stata figure Tlpersist_Oto99_totinc_noKg

Figures 2 and 3 show that trends in top-income persistence track the trend in topincome shares (Figure 1), albeit with a lag of 2-3 years. For example, the top 1\% persistence rate series flattened out around 2010 whereas the growth rate in the yearly top $1 \%$ share fell from around 2007. There is also some correlation with the business cycle, with persistence rates rising when the economy was growing. Conversely, Australia experienced a short contraction in real GDP growth around 2008/9 due to the Global Financial Crisis, and there

\footnotetext{
${ }^{10}$ Appendix Figures F2 and G2 present persistence rates for the top $0.1 \%$ and top $10 \%$ for all three time frames. ${ }^{11}$ Appendix Figures D1 and D2 show that the rise in top-income persistence is robust to analysis of alternative income definitions, namely, gross taxable income inclusive of taxable realised capital gains, and disposable (after-tax) income. When we change the income definition, we also change the composition of the top-income group.
} 
was a sharp recession around 1991, and we see a drop or flattening out in the top-income persistence rate series over the next three to four years in each case.

\section{Cross-national differences in top-income persistence?}

How do these persistence rates for Australia compare with those in other countries? Crossnational comparability of estimates of levels and trends is limited by differences in income tax rules and thus in the definition of taxable income and tax units, and because of differences across studies in methods and time periods covered. Subject to these caveats, our estimates for Australia appear to be near the top of the range of tax-data estimates for other countries.

For Australia, we estimate the fraction of the top $1 \%$ of all adults aged $15+$ remaining there one year later to range from below $70 \%$ in the 1990 s to more than $70 \%$ in the mid- to late-2010s (Figure 3). By comparison, for the USA, Auten et al. (2013, Table 3) report 1-year persistence rates between $60 \%$ and $70 \%$ between 1991 and 2009 for tax filers aged 25-60. ${ }^{12}$ The three-year persistence rates for the USA are between $29 \%$ and $37 \%$ (all referring to the pre-2010 period), whereas these rates have been hovering around 50\% in Australia since 2010.

For the UK, and using pooled data for tax years 2000/01 to 2015/16, Joyce et al. (2019, Figure 14) report that $75 \%$ of the top $1 \%$ of tax filers remained in the top $1 \%$ after one year, $60 \%$ remained after two years, and $50 \%$ after three years respectively. These are higher estimates than our corresponding ones for Australia but refer to tax filers and rates are averages for the whole period so trends cannot be seen.

For Sweden, Boschini et al. (2020, Figure C4) report one-year persistence rates for the top $0.1 \%$ and 'top $1 \%$ excluding the top $0.1 \%$ ', with separate estimates for men and women aged 20+ (but not for 'all individuals'). In the years around 2010, the one-year persistence rate for men in the 'top $1 \%$ excluding the top $0.1 \%$ ' is around $70 \%$ and a few percentage points lower for women in the same group. In other words (and with reminders about comparability issues), the Swedish one-year persistence rates appear to be of roughly the same magnitude as our estimates for Australia over the same period. However, the Swedish five-year persistence rates appear to be lower than our Australian ones for the years around 2010. The five-year persistence rate for Swedish men in the 'top $1 \%$ excluding the top $0.1 \%$ '

\footnotetext{
12 Auten et al. (2013) exclude capital gains from income as we do, but note that there are differences in definitions of income and income unit, and they focus on samples of tax filers rather than all adults (Table 1). Auten et al. restrict their analysis to tax filers aged 25-60, whereas we consider all adults aged 15+. Appendix Figure F1 shows that applying age restrictions to our Australian samples leads to even higher persistence rates.
} 
was around $30 \%$ and a few percentage points smaller for women in the 'top $1 \%$ excluding the top 0.1\%' (Boschini et al. 2020, Figure 6).

There are persistence rate estimates for the three other countries focusing on the top $0.1 \%$. For Australia, Appendix E shows one-year persistence rates for this group of between $55 \%$ and $60 \%$ for the $1991-2003$ period, above $60 \%$ for 2003-2010, and above $65 \%$ for 2010-2017. For France, Landais (2008, Figure 7) reports one-year rates for the top $0.1 \%$ of tax filers hovering around 65\% between 1998 and 2004, above our estimates for all adults aged 15+. For Germany, Jenderny (2016, Figure 1) reports rates for tax filers of between $45 \%$ and $48 \%$ for the 2001-2005 period, i.e. distinctly lower than our Australian estimates. The estimates for Canada derived by Saez and Veall (2005) are more comparable with ours because they are based on all adults (aged 20+). Saez and Veall (2005, Figure 7) report estimates ranging between $50 \%$ and $60 \%$ over the period 1982-1998, and hence of roughly the same magnitude as our Australian estimates.

\section{Additional perspectives on top income persistence}

Another approach to summarizing top-income persistence is shown by Table 2. This displays the distribution of the number of years in the top $1 \%$ over a five-year period among those ever observed in the top $1 \%$ over that five-year period. (This is the top-income analogue to statistics summarizing the distribution of number of years in poverty over a fixed time window.) By contrast with the series shown in Figures 2 and 3, this summary shows the extent to which membership of the top $1 \%$ is intermittent and highlights that turnover in topincome group membership arises from entries to as well as exits from the group.

The 'number of years in top 1\%' measure shows growth in top-income persistence since 1991 as well. The fraction of individuals in the top $1 \%$ only one year out of the five fell substantially, from around one-half for the 1991-1995 period to 38\% for the 2011-2015 period. In contrast, the fraction spending two, three, or four years out of five in the top $1 \%$ increased from around $35 \%$ to $40 \%$. The fraction spending all five years in the top $1 \%$ increased more dramatically: $15 \%$ of individuals belonged to the top $1 \%$ in every year during the 1991-1995 period but 22\% during 2011-2015. 
Table 2. Distribution of the number of years in the top $1 \%$ over a five-year period among individuals in the top $1 \%$ at least one year of the five-year period

\begin{tabular}{lrrrrrr}
\hline & \multicolumn{6}{c}{ Distribution of the number of years in top 1\% (in \%) } \\
Period & 1 & 2 & 3 & 4 & 5 & Total \\
\hline $1991-1995$ & 50.6 & 16.0 & 10.6 & 8.3 & 14.5 & 100 \\
$1996-2000$ & 50.9 & 15.8 & 9.9 & 7.9 & 15.4 & 100 \\
$2001-2005$ & 46.1 & 16.6 & 10.9 & 9.0 & 17.3 & 100 \\
$2006-2010$ & 41.4 & 18.3 & 12.5 & 9.7 & 18.2 & 100 \\
$2011-2015$ & 37.9 & 17.6 & 12.3 & 10.1 & 22.1 & 100 \\
\hline
\end{tabular}

A feature of the $T$-year persistence rate measures reported in Figures 2 and 3 is that they do not take account of how long an individual has already been in the top-income group: the measures are based on samples of the individuals who happen to belong to the top-income group in the base year. In that year, some individuals will have just joined the top 1\%; some will have been in the top $1 \%$ for several years already. Because the chances of leaving the top-income group decline with the number of years since entry - there is negative duration dependence in the exit hazard rate (results not shown) - Figures 2 and 3 provide overestimates of how long someone starting a spell in the top $1 \%$ will remain in the top $1 \% .{ }^{13} \mathrm{~A}$ further feature of Figures 2 and 3 is that they provide a one-sided perspective on turnover at the top. By conditioning on top-income group membership, the persistence measures provide no information about entry rates and their trends.

Addressing these issues enriches the description of what 'top-income persistence' entails. To do this, first we present information about probability distributions of survival in the top $1 \%$ for cohorts entering the top $1 \%$ in different years (Figure 4). Second, we report estimates of probability distributions of survival outside the top 1\% (i.e., in the poorest $99 \%$ ) for cohorts leaving the top $1 \%$ in different years (Figure 5). ${ }^{14}$ In both figures, we group years during 1991-2017 into five sub-periods when defining cohorts. For the most recent cohort, survival probabilities can only be calculated for durations up to four years (because Alife data do not extend beyond 2017). Corresponding estimates for the top $0.1 \%$ and top $10 \%$ are shown in Appendices $\mathrm{E}$ and $\mathrm{F}$ and are similar to those for the top 1\% discussed here.

Figure 4 shows clearly that the chances of remaining in the top $1 \%$ for entrants to the top 1\% between 2007-2011 and 2012-2016 are distinctly larger than the chances of

\footnotetext{
${ }^{13}$ This is a standard result from survival analysis about sampling from the 'stock' rather than a cohort of entrants.

${ }^{14} \mathrm{We}$ cannot estimate how long it takes to first enter the top-income group (i.e., not conditioning on being in top-income group at least once between 1991 and 2017) because of left censoring. Alife has no data about incomes before 1991 and so we cannot consistently estimate when individuals became at risk of entering the top $1 \%$ for the first time.
} 
remaining for entry cohorts in the 1990s (1992-1996, 1997-2001). For example, the probability of remaining at least three years in the top $1 \%$ were around $25 \%$ for the most recent cohorts but only around $18 \%$ for the two earliest cohorts. The differential survival chances exist regardless of how long it is since the individuals entered the top $1 \%$. For example, the probability of remaining in the top $1 \%$ for at least ten years since entry is around $10 \%$ for the 2007-2011 entry cohort but only around 6\% for the earliest two cohorts. The picture of top-income persistence increasing over time provided by Figure 4 is consistent with that provided by Figure 2, but what about the additional role played by re-entry?

Figure 5 shows that changing patterns of re-entry to the top $1 \%$ have reinforced topincome persistence. The probability of remaining outside the top 1\% group for three years since having left the group is around $73 \%$ for the two earliest exit cohorts but around $68 \%$ for the two most recent cohorts. These cross-cohort differences in probabilities are apparent at all durations as well. For example, the probability of remaining outside the top $1 \%$ for ten years after exiting the group is around $60 \%$ for two earliest cohorts but only 55\% for the 2007-2011 cohort.

Figure 4. Probabilities of remaining in the top $1 \%$, by duration and top $1 \%$ entry cohort

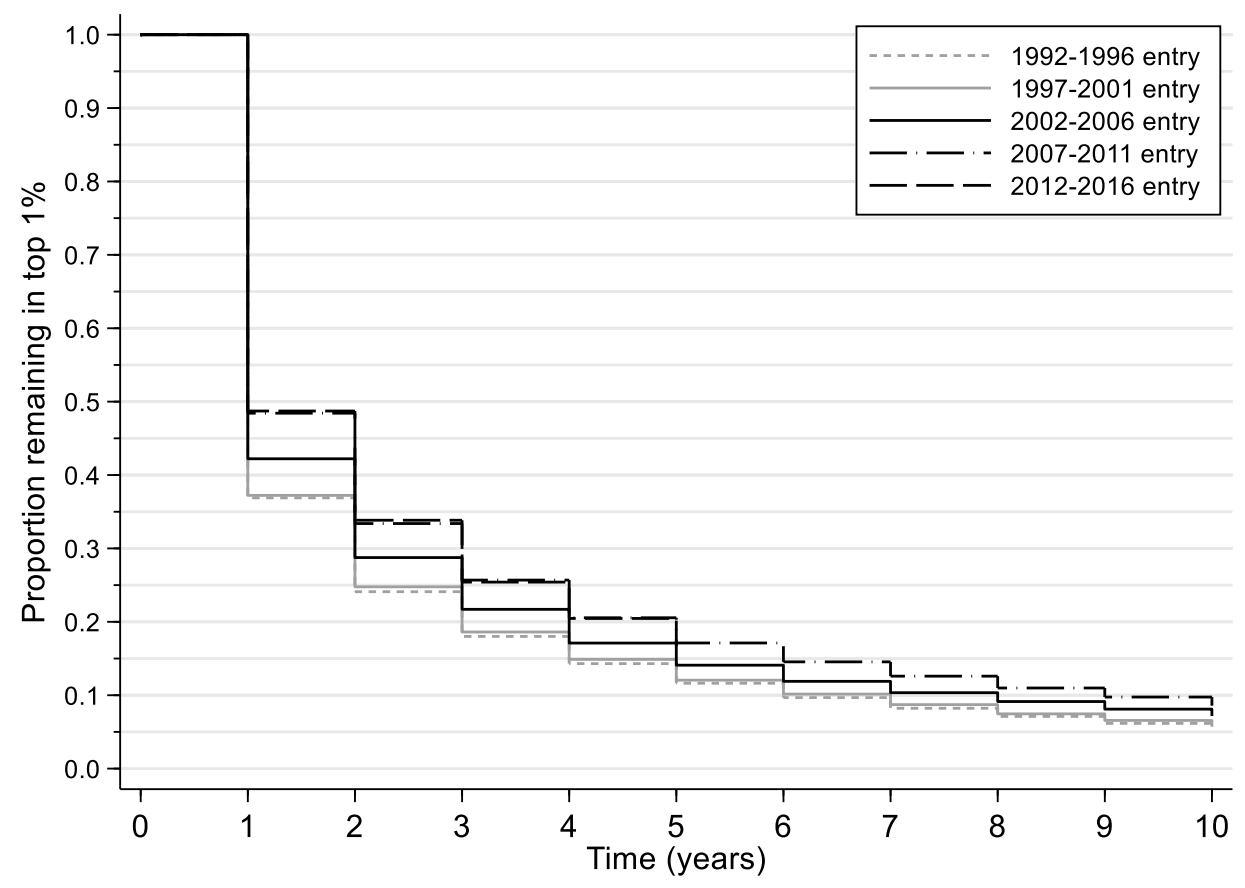

Stata figure Survival_byperiod_topl_totinc_noKg 
Figure 5. Probabilities of remaining outside the top 1\%, by duration and top $1 \%$ exit cohort

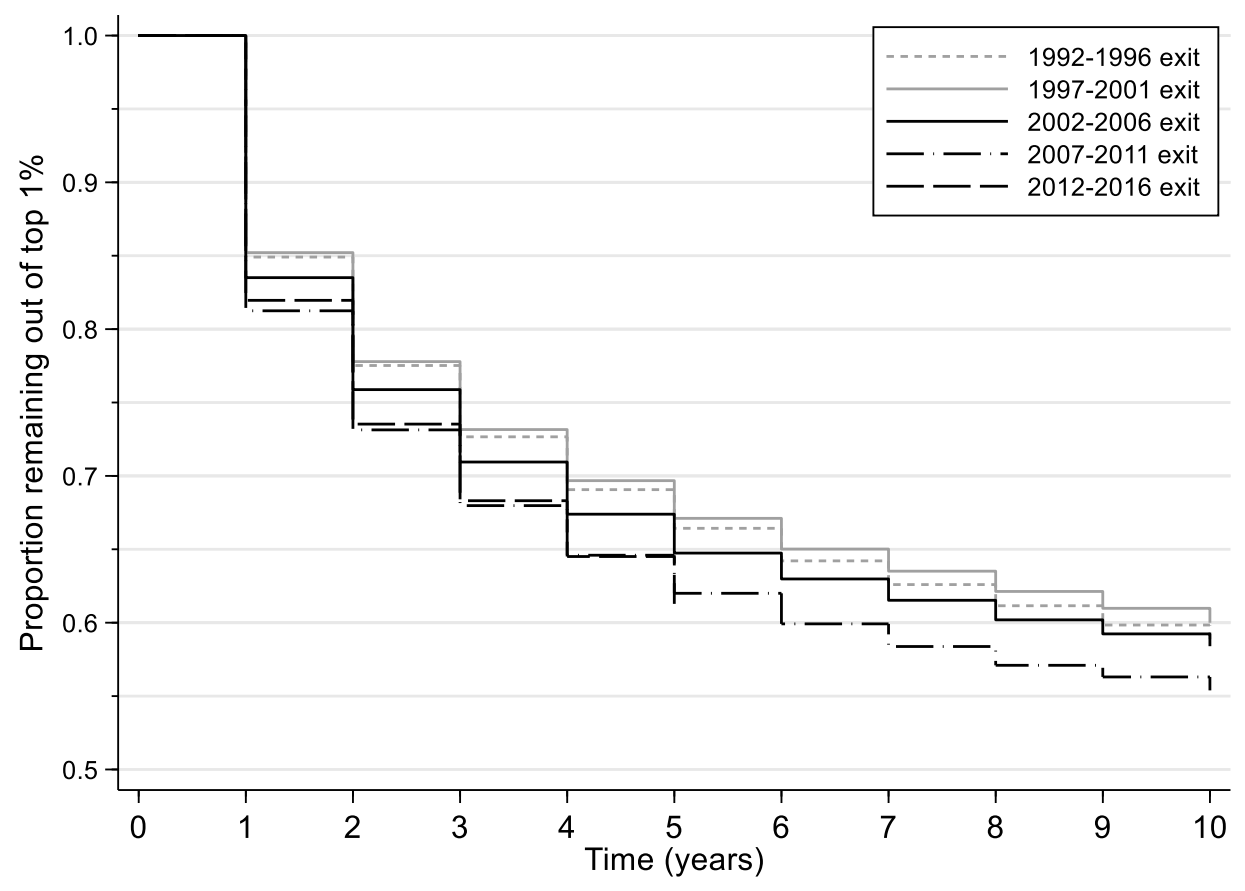

Stata figure Survival_reentry_byperiod_top1_totinc_noKg

\section{Comparisons of permanent and transitory top-income shares, and a mobility index}

Another approach to summarizing top-income mobility is to compare top-income shares calculated using income defined using a single-year measure with shares calculated using a multi-year, longitudinally-averaged, measure. The greater the gap between the multi-year average of top-income shares of one-year income and the top-income share of multi-year income, the more top-income mobility there is (the smaller is top-income persistence).

An index of top-income mobility is provided by the ratio of the multi-year averaged one-year top income share to the multi-year top income share, minus one. The index is zero if there are no transitions into or out of the top $1 \%$ in the period. The more transitions there are, and the larger the income movements accompanying those transitions, the larger is the value of the mobility index. At one extreme, if the same individuals comprise the top $1 \%$ income group year after year, the mobility index equals zero. At the other extreme, if belonging to the top $1 \%$ in a specific year were entirely random and the time frame examined long enough, the top-income share for multi-year income would be $1 \%$. This means that the upper bound for the mobility index is the average of the yearly top $1 \%$ shares over the period minus one, i.e., between approximately 5.5 and 8.5 over the period we examine. 
Figure 6 presents estimates of top 1\% shares for incomes longitudinal-averaged over three years ('three-year' incomes), as well as estimates of the three-year averages of the yearly top $1 \%$ shares over the same three years. Figure 7 has the same format as Figure 6 but uses a five-year time frame. In addition, both figures show estimates of the top-income mobility index calculated using the relevant time frames.

Figures 6 and 7 show a clear upward trend in the three-year and five-year top 1\% income shares. (The moving average of the cross-sectional yearly top $1 \%$ shares is a smoothed version of the estimates shown in Figure 1.) There were two short-lived reductions in both multi-year top 1\% share series: between 2001 and 2003 and between 2008 and 2011 for the three-year top 1\% share; and between 2002 and 2004 and between 2008 and 2012 for the five-year top $1 \%$ share.

The index summarizes how the two income share series translate into top-income mobility. What we see is an increase in top-income mobility between 1991 and 2001, followed by a clear downward trend up to 2012 and a slight reversal thereafter. Put differently, there was a decline in top-income persistence in the first decade followed by a rise in top-income persistence thereafter.

There are no estimates for other countries to compare ours with, apart for those of Aaberge et al. (2013) for Norway. Our three-year mobility index estimates for Australia are similar to the values reported by Aaberge et al. (2013, Figures 4 and 5) in the 1970s and 1980s but much lower than they found for the 1990s and 2000s. ${ }^{15}$ Put differently, the secular trend in top-income mobility in Australia was downwards from around 2000 onwards, whereas top-income mobility in Norway rose steadily between 1990 and the late-2000s. We conjecture that the cross-national differences in persistence trends are related to the differences in top-income share trends. As noted in Section I, top-income shares increased significantly more over the period in Norway than they did in Australia.

Returning to the Australian estimates in Figures 6 and 7, we observe that although the turning points in the top $1 \%$ share series and the mobility index series broadly coincide, their trends do not. For example, there are periods when top $1 \%$ shares increased but these coincide with both periods when the mobility index increased and periods when it decreased. This draws attention to a potential limitation of the mobility index. Periods of growth in the top $1 \%$ share are also periods in which there tend to be large income gains by the top $1 \%$, and these

\footnotetext{
15 The only difference between Aaberge et al.'s (2013) mobility index and ours is that they analyze absolute differences between transitory and permanent persistence rates, and we look at proportionate differences.
} 
gains can act to increase averaged one-year top-income shares relative to multi-year topincome shares. That is, it is helpful to distinguish between mobility defined in terms of absolute real income changes and mobility that changes individuals' ranks (and hence also their top-income group membership status potentially). We return to this issue in Section IV.

Appendix Figures E5 and E6 present estimates for the top 0.1\% and Appendix Figures F5 and F6 show estimates for the top 10\%. For the top $0.1 \%$, the top-income mobility index increased in the 1990s, followed a V-shape in the 2000s and then decreased in the 2010s. The top $10 \%$ mobility index shows some fluctuations but no clear trend over the period. In this case, the reduction in mobility due to increased persistence rates may have been offset by the shift to the right in the income densities, meaning that the income loss required to drop out of the top $10 \%$ increased, leading to larger income movements but among fewer individuals. We discuss this point further in Section IV.

\section{Figure 6. Permanent versus transitory top $1 \%$ shares, and mobility index: three-year windows}

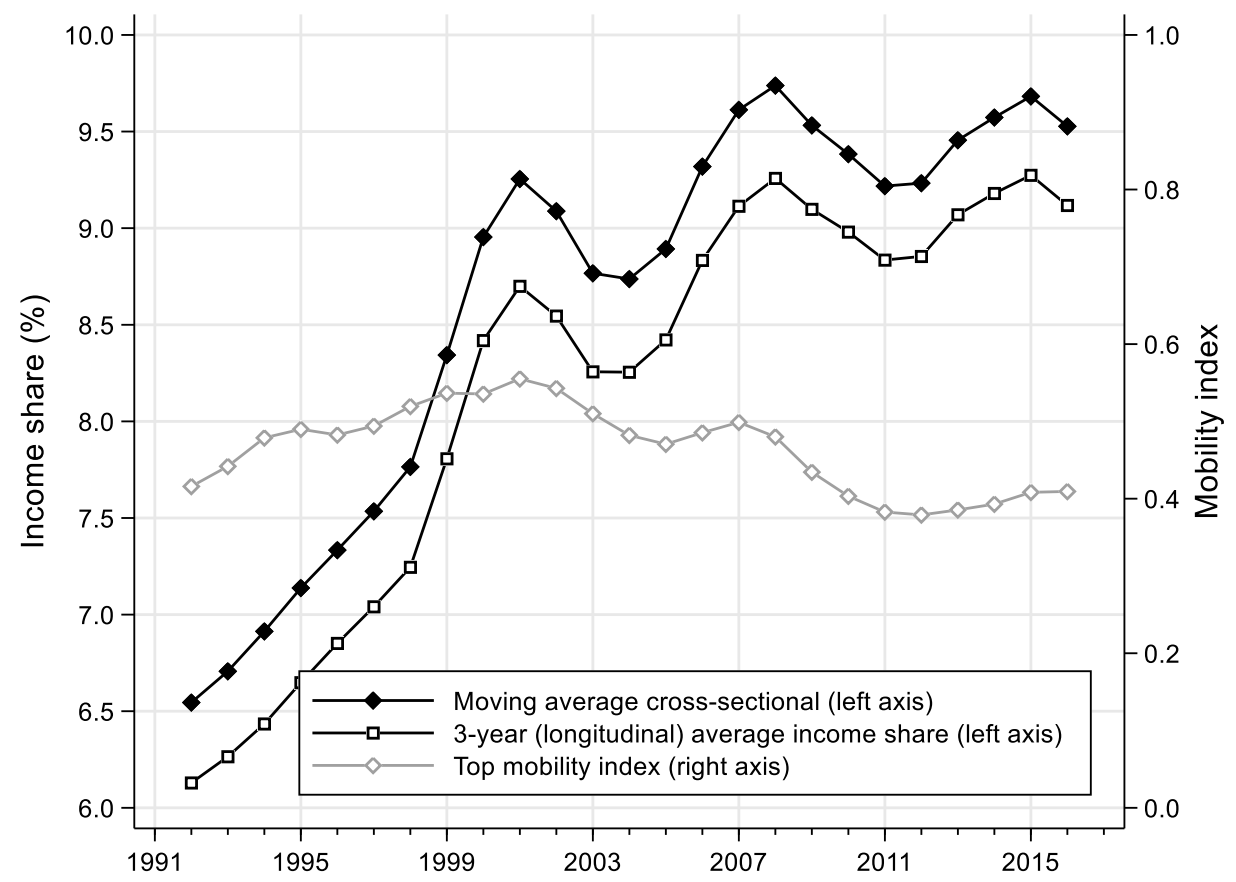

Notes: The $x$-axis labels refer to the middle year of the three-year period.

Stata figure Perm_mov3toplsh_totinc_noKg 
Figure 7. Permanent versus transitory top $1 \%$ shares, and mobility index: five-year windows

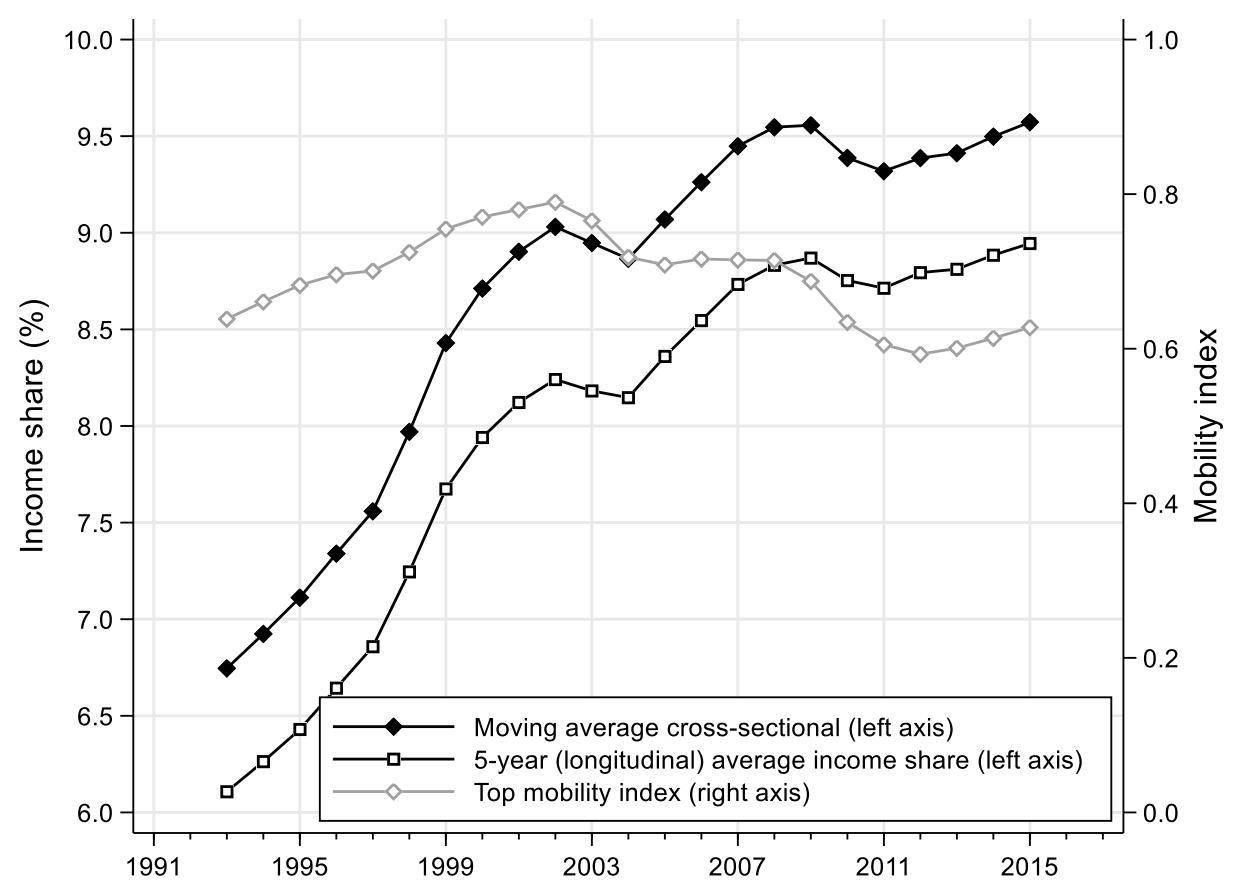

Notes: The $x$-axis labels refer to the middle year of the five-year period.

Stata figure Perm_mov5top1sh_totinc_noKg

\section{Income group origins and destinations of current top $1 \%$ group members}

We provide further information about levels and trends in top-income persistence by examining the previous-year income origins of entrants to the top $1 \%$ and the next-year income destinations of those who leave the top $1 \%$. There is an analogy with poverty analysis: if a poor person with an income just below the poverty line last year has an income $\$ 500$ above the poverty line this year, there is less low-income persistence of concern than if this year's income were only $\$ 1$ above the poverty line. Analogously, if the incomes of the individuals leaving the top $1 \%$ are just below the threshold defining the top $1 \%$ rather than well below (or those entering the top $1 \%$ come from just below the top $1 \%$ ), then the nature of top-income persistence is rather different.

Figure 8 shows the income groups that entrants to the top $1 \%$ belonged in the year prior to entry, and the income groups that those leaving the top $1 \%$ went in the year of exit. Consistent with our earlier evidence on increasing persistence, we see that those entering and leaving the top $1 \%$ are increasingly coming from and going to the top $5 \%$ to $1 \%$ group.

Figure 8, panel (a), shows that the proportion of top 1\% entrants coming from the top $5 \%$ to $1 \%$ income group has risen from approximately $60 \%$ in 1993 to approximately $80 \%$ since 2013. (The years cited refer to the years of entry into the top $1 \%$.) There was a 
particularly sharp rise between 2007 and 2008, from approximately 64\% to $75 \%$. The proportion entering from the top $10 \%$ to $5 \%$ has fallen from $25 \%$ in 1993 to just over $10 \%$ since 2013, while the proportion entering from lower down the income distribution but still lodging a tax return has declined from approximately $14 \%$ in 2000 to approximately $7 \%$ since 2011. The proportion of entrants who did not lodge a tax return in the previous year has remained relatively stable at approximately $2 \%$.

Figure 8, panel (b), shows that the proportion of those leaving the top $1 \%$ who move to the top 5\% to $1 \%$ rose between 1998 and 2011 (where the year refers to the last year before exit from the top 1\%), from approximately $48 \%$ to $70 \%$. However, since 2011 the proportion moving to the top $5 \%$ to $1 \%$ has declined somewhat, to approximately $61 \%$ in 2017 . Similar to the finding for entry to the top $1 \%$, there was a sharp rise in the proportion of those who exited to the top 5\% to $1 \%$ between 2007 and 2008. Most of the rise in the proportion going to the top $5 \%$ to $1 \%$ has been at the expense of people moving to the top $10 \%$ to $5 \%$ group.

In sum, we find that not only has the probability of exit from the top $1 \%$ declined since 1991, but also that those entering the top $1 \%$ are increasingly coming from near the top of the income distribution, and those leaving the top $1 \%$ are increasingly staying near the top of the income distribution. This reinforces our general finding of a rise in top-income persistence, but also highlights the relevance of examining changes in real incomes in addition to changes in ranks. We look at income changes in more detail in the next section. 
Figure 8. Origins and destinations of top $1 \%$ income group members

(a) Previous-year income group of new entrants to the top $1 \%$

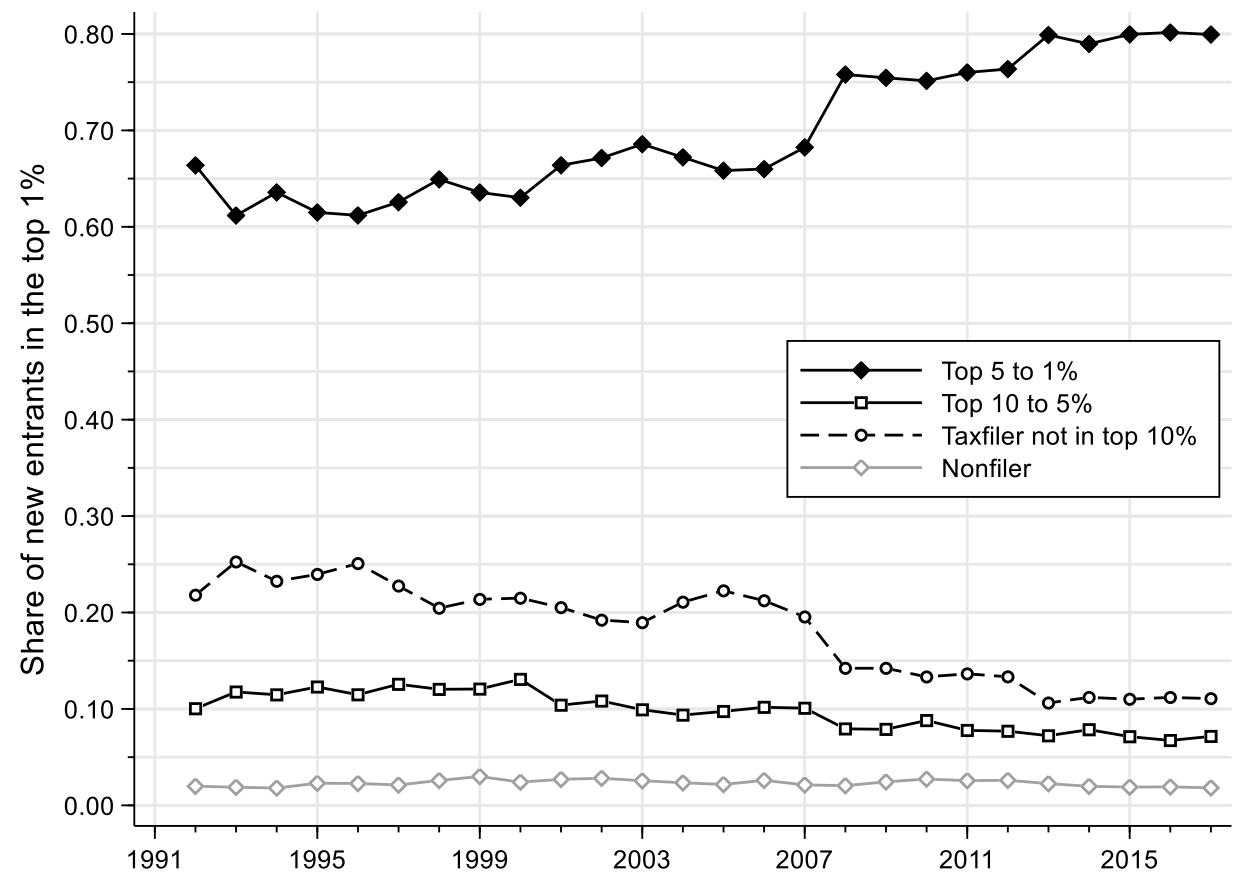

(b) Next-year income group of individuals exiting the top $1 \%$

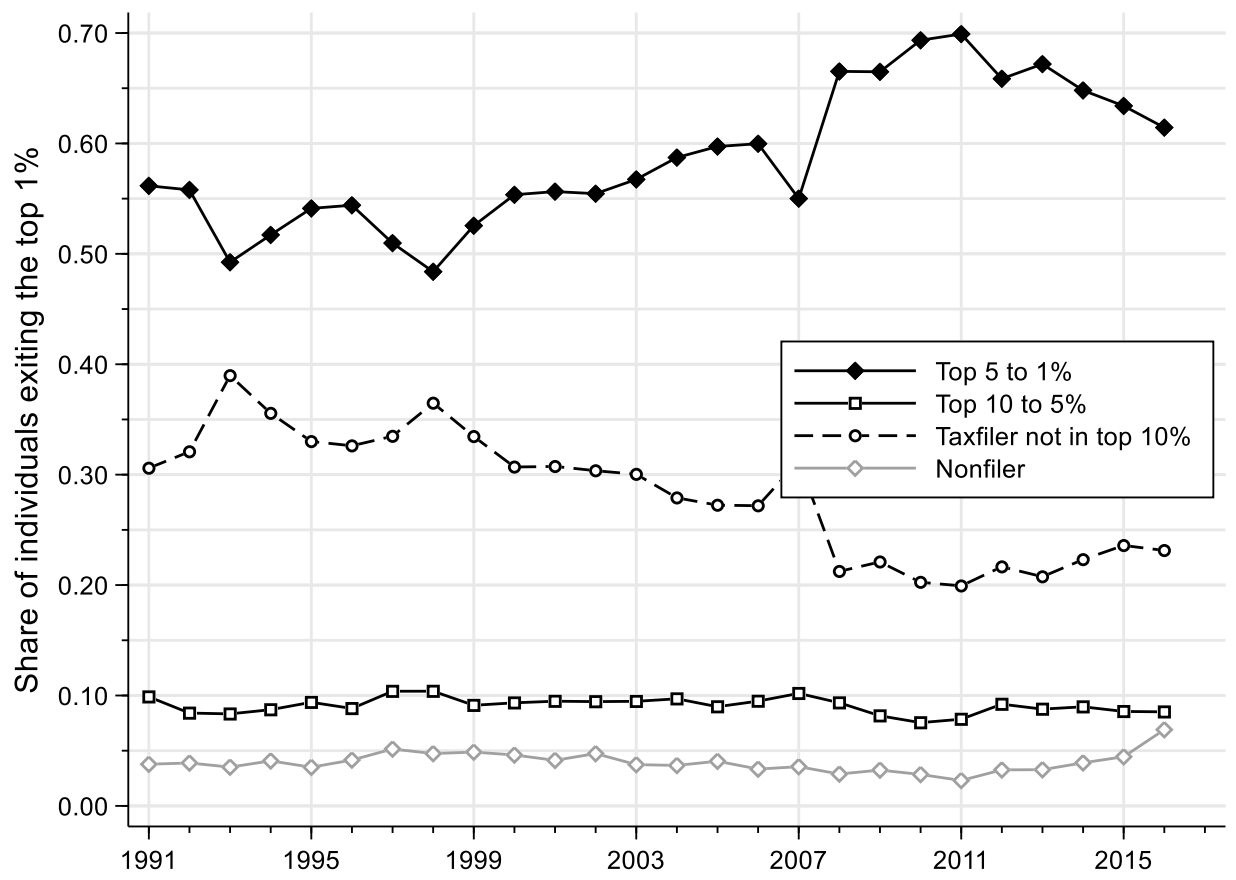

Notes: The individual is the unit of analysis. Estimates are based on the adult population (aged 15 or above). Stata figure inflow_top1_totinc_noKg, outflow_topl_totinc_noKg 


\section{The income changes associated with changes in top-income group membership}

We have documented a clear increase in top-income persistence. We have focused on positional (im)mobility but also pointed out that absolute income changes are relevant too. Building on this point, this section describes how the income changes affecting the top $1 \%$ have evolved over time, focusing on one-year income changes.

Figure 9 displays various measures of income changes from one year to the next of those in the top $1 \%$ (panel a) and those in the top 5\% to $1 \%$ (panel b). Panel (a) shows that, one year after being observed in the top $1 \%$ income group, individuals experienced an income loss of between $10 \%$ and $15 \%$ in the 1990s on average, but only between $5 \%$ and $10 \%$ in the 2000 s and 2010s. This average loss is the net result of $55 \%$ to $65 \%$ of the top $1 \%$ experiencing an income loss (of $30 \%$ to $40 \%$ on average) and the remaining $35 \%$ to $45 \%$ experiencing an income gain (of $25 \%$ to $35 \%$ on average). Some important fluctuations in these proportions are apparent. First, the average gain fluctuated between $25 \%$ and $43 \%$ over the period but it was back to its 1991 value of $26 \%$ by 2016. Second, the average income loss decreased, especially from 2007 to 2016, when it went from $40 \%$ to $31 \%$.

Changes in the average one-year income decline among those in the top $1 \%$ experiencing an income decline appear to correlate highly with the fluctuations in the oneyear persistence rates presented in Figure 2. Figure 2 shows that most of the increase in the persistence rates occurred between 2000 and 2004 and between 2007 and 2011. Both periods recorded a decrease in the average income decline of those experiencing a decline (Figure 9, panel a). Taken together, these findings suggest that reductions in the average income decline experienced by the top $1 \%$ have driven the increased persistence rate in that group to some extent. This effect can be mitigated (reinforced) by reductions (increases) in the proportion facing a decline, but Figure 9 shows that the proportion with a loss was in 2016 close to its 1991 level. Indeed, the figure also shows that the proportion of people in the top $1 \%$ experiencing an income decline that drops them out of the top $1 \%$ has steadily declined since 2006, from $57 \%$ to $43 \%$ in 2016.

Another factor potentially contributing to higher persistence rates is that individuals below the $99^{\text {th }}$ percentile ( $p 99$ ) experienced smaller and/or fewer income gains. Figure 9 , panel (b), presents evidence for the top 5\% to $1 \%$ income group. The findings for the 19912016 period as a whole are not conclusive. There was a decline in the average increase in income among those experiencing an increase since 2006 and the proportion of the top 5\% to $1 \%$ experiencing an increase in income has also declined since 2011. However, there has been 
little net change in the proportion of this income group experiencing an income increase putting them in the top $1 \%$ and, indeed, there has been a slight rise in this proportion since 2010 when it was around $10 \%$, to around $15 \%$ in 2016. 


\section{Figure 9. Average yearly income changes}

\section{(a) Top $1 \%$}

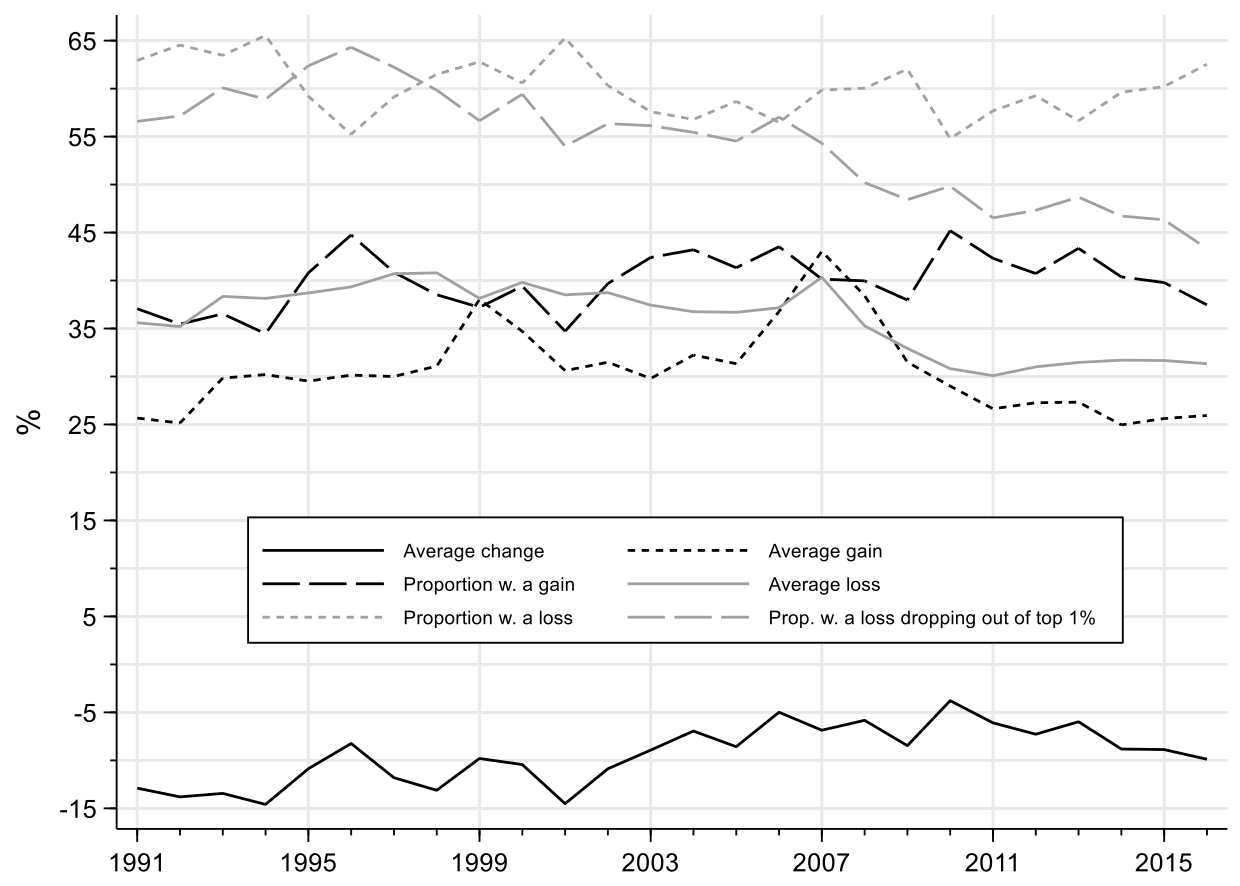

\section{(b) Top $5 \%$ to $1 \%$}

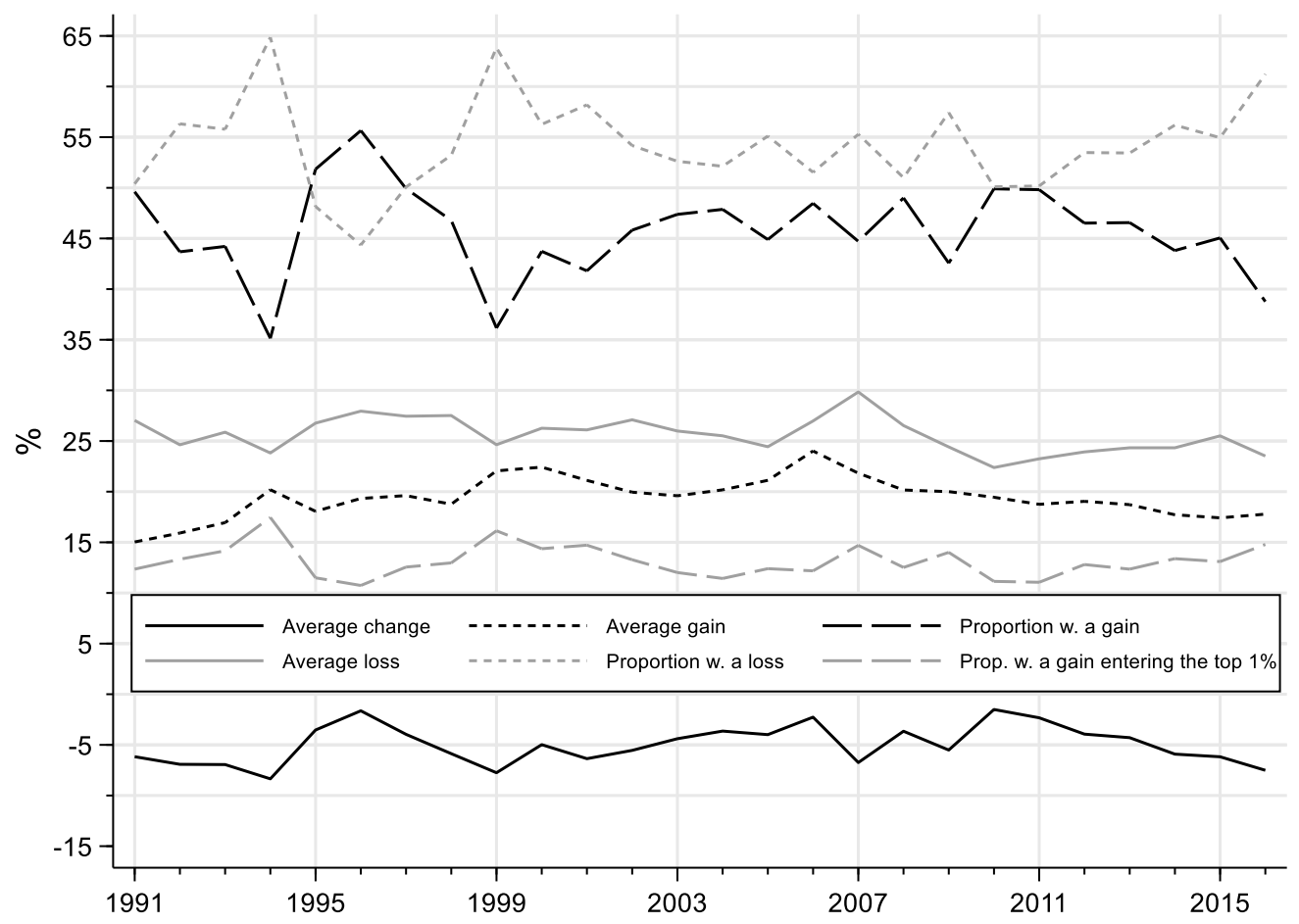

Notes: Estimates for year $t$ refer to income changes between year $t$ and $t+1$ for those in the top $1 \%$ income group in year $t$. Average loss (gain) refers to the mean income loss (gain) among those with a loss (gain). Stata figure avincchanges_top1_totinc_noKg_b, avinc_changes_top5_1_totinc_noKg_b_ 
Figure 10 shows the distribution of income within the top 1\%, plotting the density of relative distance to $p 99$ in 1991, 2001, 2011, and 2017. (Relative distance is the percentage difference between observed income and $p 99$.) A large proportion of top $1 \%$ income recipients have incomes just above $p 99$, with the overwhelming majority having incomes that are at most $50 \%$ larger than $p 99$. Given the increase in top-income persistence, we would expect these densities to have shifted to the right, indicating a move away from $p 99$. Indeed, this type of shift occurred between 1991 and 2001, but there was no substantial shift thereafter, when persistence was increasing.

Together with Figure 2, these findings suggest that the increased persistence rates are unlikely to be explained by a 'rungs of the ladder growing further apart' story but, instead, by a change in the nature of income dynamics. We look at the ladder rungs story further shortly.

Appendix E provides evidence of a similar story for the top $0.1 \%$, with Figure E5 showing a reduction in the average income loss and no major shift to the right for the income densities besides the 1991-2001 shift (Figure E6). ${ }^{16}$ The story for the top $10 \%$ is somewhat different. Appendix Figure F5 shows no clear downward trend in the average loss. These somewhat more stable income dynamics patterns are accompanied by a series of shifts to the right of the income densities (Figure F6).

\footnotetext{
${ }^{16}$ The large increase in average income gains apparent in 2008 in Figure E7 is due to three outliers, each experiencing an income gain of more than $\$ 15$ million.
} 
Figure 10. The distribution of relative income distance to the $99^{\text {th }}$ percentile for the top $1 \%$, kernel density estimates

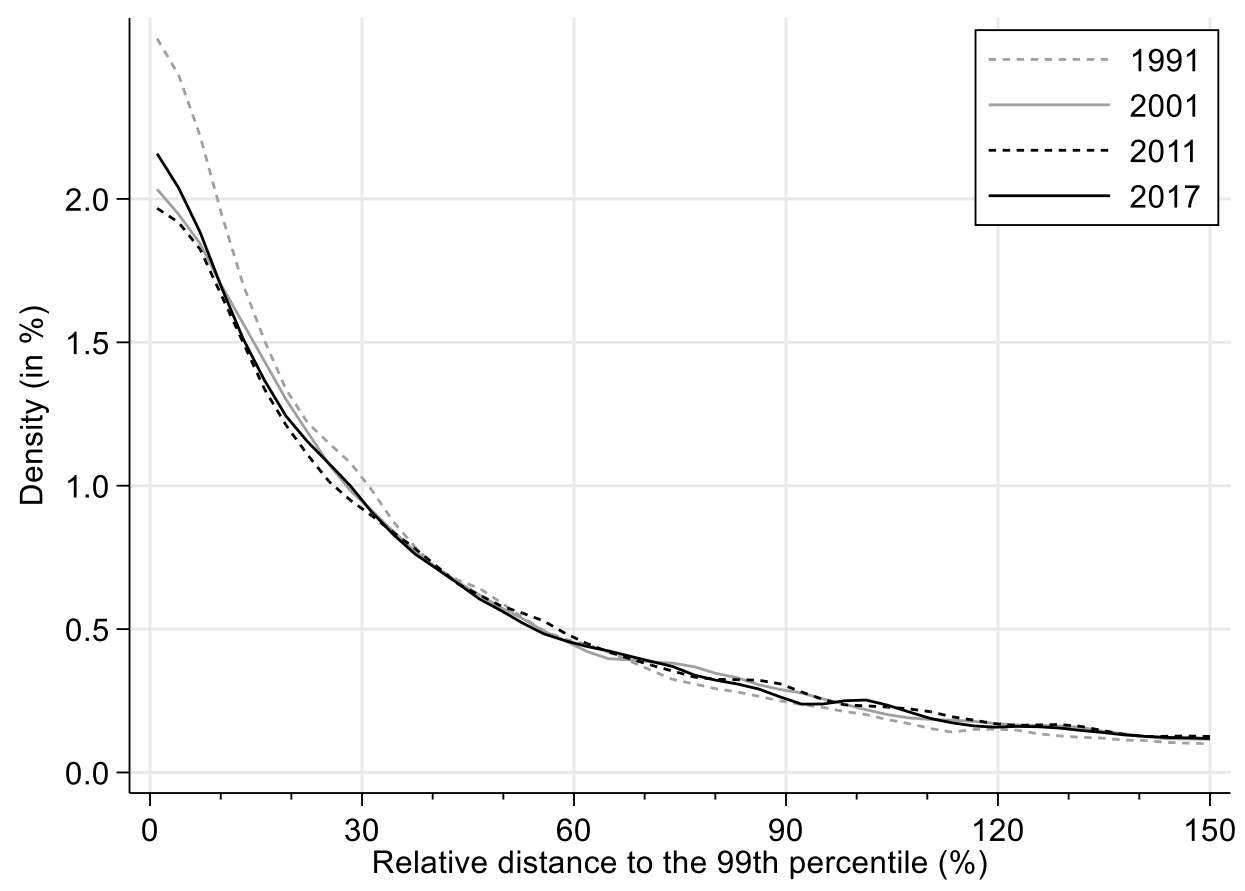

Notes: Kernel density estimates are calculated for the distribution of relative income distance to $p 99$ using an Epanechnikov kernel and bandwidth of 1 . The densities are truncated at incomes $150 \%$ above $p 99$. Relative income distance is the percentage gap between observed income and $p 99$.

Stata figure discden_lpoly_top1_totinc_noKg

Figure 11 further probes whether the 'rungs of the ladder' have been moving further apart. It presents the evolution of percentile ratios $p 99.9 / p 99, p 99 / p 95, p 95 / p 90$, and $p 90 / p 60$. Although all ratios have increased since 1991, the increases have been larger as we move closer to the top. Such growing disparities make positional top-income mobility more difficult as they increase the income changes required to move across top income groups, for example, from the top $1 \%$ income group to the top $0.1 \%$ income group. However, changes in the $p 99 / p 95$ and $p 99 / p 90$ ratios - the most relevant for top $1 \%$ persistence - have been small since 2000, and thus over the period when the increase in top-income persistence occurred. This is further evidence that the 'rungs of ladder growing further apart' story is not the main explanation for the increased top-income persistence documented in the preceding section. 
Figure 11. Income percentile ratios, by year

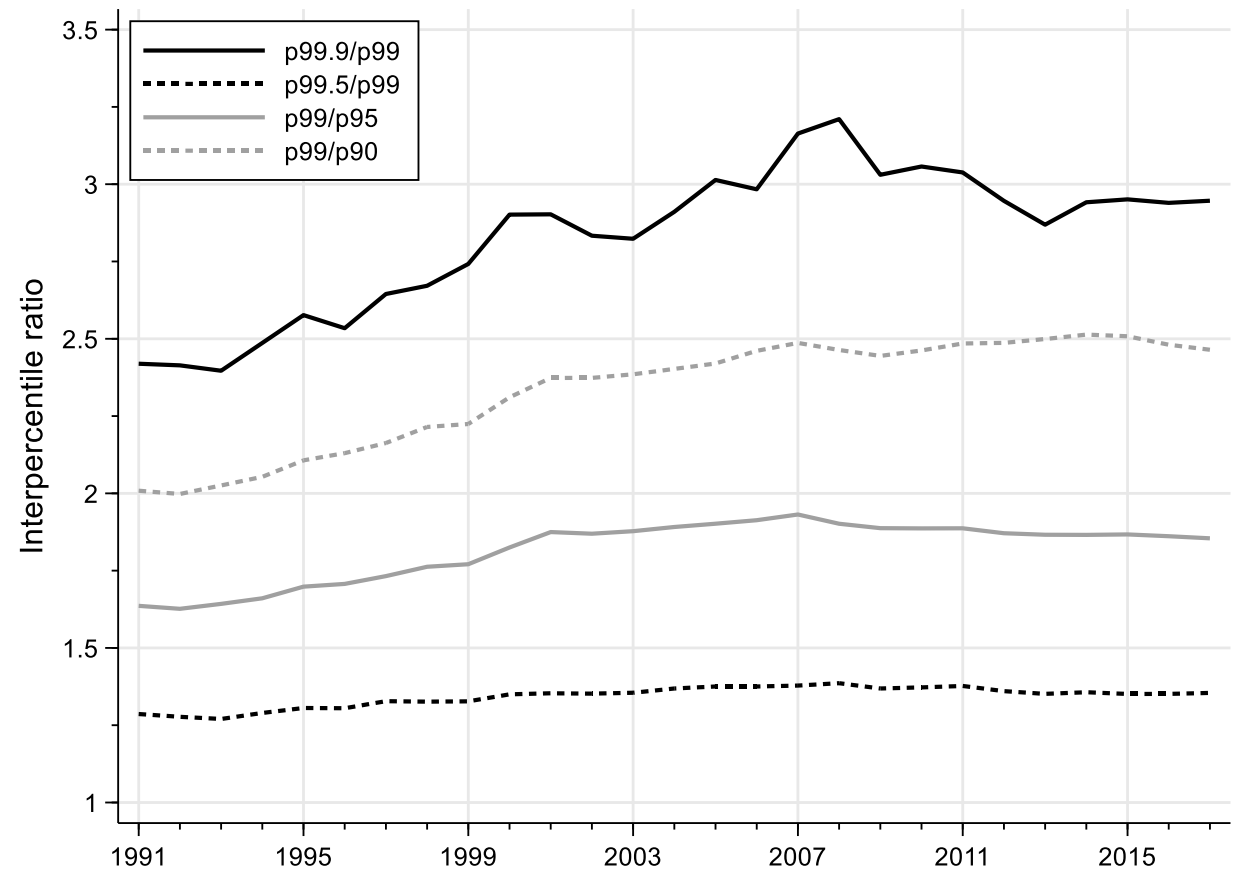

Notes: The individual is the unit of analysis. Estimates are based on the adult population (aged 15 or above). Source: Authors' calculations based on ALife and ABS population data.

Stata figure (local) percentile_ratios

\section{Differences in top-income persistence across population subgroups}

Having demonstrated a rise in top-income persistence, we wish to account for it. In this section, we examine differences in top-income persistence levels and trends across population subgroups, first using breakdowns by main source of income and by sex, and then using multivariate regression analysis.

\section{Top income persistence by main income source and sex}

Alife allows us to present breakdowns of top-income persistence statistics by a range of individual characteristics. Here we report breakdowns by the characteristics most used in topincome analysis, namely main income source and sex. We show that there has been a secular rise in top-income persistence rates in all subgroups defined by these characteristics.

What accounts for an increase in the population top-income persistence rate depends on the subgroups' persistence rates, the relative size of the two subgroups, and how each of these components changes over time. To be specific, suppose the population is exhaustively partitioned into two subgroups. The top-income persistence rate (defined as for Figure 2) for 
the population is simply the weighted average of the persistence rates of the two subgroups where the weights are the subgroup fractions of the top income group. An increase in either subgroup's top-income persistence rate between two years will increase the population persistence rate (with the contribution of the increase contingent on the subgroup's share in the top income group). However, an increase in a subgroup's share in the top income group increases the overall persistence rate only if that subgroup's persistence rate is greater the persistence rate for the other subgroup; if not, the change in top-income composition has an offsetting effect on the overall persistence rate. ${ }^{17}$

Figure 12 displays persistence rates (defined as for Figure 2) separately for individuals distinguished by whether their main source of income is labour income or non-labour income. Labour income comprises wages and salaries only, while non-labour income comprises all other income including income from investments, businesses, and government benefits. For this exercise, we treat the incomes of self-employed individuals as 70\% labour income and $30 \%$ non-labour income. We define the individuals with main income source as labour income to those with a labour income share of total income that is greater than one half in the base year of the $T$-year persistence rate calculation. (We ignore the fact than an individual's main source of income might change from one year to the next.) The remaining individuals form the non-labour income group. This group is substantially smaller than the labour income group, making up just under $25 \%$ of all adults in the top $1 \%$ in the early 1990 s and in the mid2010s, though increasing to nearly 28\% of the top $1 \%$ in 2007 (Appendix Figure C1).

Figure 12, panel (a), shows persistence rates for individuals in the top $1 \%$ in base year $t$ in the labour income group, whereas panel (b) shows persistence rates for individuals in the non-labour income group. There is more volatility in persistence rates among individuals whose main source is non-labour income, reflecting greater volatility in business incomes and greater cyclicality in investment and business incomes than labour incomes. In particular, there were greater falls in persistence rates for individuals whose main income source was non-labour income around the time of the Global Financial Crisis (mid- to late-2000s). However, both groups experienced rising persistence rates over the 1991-2017 period as a whole.

\footnotetext{
${ }^{17}$ The population top-income persistence rate for a specific base year, $r=p r_{1}+(1-p) r_{2}$ where $p$ is the proportion of the top-income group from subgroup $1,1-p$ is the proportion of the top-income group from subgroup 2 , and $r_{j}$ is the persistence rate for subgroup $j=1,2$. Hence, the change over time in $r, \dot{r}=p \dot{r}_{1}+(1-p) \dot{r}_{2}+$ $\dot{p}\left(r_{1}-r_{2}\right)$.
} 
The magnitude of the increase in persistence rate was greater for the non-labour income group. Its three-year persistence rate was $43 \%$ in 1991 , rising to $52 \%$ in 2017 , an increase of 9 percentage points (ppt) or $21 \%$. In contrast, for the non-labour income group, the three-year persistence rate rose from $32 \%$ to $45 \%$, an increase of 13 ppt or $41 \%$. (Similar cross-group differentials are apparent for the one-year and five-year persistence rates.) However, the contribution to the increase in the population persistence rate of the larger increase in the non-labour income group's persistence rate is down-weighted because the labour income group was always substantially larger in size.

Figure 13 compares top $1 \%$ persistence rates for women (panel a) and men (panel b). In the early 1990s, persistence rates were markedly higher for men than women, whether one looks at one-, three-, or five-year rates. Thereafter, persistence rates grew both for men and women, but growth was greater for women, so sex differentials in persistence rates narrowed between 1991 and 2017. For example, the three-year persistence rate for men in the top 1\% was $43 \%$ in 1991, rising to $51 \%$ in 2017 , an increase of 8 ppt or $19 \%$. In contrast, for women in the top $1 \%$, the three-year persistence rate rose from $27 \%$ to $47 \%$, an increase of 20 ppt or $52 \%$. (Similar cross-group differentials are apparent for the one-year and five-year persistence rates.) Boschini et al. (2020) show that Sweden's experience was similar to Australia's: topincome persistence rates initially lower for women but converging toward the rates for men.

The Australian difference between the sexes in increases in top-income persistence rates does not clearly account for the secular rise in the population persistence rate. The proportion of the top $1 \%$ that is female rose steadily from around $17 \%$ in the early 1990 s to almost 24\% in 2017 (Appendix Figure C1) but remained substantially smaller than the fraction for men. This has two consequences. One, although the rise in top-income persistence rates for women was greater for women than men, it gets a low weight (relative to the weight given to the rise in the men's persistence rate). Second, because the top $1 \%$ persistence rate for women remained below that for men, the increasing fraction of women in the top $1 \%$ contributed to a reduction in the population persistence rate (see footnote 17).

We have also undertaken breakdowns by occupation, age group and state of residence (available from the authors on request), and these also reveal no clear differences in topincome persistence trends across subgroups. 
Figure 12. Persistence rates for the top $1 \%$, by main source of income and year

(a) Main source is labour income

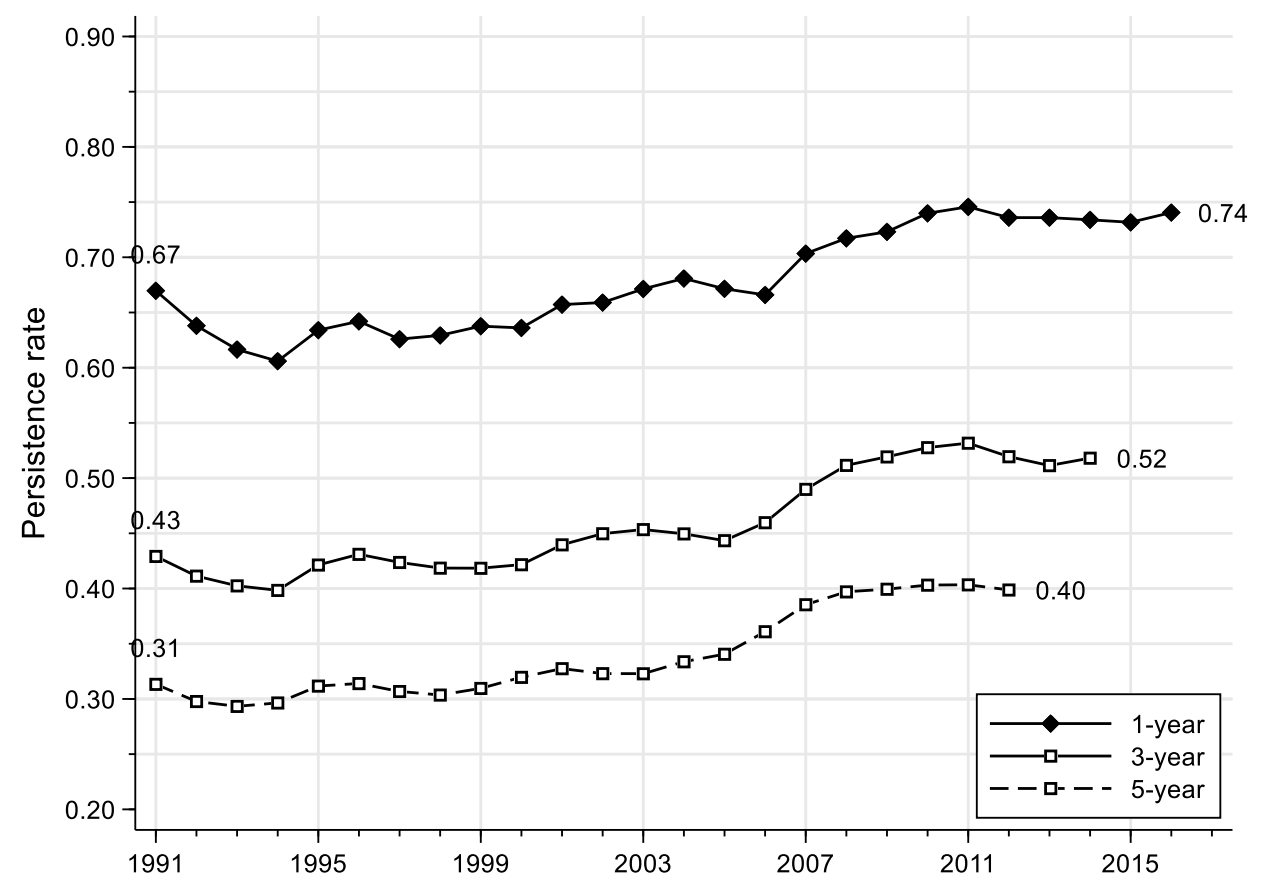

(b) Main source is non-labour income

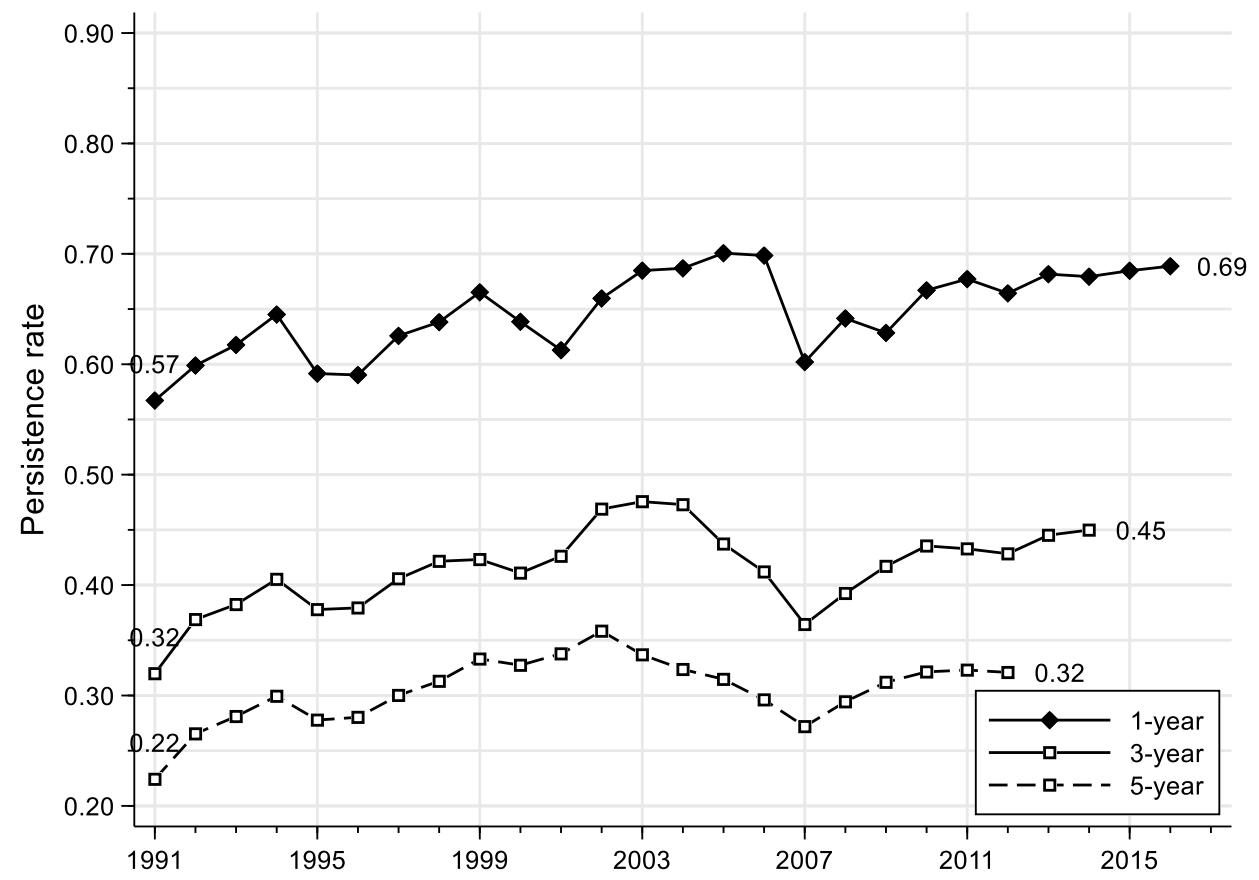

Notes: The persistence rate is the share of individuals in the top $1 \%$ in the base year who appear every year in top $1 \%$ between the base year and then in the subsequent 1,3 and 5 years. The definition of 'main source' is in the main text.

Stata figures persist5_lab_0to99_top1_totinc_noKg,persist5_cap_0to99_top1_totinc_noKg 
Figure 13. Persistence rates for the top $1 \%$ income group, by sex and year

(a) Women

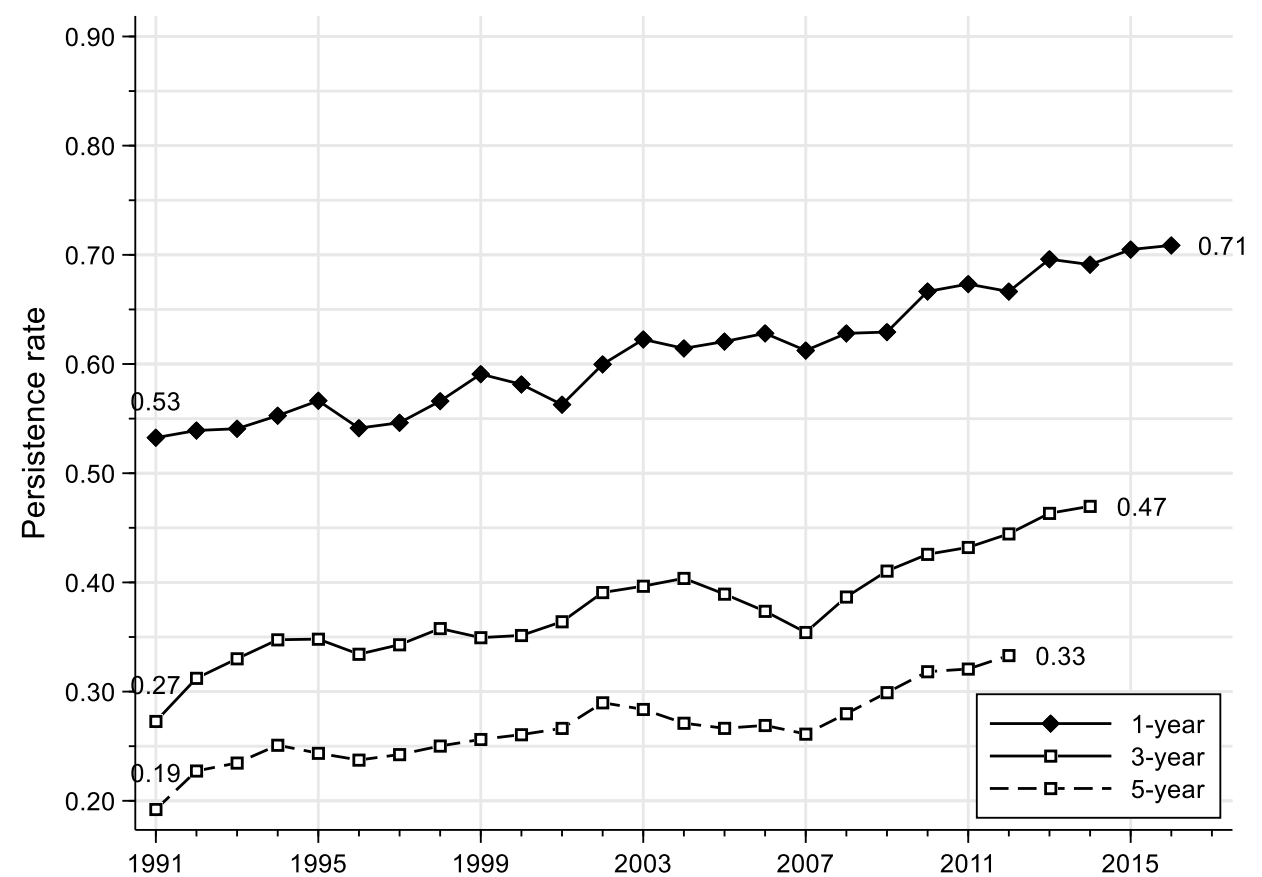

(b) Men

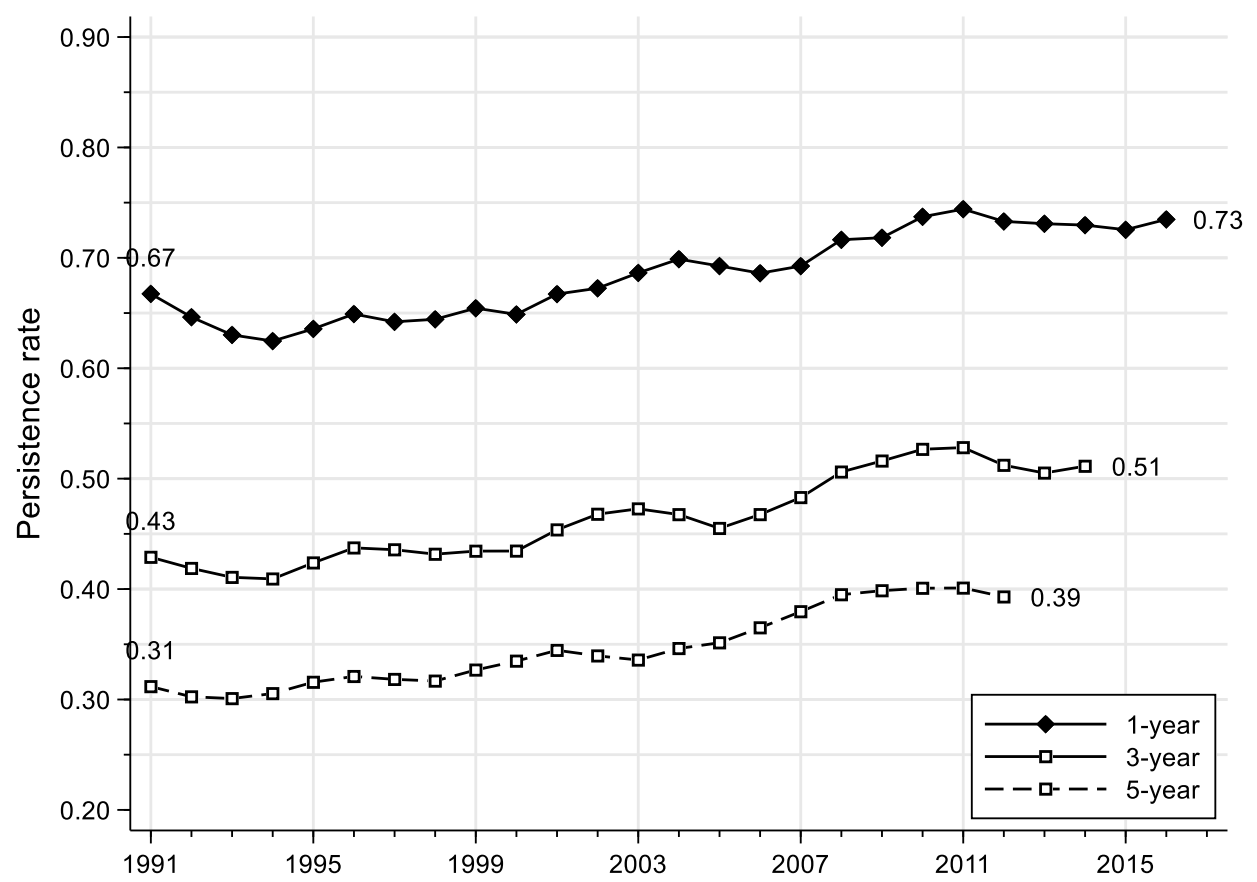

Notes: The persistence rate is the share of individuals in the top $1 \%$ in the base year who appear every year in top $1 \%$ between the base year and then in the subsequent 1,3 and 5 years.

Stata figures persist5_M_Oto99_top1_totinc_noKg, persist5_F_Oto99_top1_totinc_noKg 


\section{Multivariate regression analysis of top income-persistence}

To investigate in greater detail how top-income persistence differs across individuals, we fit two binary logit regression models: the first for the probability of top $1 \%$ membership in year $t$ for individuals in the top $1 \%$ in year $t-1$ (top-income stayer model), and the second for the probability of top $1 \%$ membership in year $t$ for all tax filers not in the top $1 \%$ in year $t-1$ (topincome joiner model). ${ }^{18}$ When fitting each regression model, we pool the data for the whole period 1991-2017, and use as explanatory variables sex, age group, federal state of residence, self-employment status, main source of income and time-period (1991-1999, 2000-2008, and 2009-2017). Each is measured at $t-1$. In the top-income stayer model, we also use the individual's normalized rank within the top $1 \%$ at $t-1$ as an explanatory variable. For each regression model, we also interact sex and (two of the three) time-period binary indicator variables with each of the other covariates to investigate subgroup and temporal differences in more detail.

Tables 3 and 4 report the average partial effects (APEs) of each explanatory variables for the top-income stayer and joiner models respectively. The first pair of columns (labelled 'unconditional') shows the APE for each covariate and its standard error (SE). The other columns show APEs and SEs calculated for subsamples defined by time period and sex, and hence changes over time and differences between men and women.

Consider first the factors associated with the one-year top-income stayer probability (Table 3). The time-period indicators show an increase in persistence even after controlling for personal characteristics. Compared with 1991-1999, the top 1\% stayer probability was 1.4 percentage points higher in the 2000-2008 period and 6.6 percentage points higher in 20092017.

Women have a smaller top $1 \%$ stayer probabilities than men. The overall gap is 3.2 percentage points, but it declined from 3.8 percentage points in the pre-2009 period to 2.3 percentage points in the post-2009 period. Thus, although there was a notable increase in the share of the top $1 \%$ that is female (Appendix Figure C1) which would have acted to reduce top income persistence, this was counteracted by an increase in persistence among women compared with men.

Normalised rank within the top $1 \%$ is a strong predictor of top-income stayer probabilities, but its effects remained stable over time and are similar for men and women.

\footnotetext{
${ }^{18}$ The estimation sample for the top-income joiner model excludes individuals who do not have Alife records in year $t$ (or before), i.e., non-tax filers.
} 
Top-income stayer probabilities are highest for individuals aged 35-44, followed by those aged 45-54, a result that holds for both men and women and in both the pre- and post2009 periods. Stayer probabilities are lowest among those aged 55-64, likely reflecting the effects of retirement for this age group but, in the 2009-2017 period, those aged under 35 had equally low probabilities of remaining in the top $1 \%$. Indeed, it is clear that individuals in both of the two oldest age groups $(55-64,65+)$ experienced larger increases in top-income staying probabilities between the pre-2009 period and the post-2009 period than younger individuals. This, along with the growth in the share of the top 1\% aged 55-64 (Appendix Figure $\mathrm{C} 2$ ), is therefore an important source in the rise of overall top-income persistence.

Individuals living in New South Wales have the largest top 1\% stayer probabilities, though differences between them and individuals living in every other state, except Victoria, were lower in the post-2009 period. Residents of Western Australia have relatively low stayer probabilities but experienced a greater increase between the pre-2009 and post-2009 periods than did residents of most other states. Thus, similar to what we find for women, while the growth in Western Australians' share of the top 1\% (Appendix Figure C3) would have acted to reduce top-income persistence, this would have been offset by the relatively large growth in top $1 \%$ persistence for residents in that state.

In the pre-2009 period, self-employed individuals in the top $1 \%$ did not have a significantly different probability of remaining in the top $1 \%$ than other members of the top 1\%. However, in the 2009-2017 period, self-employment was associated with a $1.1 \mathrm{ppt}$ lower probability of remaining in the top $1 \%$. Note, however, that the proportion of the top $1 \%$ who are self-employed fell between 2007 and 2015 (Appendix Figure C1).

Top $1 \%$ members for whom labour is the main source of income (defined as earlier) have a $6.6 \mathrm{ppt}$ higher probability of remaining in the top $1 \%$ than those whose main source is non-labour income. This gap grew between the pre- and post-2009 periods, from 4.7 ppt to $9.5 \mathrm{ppt}$. Interestingly, however, the proportion of the top $1 \%$ for whom labour is the main source of income fell between 2007 and 2013 (Appendix Figure C1), which would have acted to reduce top $1 \%$ persistence rates.

We now turn to the top $1 \%$ joiner model: see Table 4 . The time-period indicator variables show a small decline over time in the probability of entry to the top $1 \%$, hence contributing to the rise in top-income persistence more generally. Compared with the 19911999 period and controlling for personal characteristics, the probability of entering the top $1 \%$ was 0.05 ppt lower in the 2000-2008 period and 0.13 ppt lower in the 2009-2017 period. 
The probability of entering the top $1 \%$ is smaller for women than men by $0.44 \mathrm{ppt}$, but the gap declined from 0.50 pre-2009 to 0.38 post-2009. Individuals aged under 35 are the least likely to enter the top $1 \%$. Prior to 2009 , persons aged 55-64 were the most likely to enter the top $1 \%$ but, post-2009, those aged 35-44 have had the highest top 1\% entry probability, followed by those aged 45-54 and then those in the 55-64 age group. Persons aged $65+$ also experienced a relative decline in the probability of entering the top $1 \%$. These patterns by age hold for both men and women.

The probability of entering the top 1\% was largest for residents of New South Wales in the pre-2009 period, but Western Australian residents had the highest probability of entering the top $1 \%$ in the $2009-2017$ period. Again, these patterns by state hold for both men and women.

Self-employed individuals have a higher probability of entering the top $1 \%$ than other tax filers outside the top $1 \%$, and the gap increased from $0.09 \mathrm{ppt}$ to $0.13 \mathrm{ppt}$ between the preand post-2009 periods. Although individuals with labour income as their main income source were more likely than others to enter the top $1 \%$ before 2009 , by $0.07 \mathrm{ppt}$, they became less likely to do so after 2009 , by 0.19 ppt. 
Table 3. Probability of top $1 \%$ membership in year $t$ for top $1 \%$ members in year $t-1$ (stayer model)

\begin{tabular}{|c|c|c|c|c|c|c|c|c|c|c|c|c|c|c|}
\hline & \multicolumn{2}{|c|}{ Unconditional } & \multicolumn{2}{|c|}{$\begin{array}{c}2009-17 \\
\text { dummy }=0\end{array}$} & \multicolumn{2}{|c|}{$\begin{array}{c}2009-17 \\
\text { dummy=1 }\end{array}$} & \multicolumn{2}{|c|}{$\begin{array}{c}2009-17 \\
\text { dummy }=0 \& \\
\text { women }=0\end{array}$} & \multicolumn{2}{|c|}{$\begin{array}{c}2009-17 \\
\text { dummy=1 \& } \\
\text { women=0 }\end{array}$} & \multicolumn{2}{|c|}{$\begin{array}{c}2009-17 \\
\text { dummy=0 \& } \\
\text { women=1 }\end{array}$} & \multicolumn{2}{|c|}{$\begin{array}{c}2009-17 \\
\text { dummy=1 \& } \\
\text { women=1 }\end{array}$} \\
\hline & APE & SE & APE & SE & APE & SE & APE & $\mathrm{SE}$ & APE & SE & APE & SE & APE & $\mathrm{SE}$ \\
\hline $\begin{array}{l}\text { Women } \\
\text { Normalised rank in top } 1 \%\end{array}$ & $-3.206 * * *$ & 0.192 & $-3.753 * * *$ & 0.296 & $-2.289 * * *$ & 0.334 & & & & & & & & \\
\hline$[0,100]$ & $0.478 * * *$ & 0.002 & $0.478 * * *$ & 0.003 & $0.478 * * *$ & 0.004 & $0.484 * * *$ & 0.004 & $0.488 * * *$ & 0.005 & $0.461 * * *$ & 0.008 & $0.445 * * *$ & 0.009 \\
\hline \multicolumn{15}{|l|}{ Age (ref. is under 35) } \\
\hline $35-44$ & $6.495^{* * *}$ & 0.286 & $5.874 * * *$ & 0.392 & $7.436^{* * *}$ & 0.536 & $5.803 * * *$ & 0.388 & $7.330 * * *$ & 0.528 & $6.198 * * *$ & 0.411 & $7.895 * * *$ & 0.572 \\
\hline $45-54$ & $5.524 * * *$ & 0.287 & $5.081 * * *$ & 0.393 & $6.289 * * *$ & 0.536 & $5.024 * * *$ & 0.389 & $6.203 * * *$ & 0.529 & $5.342 * * *$ & 0.412 & $6.662 * * *$ & 0.572 \\
\hline $55-64$ & $-4.105 * * *$ & 0.314 & $-6.904 * * *$ & 0.445 & 0.344 & 0.583 & $-6.836^{* * *}$ & 0.442 & 0.347 & 0.574 & $-7.241 * * *$ & 0.464 & 0.325 & 0.62 \\
\hline $65+$ & 0.491 & 0.378 & $-2.401 * * *$ & 0.537 & $4.808 * * *$ & 0.681 & $-2.373 * * *$ & 0.533 & $4.743 * * *$ & 0.671 & $-2.533 * * *$ & 0.56 & $5.095 * * *$ & 0.728 \\
\hline \multicolumn{15}{|l|}{ State (ref. is NSW) } \\
\hline Queensland & $-3.816 * * *$ & 0.225 & $-4.683 * * *$ & 0.333 & $-2.580 * * *$ & 0.389 & $-4.632 * * *$ & 0.33 & $-2.544 * * *$ & 0.383 & $-4.925 * * *$ & 0.349 & $-2.739 * * *$ & 0.416 \\
\hline South Australia & $-1.954 * * *$ & 0.343 & $-2.715 * * *$ & 0.493 & -0.829 & 0.609 & $-2.683 * * *$ & 0.488 & -0.817 & 0.6 & $-2.864 * * *$ & 0.517 & -0.881 & 0.651 \\
\hline Victoria & $-0.725 * * *$ & 0.185 & $-0.576^{* *}$ & 0.275 & $-0.976 * * *$ & 0.333 & $-0.570 * *$ & 0.272 & $-0.962 * * *$ & 0.328 & $-0.606^{* *}$ & 0.29 & $-1.035 * * *$ & 0.356 \\
\hline Western Australia & $-2.822 * * *$ & 0.244 & $-3.613 * * *$ & 0.377 & $-1.768 * * *$ & 0.397 & $-3.574 * * *$ & 0.373 & $-1.745 * * *$ & 0.39 & $-3.794 * * *$ & 0.396 & $-1.867 * * *$ & 0.425 \\
\hline ACT, NT \& Tasmania & $-4.076 * * *$ & 0.389 & $-5.160 * * *$ & 0.561 & $-2.424 * * *$ & 0.697 & $-5.102 * * *$ & 0.556 & $-2.388 * * *$ & 0.686 & $-5.435 * * *$ & 0.586 & $-2.582 * * *$ & 0.744 \\
\hline Self-employed & $-0.354 *$ & 0.204 & 0.099 & 0.304 & $-1.109 * * *$ & 0.361 & 0.096 & 0.301 & $-1.095 * * *$ & 0.355 & 0.117 & 0.319 & $-1.169 * * *$ & 0.385 \\
\hline Main income source is labour & $6.585^{* * *}$ & 0.208 & $4.691 * * *$ & 0.31 & $9.500 * * *$ & 0.371 & $4.642 * * *$ & 0.308 & $9.371 * * *$ & 0.368 & $4.908 * * *$ & 0.32 & $10.065^{* * *}$ & 0.388 \\
\hline \multicolumn{15}{|l|}{ Period (ref. is 1991-99) } \\
\hline 2000-08 & $1.397 * * *$ & 0.188 & & & & & & & & & & & & \\
\hline $2009-17$ & $6.636^{* * *}$ & 0.187 & & & & & & & & & & & & \\
\hline
\end{tabular}

Notes: APE: average partial effect in percentage points. Derived from logit model of the probability of staying in the top 1\% of the adult income distribution in year $t$ conditional on all observables in year $t-1$. SE: standard error. The estimation sample consists of all individuals in the top $1 \%$ in year $t-1$. Sample size is 362,830 . Estimates account for interaction terms. $* \mathrm{p}<0.10, * * \mathrm{p}<0.05, * * * \mathrm{p}<0.01$. 
Table 4. Probability of top $1 \%$ membership in year $t$ for non-top $1 \%$ tax filers in year $t-1$ (joiner model)

\begin{tabular}{|c|c|c|c|c|c|c|c|c|c|c|c|c|c|c|}
\hline & \multicolumn{2}{|c|}{ Unconditional } & \multicolumn{2}{|c|}{$\begin{array}{c}2009-17 \\
\text { dummy=0 }\end{array}$} & \multicolumn{2}{|c|}{$\begin{array}{c}2009-17 \\
\text { dummy=1 }\end{array}$} & \multicolumn{2}{|c|}{$\begin{array}{c}2009-17 \\
\text { dummy }=0 \& \\
\text { women }=0\end{array}$} & \multicolumn{2}{|c|}{$\begin{array}{c}2009-17 \\
\text { dummy }=1 \& \\
\text { women=0 }\end{array}$} & \multicolumn{2}{|c|}{$\begin{array}{c}2009-17 \\
\text { dummy }=0 \& \\
\text { women=1 }\end{array}$} & \multicolumn{2}{|c|}{$\begin{array}{c}2009-17 \\
\text { dummy=1 \& } \\
\text { women=1 }\end{array}$} \\
\hline & APE & SE & APE & $\mathrm{SE}$ & APE & $\mathrm{SE}$ & APE & SE & APE & SE & APE & SE & APE & SE \\
\hline Women & $-0.441 * * *$ & 0.003 & $-0.497 * * *$ & 0.004 & $-0.376^{* * *}$ & 0.004 & & & & & & & & \\
\hline \multicolumn{15}{|l|}{ Age (ref. is under 35) } \\
\hline $35-44$ & $0.492 * * *$ & 0.004 & $0.497 * * *$ & 0.006 & $0.492 * * *$ & 0.007 & $0.714 * * *$ & 0.009 & $0.707 * * *$ & 0.01 & $0.253 * * *$ & 0.003 & $0.255^{* * *}$ & 0.004 \\
\hline $45-54$ & $0.476^{* * *}$ & 0.004 & $0.507 * * *$ & 0.006 & $0.443 * * *$ & 0.007 & $0.728 * * *$ & 0.009 & $0.636 * * *$ & 0.01 & $0.258 * * *$ & 0.004 & $0.229 * * *$ & 0.004 \\
\hline $55-64$ & $0.469 * * *$ & 0.005 & $0.576^{* * *}$ & 0.008 & $0.318 * * *$ & 0.007 & $0.826^{* * *}$ & 0.012 & $0.456 * * *$ & 0.01 & $0.294 * * *$ & 0.005 & $0.165^{* * *}$ & 0.004 \\
\hline $65+$ & $0.195^{* * *}$ & 0.005 & $0.267 * * *$ & 0.01 & $0.097 * * *$ & 0.007 & $0.384 * * *$ & 0.014 & $0.140 * * *$ & 0.01 & $0.136 * * *$ & 0.005 & $0.050 * * *$ & 0.004 \\
\hline \multicolumn{15}{|l|}{ State (ref. is NSW) } \\
\hline Queensland & $-0.168 * * *$ & 0.004 & $-0.204 * * *$ & 0.006 & $-0.116^{* * *}$ & 0.006 & $-0.293^{* * *}$ & 0.009 & $-0.166^{* * *}$ & 0.009 & $-0.105 * * *$ & 0.003 & $-0.060 * * *$ & 0.003 \\
\hline South Australia & $-0.233 * * *$ & 0.005 & $-0.267 * * *$ & 0.008 & $-0.188 * * *$ & 0.008 & $-0.384 * * *$ & 0.011 & $-0.271 * * *$ & 0.011 & $-0.137 * * *$ & 0.004 & $-0.098 * * *$ & 0.004 \\
\hline Victoria & $-0.103 * * *$ & 0.004 & $-0.130 * * *$ & 0.006 & $-0.066^{* * *}$ & 0.006 & $-0.187 * * *$ & 0.009 & $-0.095^{* * *}$ & 0.009 & $-0.067 * * *$ & 0.003 & $-0.035^{* * *}$ & 0.003 \\
\hline Western Australia & $0.048 * * *$ & 0.005 & $-0.070 * * *$ & 0.008 & $0.212 * * *$ & 0.01 & $-0.101 * * *$ & 0.012 & $0.305^{* * *}$ & 0.015 & $-0.036 * * *$ & 0.004 & $0.111 * * *$ & 0.006 \\
\hline ACT, NT \& Tasmania & $-0.132 * * *$ & 0.006 & $-0.131 * * *$ & 0.011 & $-0.130 * * *$ & 0.01 & $-0.188 * * *$ & 0.015 & $-0.187 * * *$ & 0.014 & $-0.067 * * *$ & 0.005 & $-0.068 * * *$ & 0.005 \\
\hline Self-employed & $0.106^{* * *}$ & 0.005 & $0.086^{* * *}$ & 0.007 & $0.126 * * *$ & 0.009 & $0.123 * * *$ & 0.01 & $0.181 * * *$ & 0.012 & $0.045^{* * *}$ & 0.004 & $0.067 * * *$ & 0.005 \\
\hline Main income source is labour & $-0.060 * * *$ & 0.004 & $0.037 * * *$ & 0.006 & $-0.193 * * *$ & 0.009 & $0.054 * * *$ & 0.009 & $-0.275^{* * *}$ & 0.013 & $0.018 * * *$ & 0.003 & $-0.101 * * *$ & 0.005 \\
\hline \multicolumn{15}{|l|}{ Period (ref. is 1991-99) } \\
\hline 2000-08 & $-0.047 * * *$ & 0.004 & & & & & & & & & & & & \\
\hline $2009-17$ & $-0.127 * * *$ & 0.004 & & & & & & & & & & & & \\
\hline
\end{tabular}

Notes. APE: average partial effect in percentage points. Derived from logit model of the probability of entering the top 1\% of the adult income distribution in year $\mathrm{t}$ conditional on all observables in year $t-1$. SE: Standard error. The estimation sample consists of tax filers not in the top $1 \%$ in year $t-1$. Sample size is 24,516,592. Estimates account for interaction terms. $* \mathrm{p}<0.10, * * \mathrm{p}<0.05, * * * \mathrm{p}<0.01$. 


\section{Summary and conclusions}

We have documented top-income persistence levels and trends for Australia using multiple perspectives, exploiting the advantages of newly available longitudinal income tax data. We find a distinct rise in top-income persistence over the 1991-2017 period with most of the increase occurring in the mid-2000s and late-2010s. That is, over a period in which yearly top-income shares were rising, there was also a growing inequality in the opportunities to have a top income.

Around the mid- to late-2010s, top-income persistence in Australia was towards the top of the range found for other countries with estimates derived from tax data - though we would reiterate that cross-national differences are difficult to assess because of comparability issues. Improving comparability in terms of definitions, samples, and time periods covered is an important task for future cross-national research.

Also important for future research is further analysis of the drivers of top-income persistence. Our univariate breakdowns and multivariate regression analysis reveal that topincome persistence rates rose among all the population subgroups (defined by sex, main income source, age, and state of residence). We have also pointed out how changes in the composition of the top-income group can offset the impacts on overall top-income persistence of rises in top-income persistence for specific subgroups. An in-depth account of why topincome persistence has risen in Australia considering the roles of changing incomes and topincome thresholds, and changing top-income group composition, is a story yet to be told.

\section{References}

Aaberge, R., Atkinson, A. B., and Modalsli, J. 2013. The ins and outs of top income mobility. IZA Discussion Paper No. 7729. Bonn: IZA.

Atkinson, A. B., and Leigh, A. 2007. The distribution of top incomes in Australia. Economic Record 83 (262): 247-261.

Atkinson, A. B., Piketty, T., and Seaz, E. 2011. Top Incomes in the long run of history. Journal of Economic Literature, 49 (1), 3-71.

Auten, G. and Gee, G. 2009. Income mobility in the United States: new evidence from income tax data. National Tax Journal, 57 (2): 301-328.

Auten, G., Gee, G., and Turner, N. 2013. Income inequality, mobility, and turnover at the top 
in the US, 1987-2010. American Economic Review: Papers \& Proceedings, 103 (3): $168-172$.

Boschini, A., Gunnarsson, K., and Roine, J. 2020. Women in top incomes: evidence from Sweden 1974-2013. Journal of Public Economics, 181: 104115.

Burkhauser, R. V., Hahn, M. H., and Wilkins, R. 2015. Measuring top incomes using tax record data: a cautionary tale from Australia. Journal of Economic Inequality, 13 (2): $181-205$.

Burkhauser, R. V, Hahn, M. H., and Wilkins, R. 2018. Transitioning from an historical to a contemporary use of tax record data for measuring top incomes in Australia. Economic Papers, 37 (2): 1-33.

Jenderny, K. 2016. Mobility of top incomes in Germany. Review of Income and Wealth, 62 (2): 245-265.

Joyce, R., Pope, T., and Roantree, B. 2019. The characteristics and incomes of the top $1 \%$. Briefing Note BN254. London: Institute for Fiscal Studies.

Kopczuk, W., Saez, E. and Song, J. 2010. Earnings inequality and mobility in the United States: evidence from Social Security data since 1937. Quarterly Journal of Economics, $125(1), 92-128$.

Landais, C. 2008. Top incomes in France: booming inequalities? Unpublished paper. Paris:

Paris School of Economics. http://econ.lse.ac.uk/staff/clandais/cgibin/Articles/topincomes.pdf.

Morelli, S., Smeeding, T., and Thompson, J. 2015. Post-1970 trends in within-country inequality and poverty: rich and middle income countries. In: Atkinson, A.B. and F. Bourguignon (eds.) Handbook of Income Distribution, Volume 2. Amsterdam: ElsevierNorth Holland.

Martínez, I. Z. 2017. Who is a top earner and for how long? Top income mobility in Switzerland. Paper presented at the first WID.World Conference, Paris. http://wid.world/wp-content/uploads/2017/11/099-Martinez-mobility_topearners.pdf.

Saez, E. and Veall, M. R. 2005. The evolution of high incomes in Northern America: lessons from Canadian evidence. American Economic Review, 95 (3): 831-849.

Shorrocks, A. F. 1978. 'Income inequality and income mobility', Journal of Economic Theory, 19 (2): 376-393. 
Appendix A. ATO adjustment of Employment Termination Payments

Table A1. ATO adjustment of Employment Termination Payments (2000-2016, in current dollars)

\begin{tabular}{rrr}
\hline Tax year & Total adjustment & Mean adjustment \\
\hline 1991 & $-8,241,221$ & $-343,384$ \\
1992 & $-14,613,357$ & $-608,890$ \\
1993 & $-11,291,962$ & $-470,498$ \\
1994 & $-15,332,505$ & $-638,854$ \\
1995 & $-15,336,185$ & $-639,008$ \\
1996 & $-10,649,353$ & $-443,723$ \\
1997 & $-16,235,498$ & $-676,479$ \\
1998 & $-16,477,313$ & $-686,555$ \\
1999 & $-27,519,147$ & $-1,146,631$ \\
2000 & $-42,319,718$ & $-1,763,322$ \\
2001 & $-15,676,018$ & $-653,167$ \\
2002 & $-27,836,179$ & $-1,159,841$ \\
2003 & $-24,939,858$ & $-1,039,161$ \\
2004 & $-18,548,200$ & $-772,842$ \\
2005 & $-20,565,614$ & $-856,901$ \\
2006 & $-21,123,878$ & $-880,162$ \\
2007 & $-32,612,964$ & $-1,358,874$ \\
2008 & $-47,913,907$ & $-1,996,413$ \\
2009 & $-51,932,913$ & $-2,163,871$ \\
2010 & $-51,184,871$ & $-2,132,703$ \\
2011 & $-56,628,558$ & $-2,359,523$ \\
2012 & $-34,672,593$ & $-1,444,691$ \\
2013 & $-20,742,471$ & $-864,270$ \\
2014 & $-36,156,344$ & $-1,506,514$ \\
2015 & $-14,594,126$ & $-608,089$ \\
2016 & $-23,385,390$ & $-974,391$ \\
2017 & -19181113 & -799213 \\
\hline
\end{tabular}

Notes: Employment termination payment is a lump sum payment made as a result of the termination of a person's employment.

Source: ATO (private communication). 


\section{Appendix B. Comparison with earlier top 1\% income share estimates}

Figure B1 compares top 1\% income shares obtained with ALife data to the estimates of Burkhauser et al. (2018) based on customised ATO tables (labelled 'ATO cust. tab. (EP 2018)'). The Burkhauser et al. (2018) estimates are lower than our Alife estimates but show the same trends.

Figure B1. Comparing ALife and Burkhauser et al. (2018) top 1\% income shares from 2000 to 2016

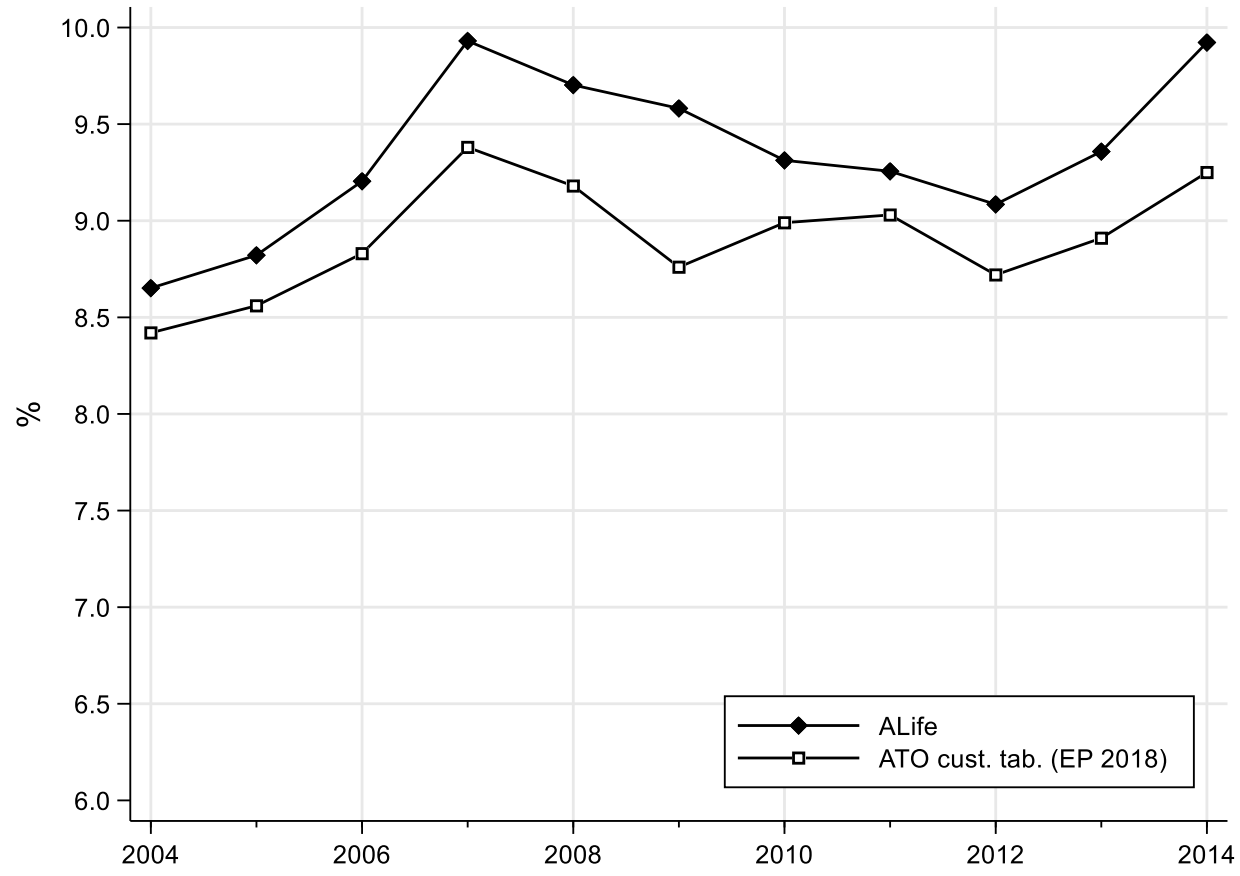

Stata figure toplshb 


\section{Appendix C. Composition of the top 1\% income group}

Figures $\mathrm{C} 1$ to $\mathrm{C} 3$ give an overview of the composition of the top $1 \%$ income group in terms of sex, main source of income, self-employment status, age group, and state of residence.

Figure C1. Top 1\% composition by sex, self-employment status and main income source

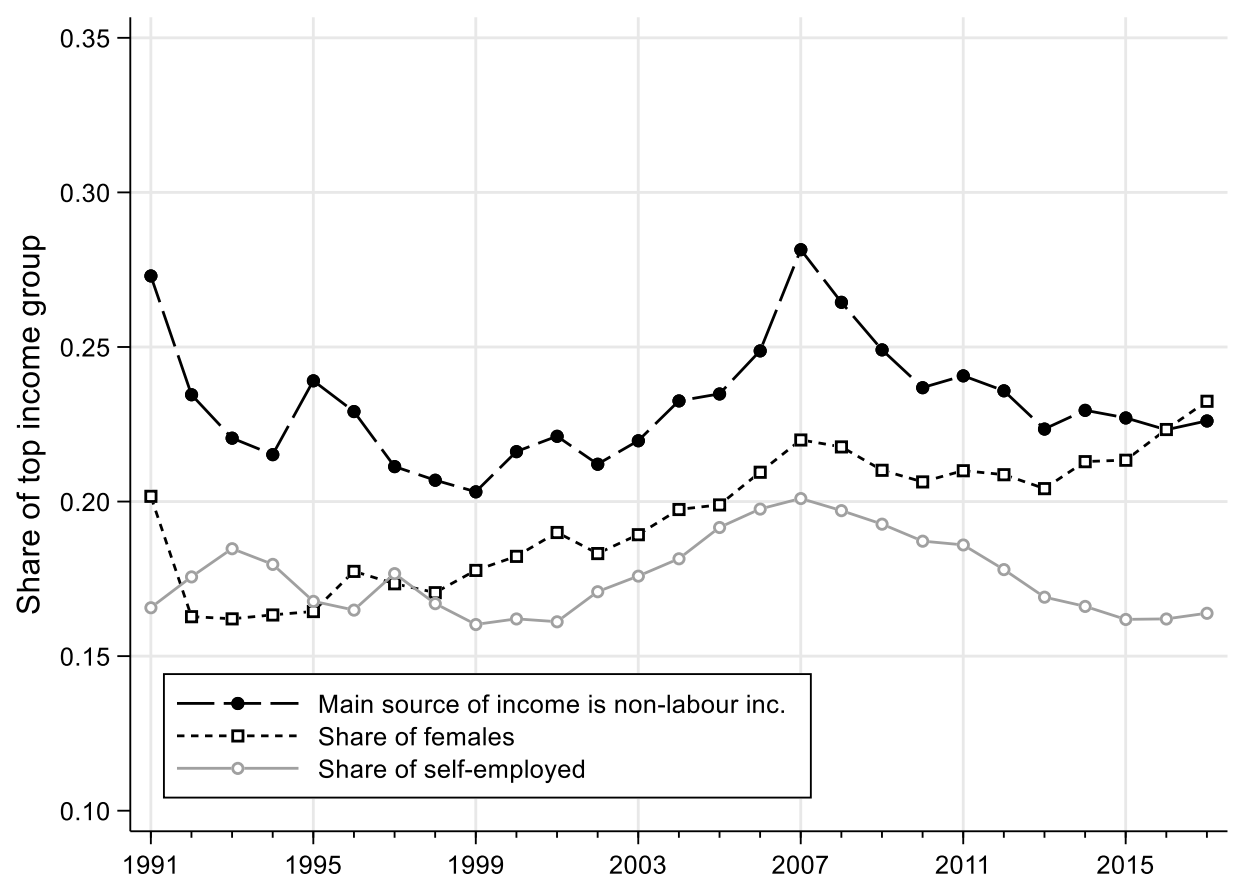

Stata figure top1_sex_age_src_self_totinc_noKg

Figure C2. Top 1\% composition by age group

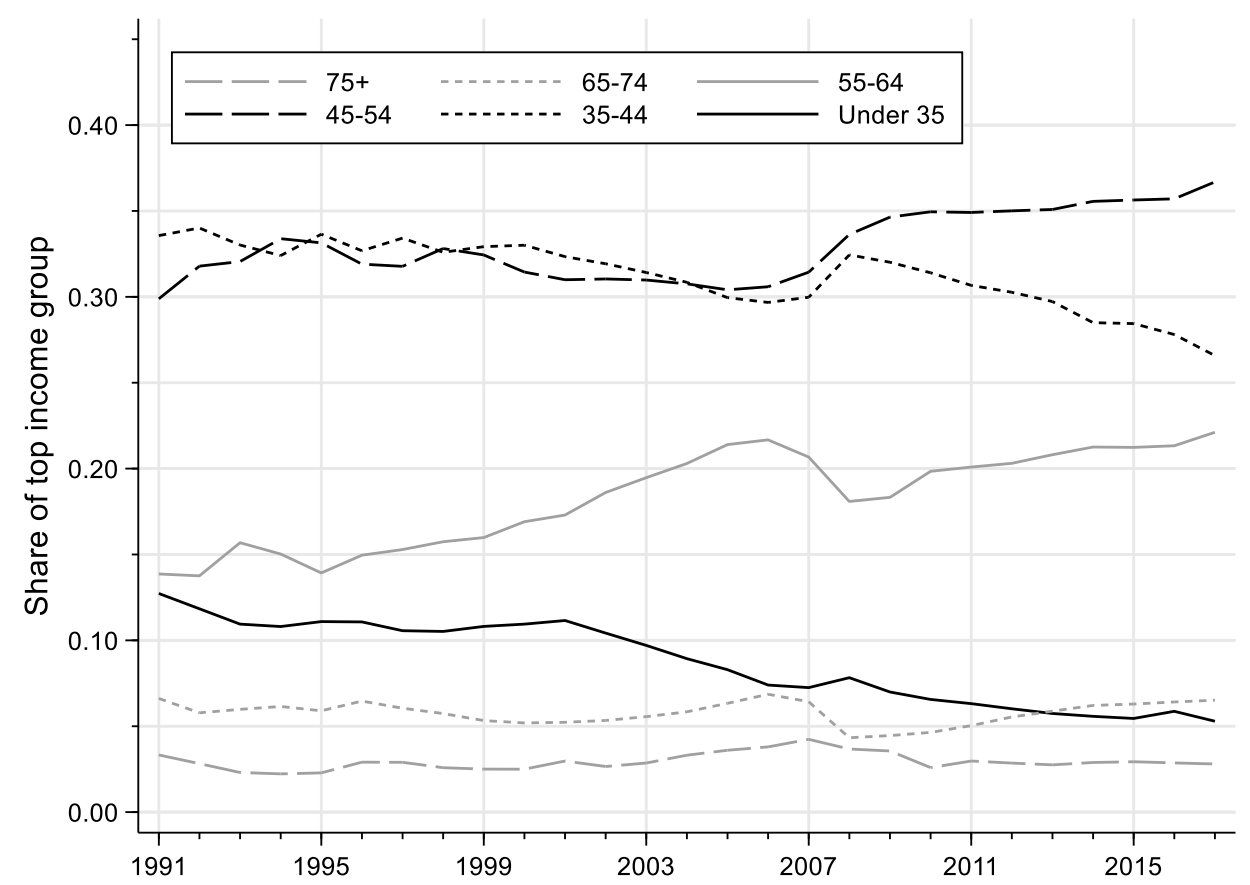

Stata figure top1_agecomp_totinc_noKg_b 
Figure C3. Top $1 \%$ composition by state of residence

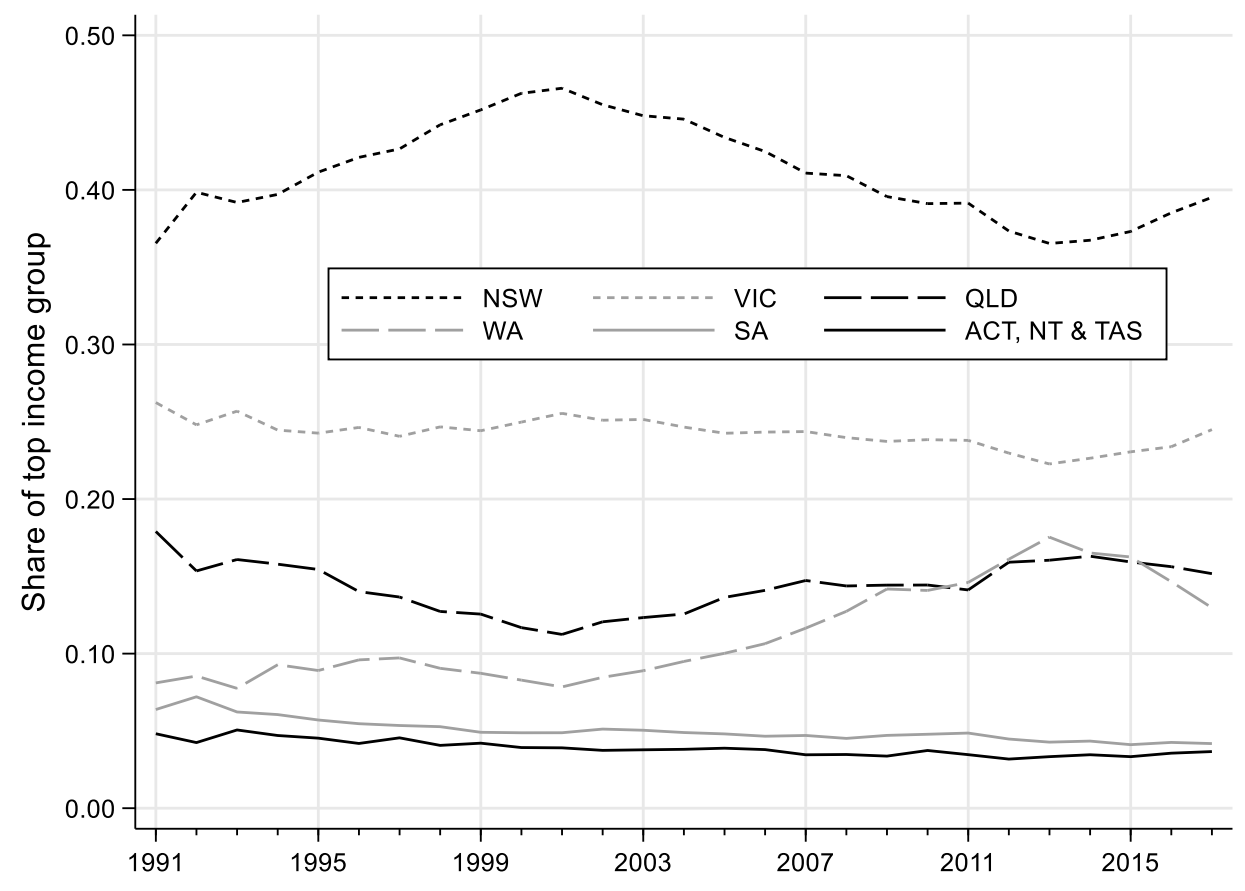

Stata figure topl_statecomp_totinc_noKg 
Appendix D. Persistence rates in the top $1 \%$ for alternative income definitions and age groups

Figure D1. Persistence rate in the top $1 \%$ income group, including taxable realised capital gains

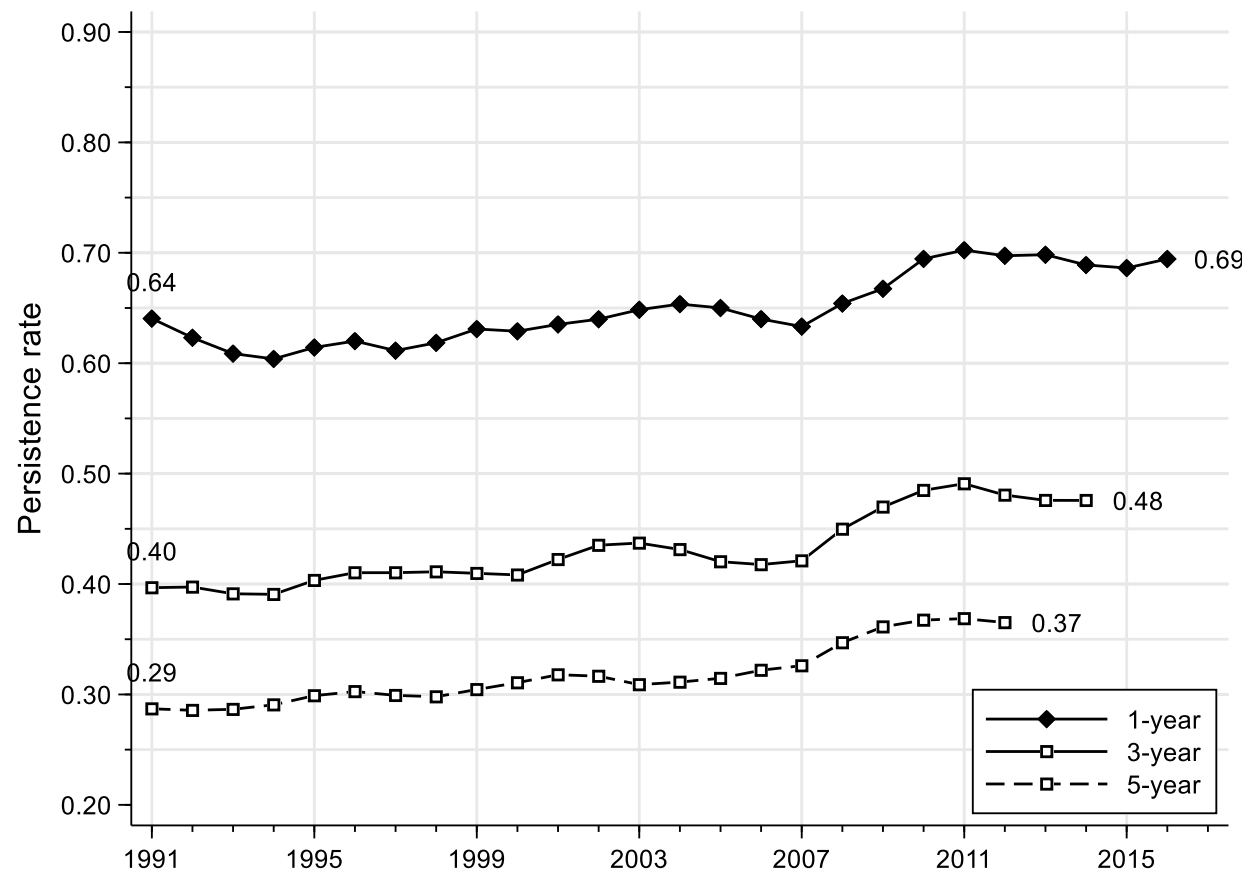

Notes: The persistence rate is the share of individuals in the top $1 \%$ in the base year who appear every year in top $1 \%$ between the base year and then in the subsequent 1,3 and 5 years.

Stata figure persist5_0to99_topl_totinc

\section{Figure D2. Persistence rate in the top $1 \%$ of after-tax income}

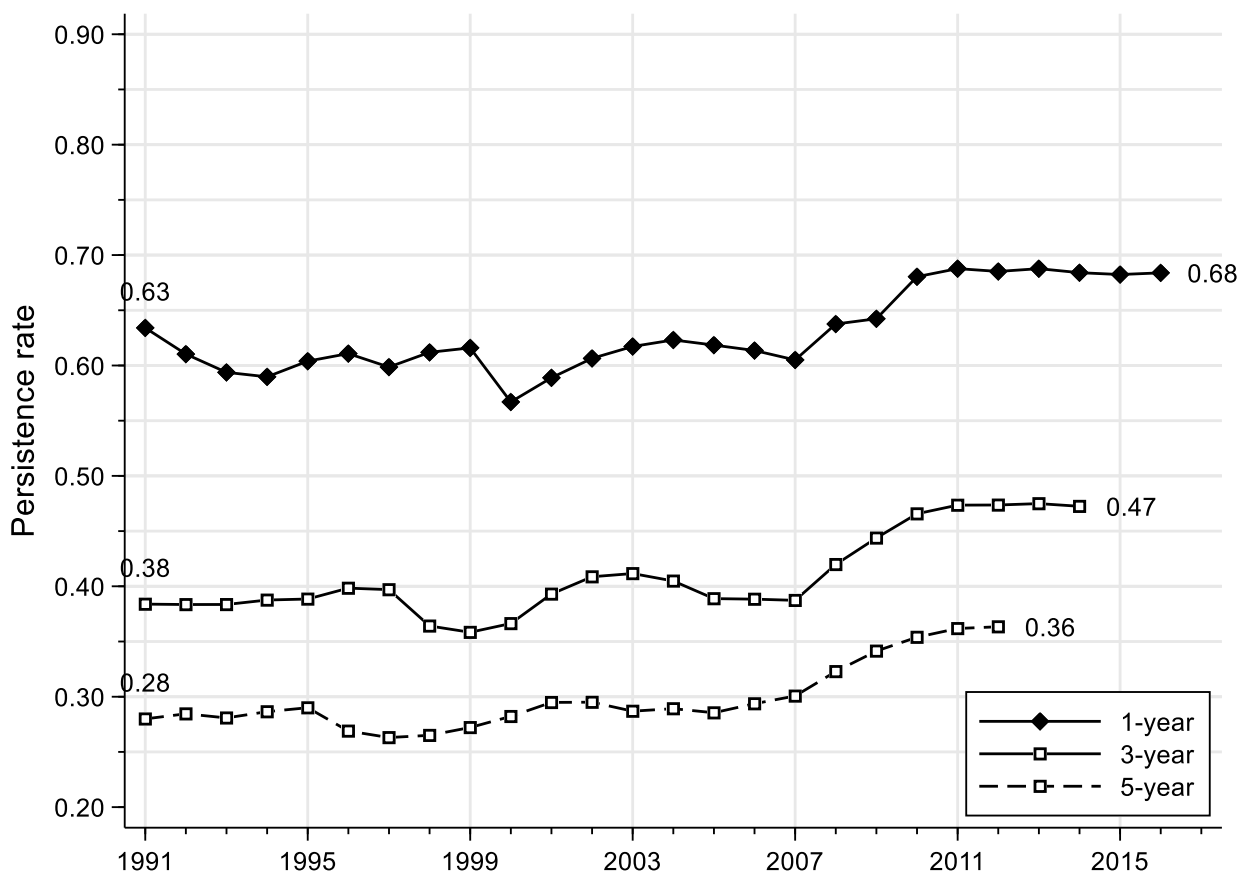

Notes: The persistence rate is the share of individuals in the top $1 \%$ in the base year who appear every year in top $1 \%$ between the base year and then in the subsequent 1,3 , and 5 years.

Stata figure persist5_Oto99_topl_net 
Figure D3. Persistence rate in the top 1\% income group for those aged 50 or under

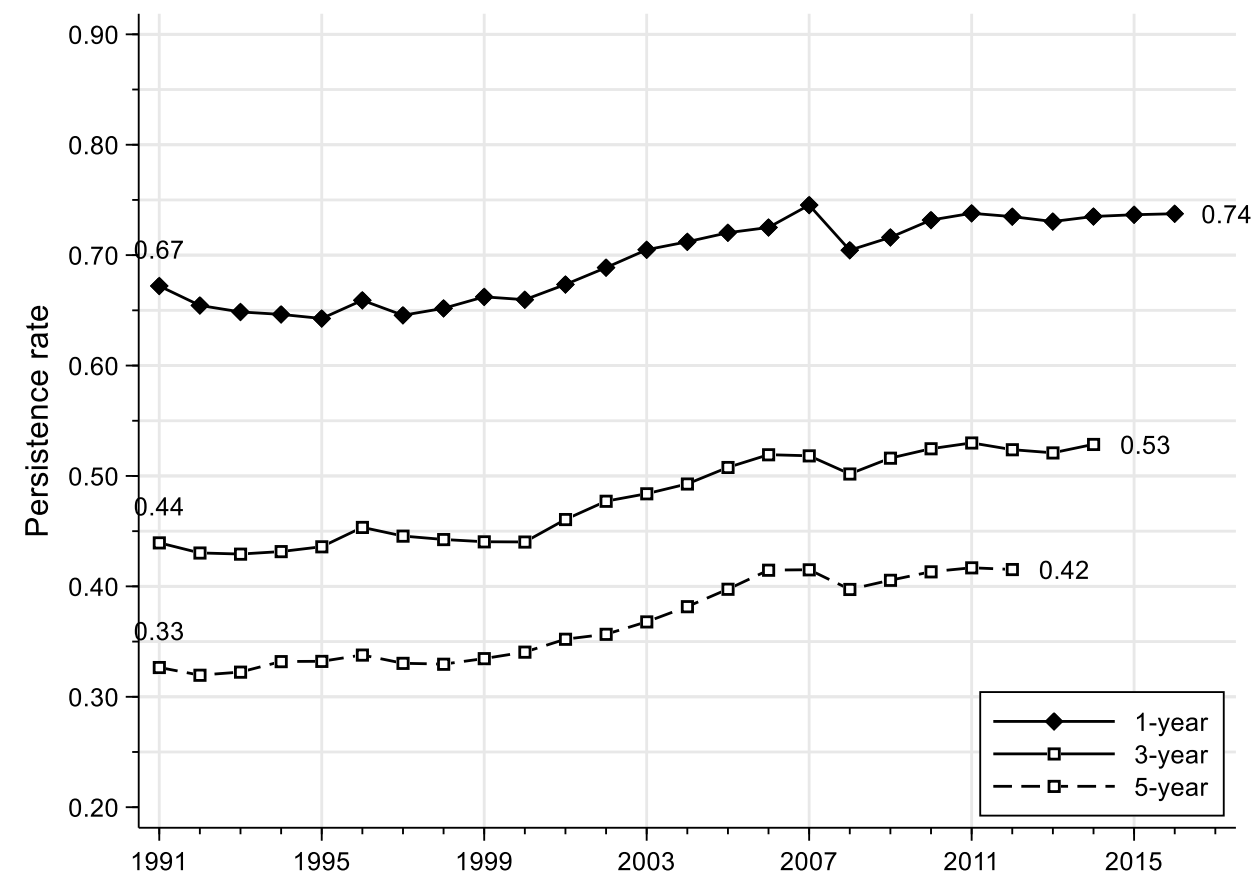

Notes: The persistence rate is the share of individuals aged 50 or under in the top $1 \%$ in the base year who appear every year in top $1 \%$ between the base year and then in the subsequent 1,3 , and 5 years.

Stata figure persist5_Oto50_top1_totinc_noKg

Figure D4. Persistence rate in the top $1 \%$ of labour income

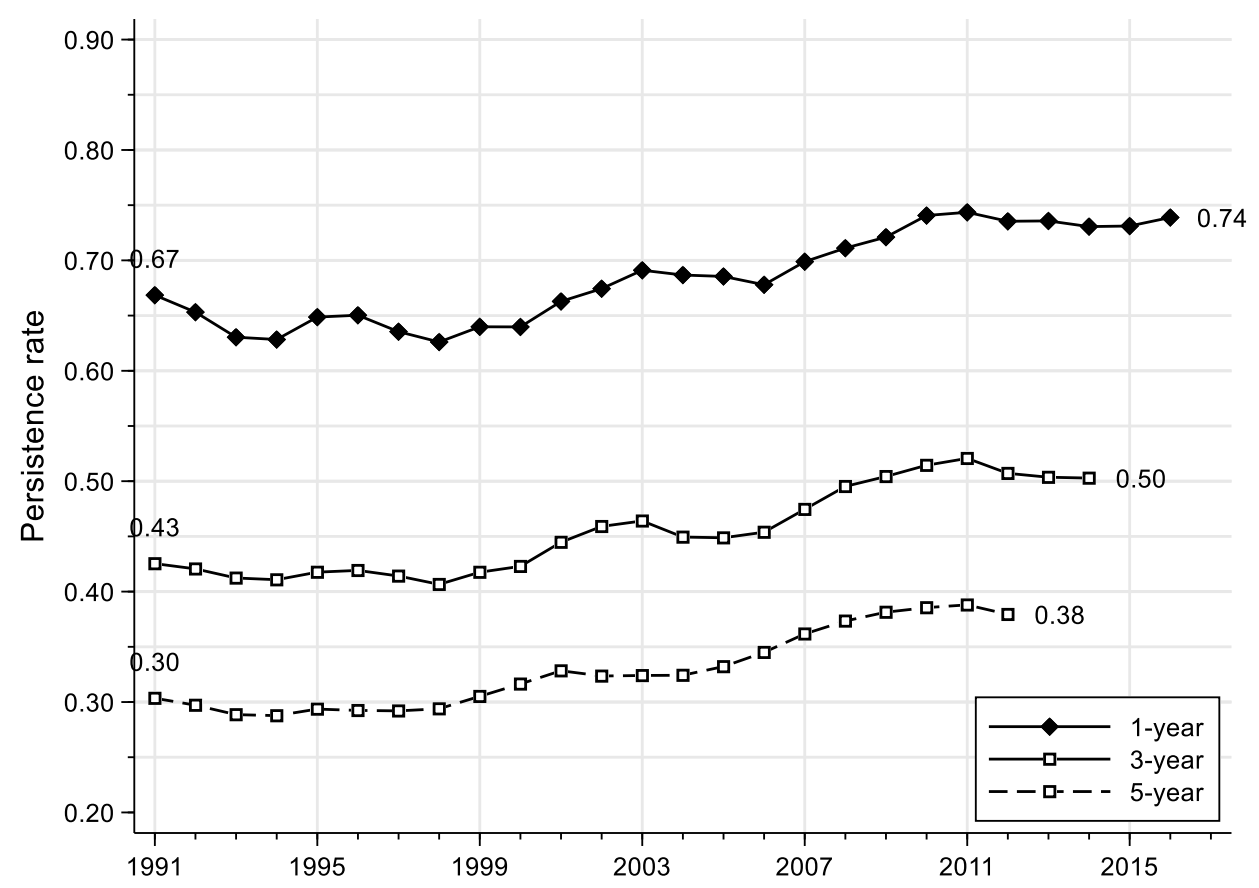

Notes: The persistence rate is the share of individuals in the top $1 \%$ in the base year who appear every year in top $1 \%$ between the base year and then in the subsequent 1,3 , and 5 years.

Stata figure persist5_Oto99_top1_labour 
Figure D5 Persistence rate in the top $1 \%$ of non-labour income

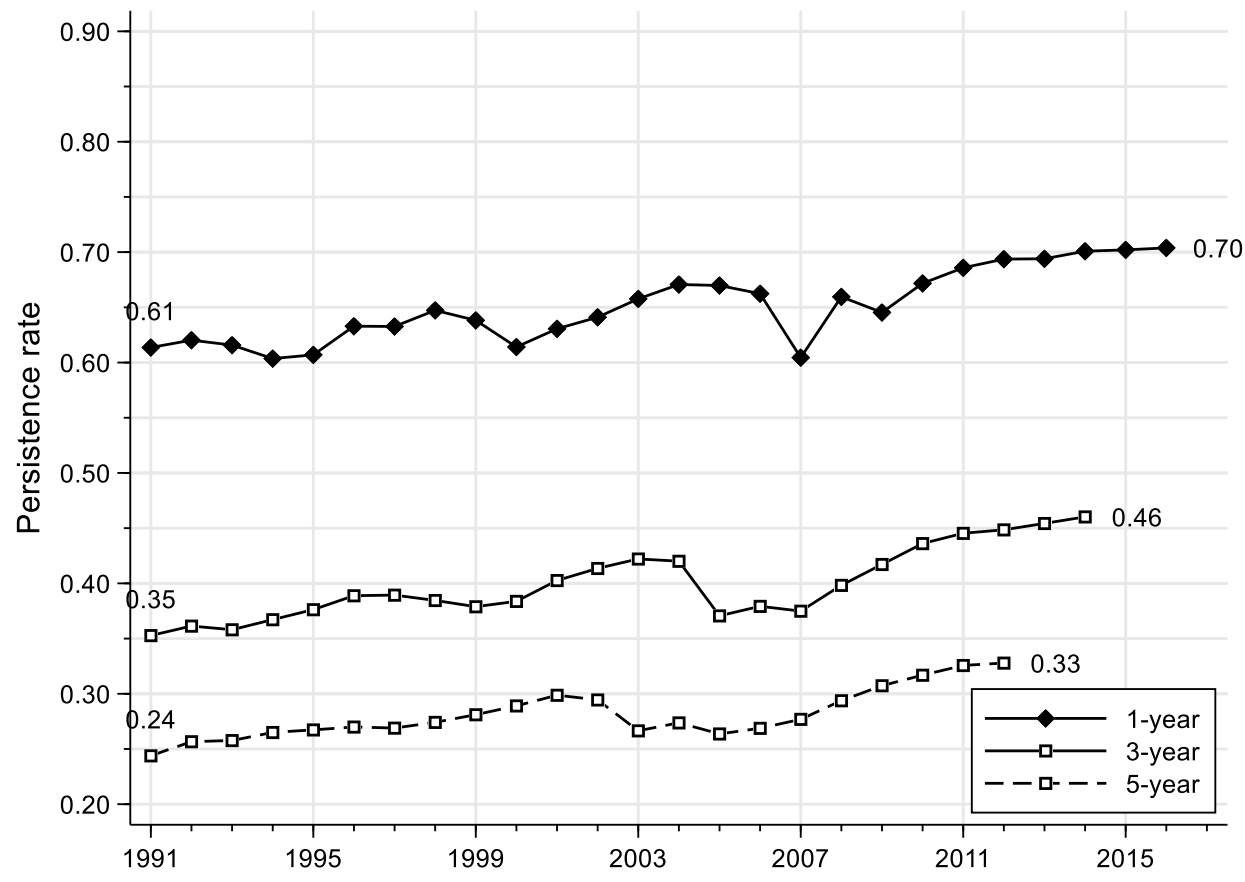

Notes: The persistence rate is the share of individuals in the top $1 \%$ in the base year who appear every year in top $1 \%$ between the base year and then in the subsequent 1,3 and 5 years.

Stata figure persist5_Oto99_top1_nonlabour 


\section{Appendix E. Top $0.1 \%$ results}

\section{Figure E1. Top 0.1\% income share}

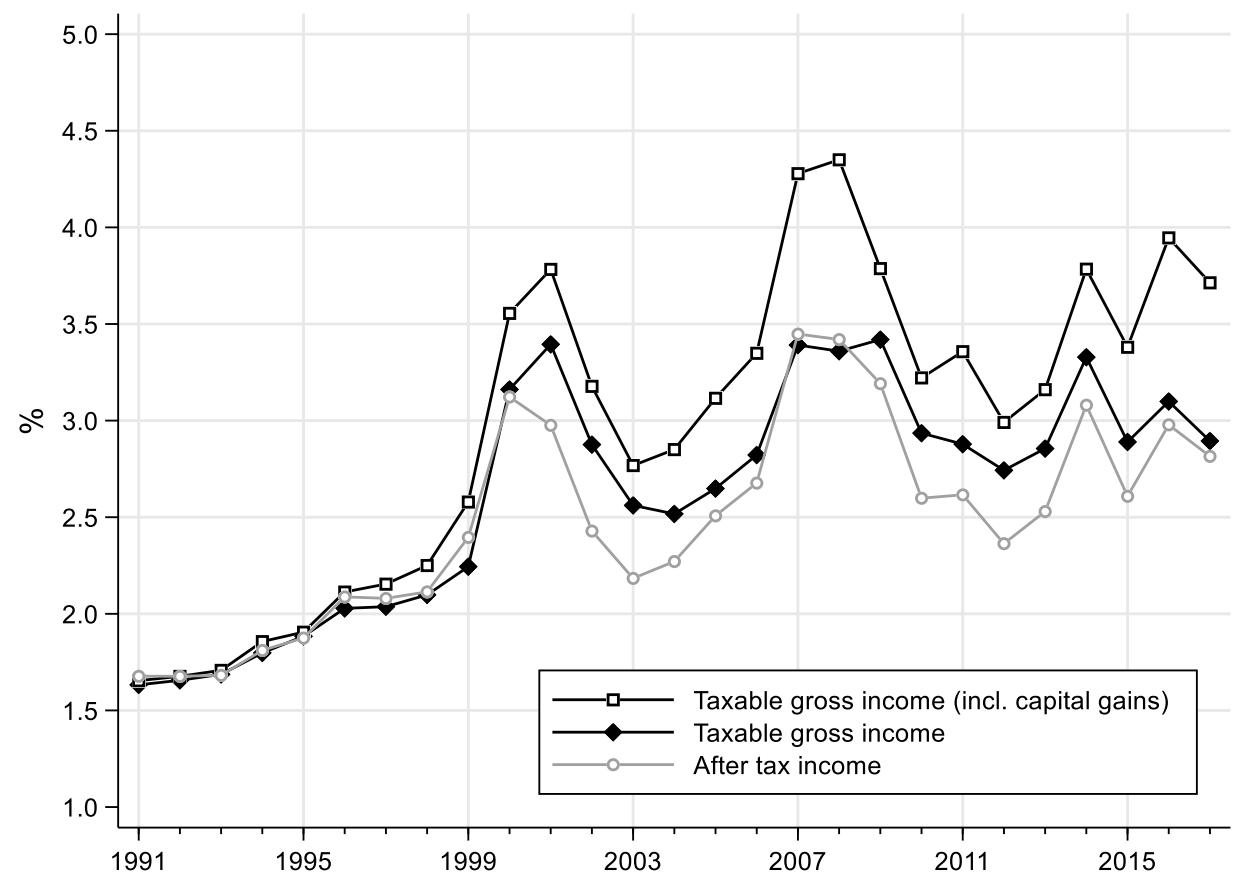

Notes: For after-tax income, the income control totals are reduced by the sum of all income tax collected according to ALife data. After-tax income includes realised capital gains, dividend imputation credits as well as other tax rebates and offsets.

Stata figure top01shc

Figure E2. Persistence rates in the top $0.1 \%$ income group

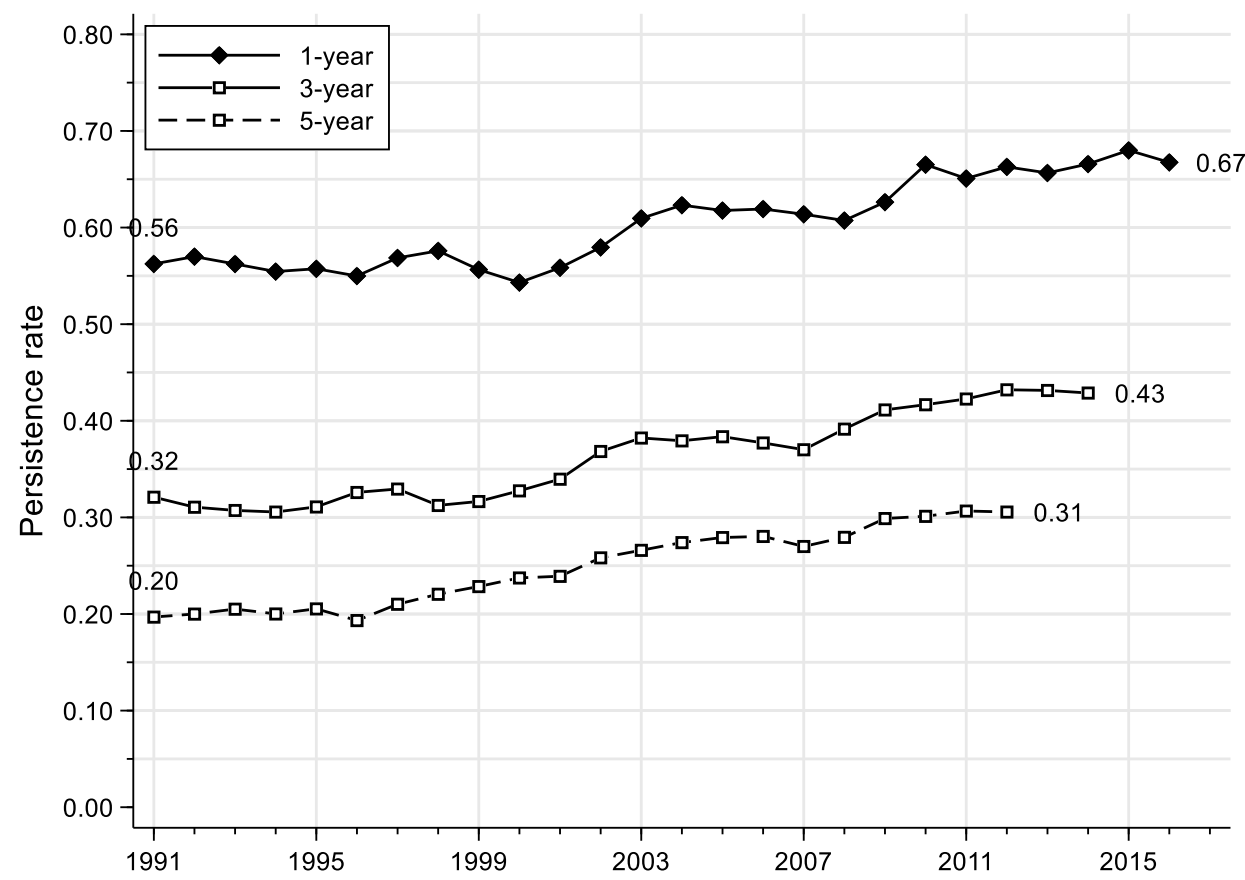

Notes: The persistence rate is the share of individuals in the top $0.1 \%$ in the base year who appear every year in top $0.1 \%$ between the base year and then in the subsequent 1,3 , and 5 years.

Stata figure persist5_Oto99_top01_totinc_noKg 
Figure E3. Probabilities of remaining in the top $0.1 \%$, by duration and top $0.1 \%$ entry cohort

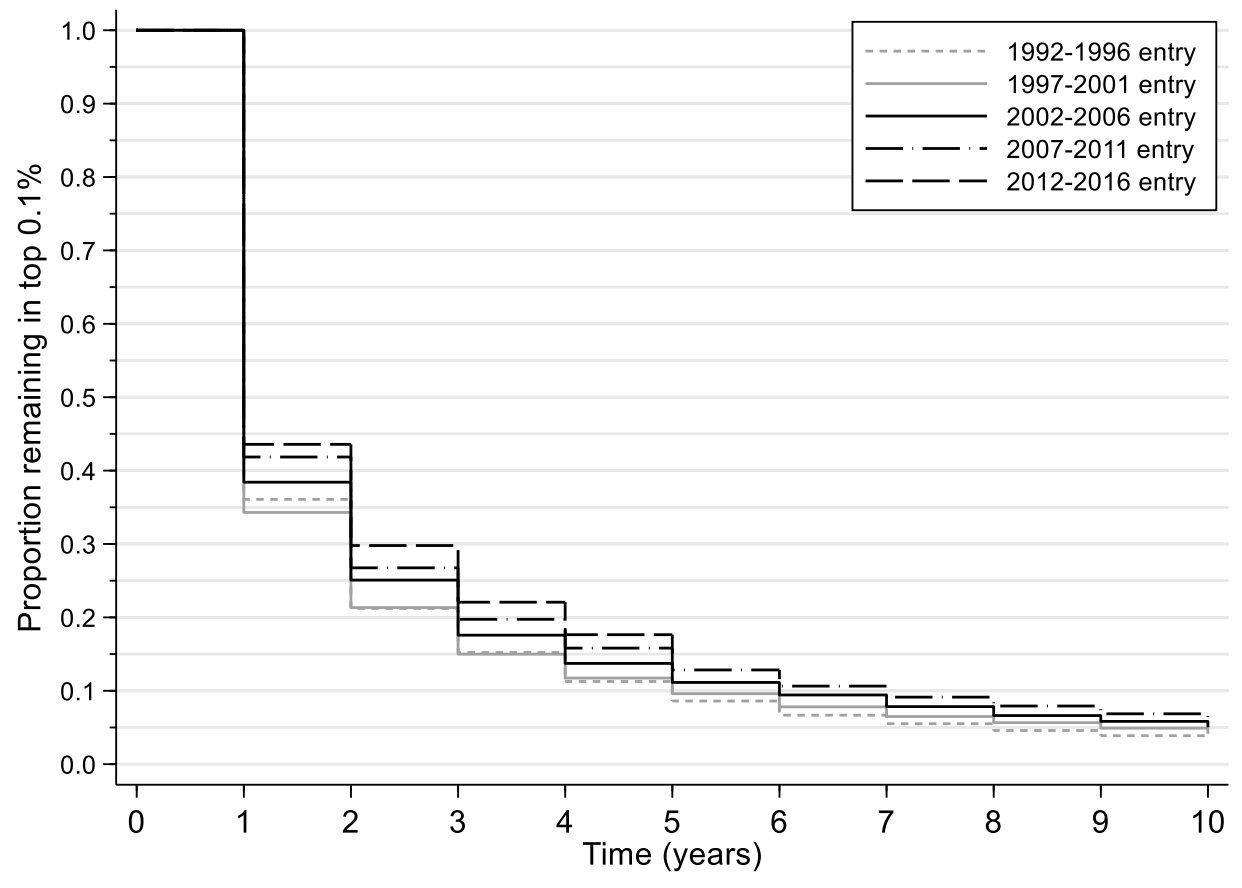

Stata figure Survival_byperiod_top01_totinc_noKg

Figure E4. Probabilities of remaining outside the top $0.1 \%$, by duration and top $0.1 \%$ exit cohort

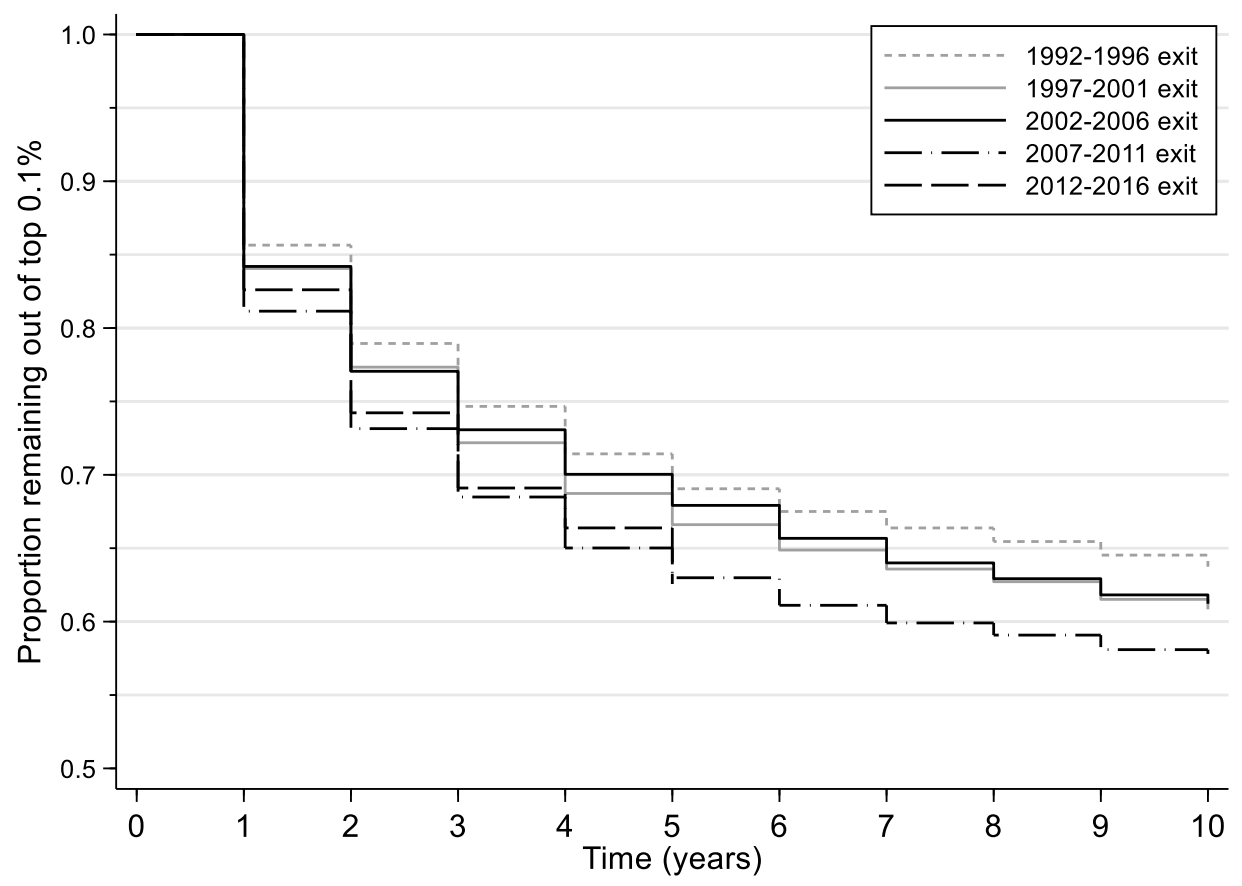

Statafigure Survival_reentry_byperiod_top01_totinc_noKg 
Figure E5. Three-year top $0.1 \%$ permanent and average yearly income shares

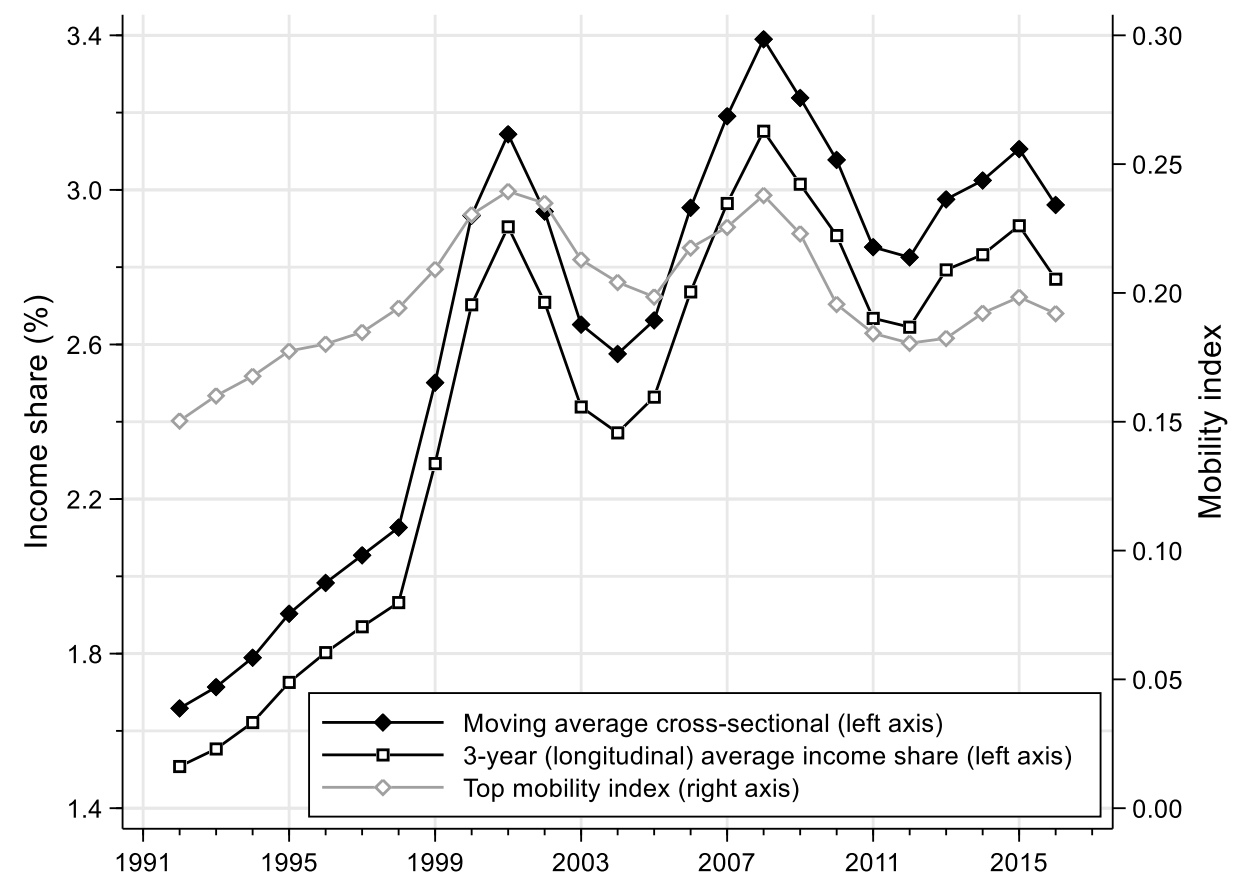

Notes: The $x$-axis labels refer to the middle year of the 3-year period.

Stata figure Perm_mov3top01sh_totinc_noKg

Figure E6. Five-year top $0.1 \%$ permanent and average yearly relative income shares

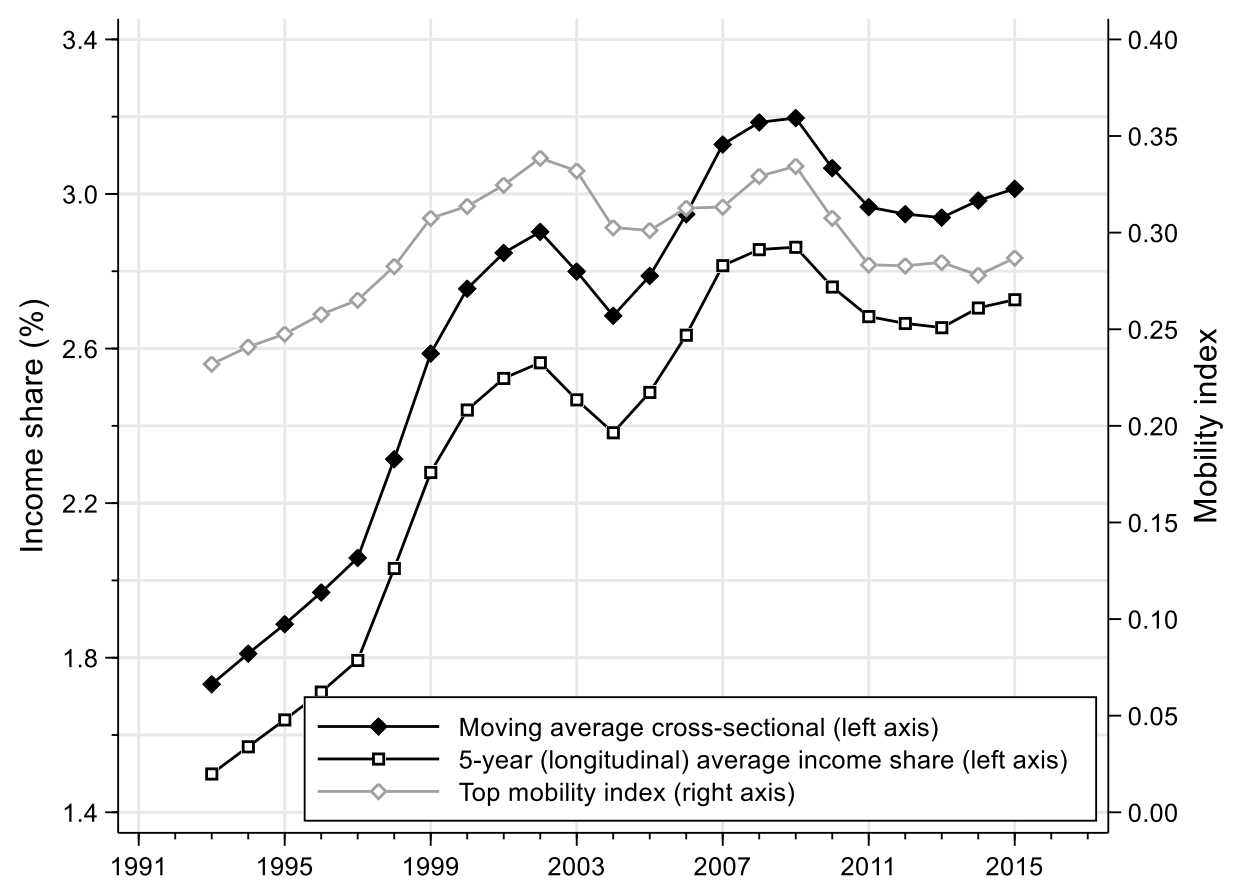

Notes: The $x$-axis labels refer to the middle year of the 5-year period.

Stata figure Perm_mov5top01sh_totinc_noKg 
Figure E7. Average yearly income changes for the top $0.1 \%$

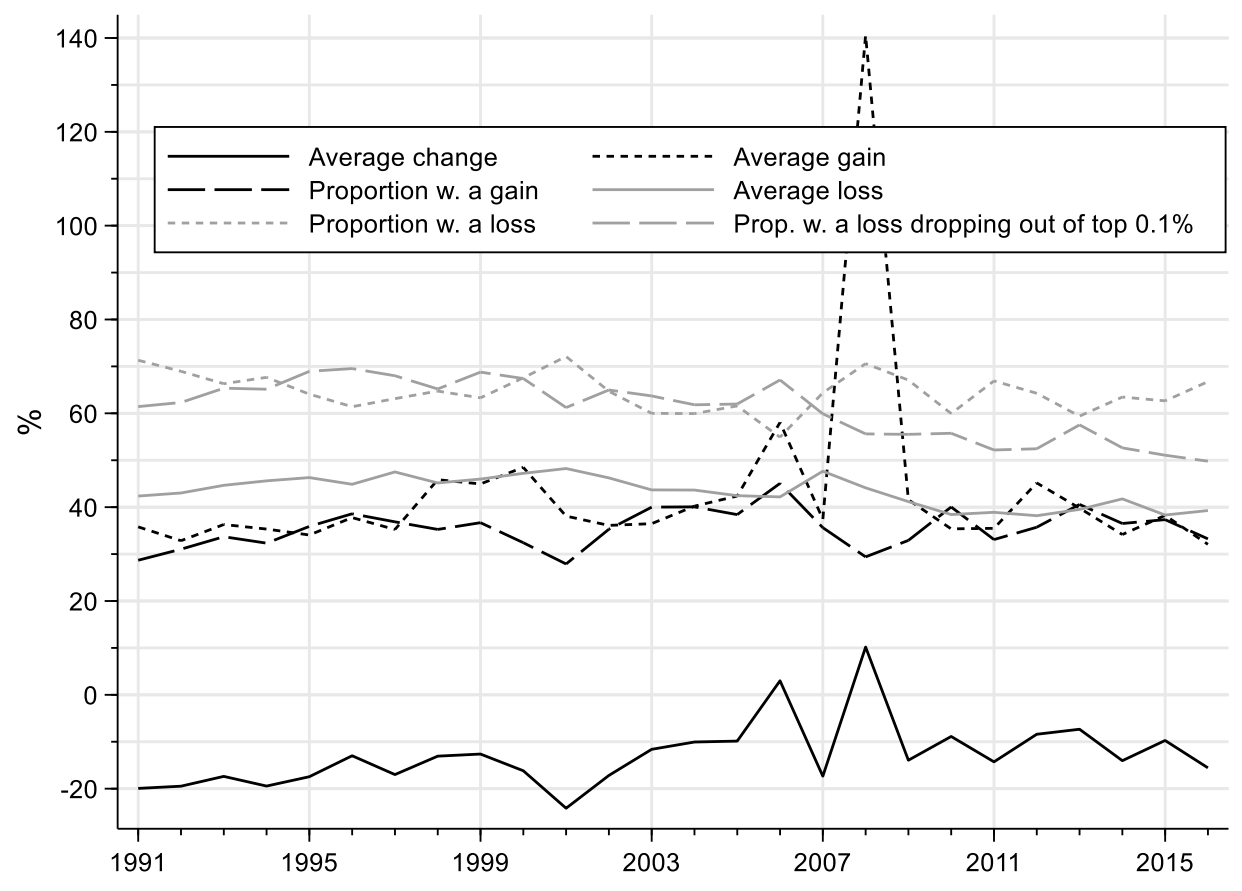

Stata figure avinc_changes_top01_totinc_noKg_b

Figure E8. Density estimates of the relative income distance to the $99.9^{\text {th }}$ income percentile for the top $0.1 \%$

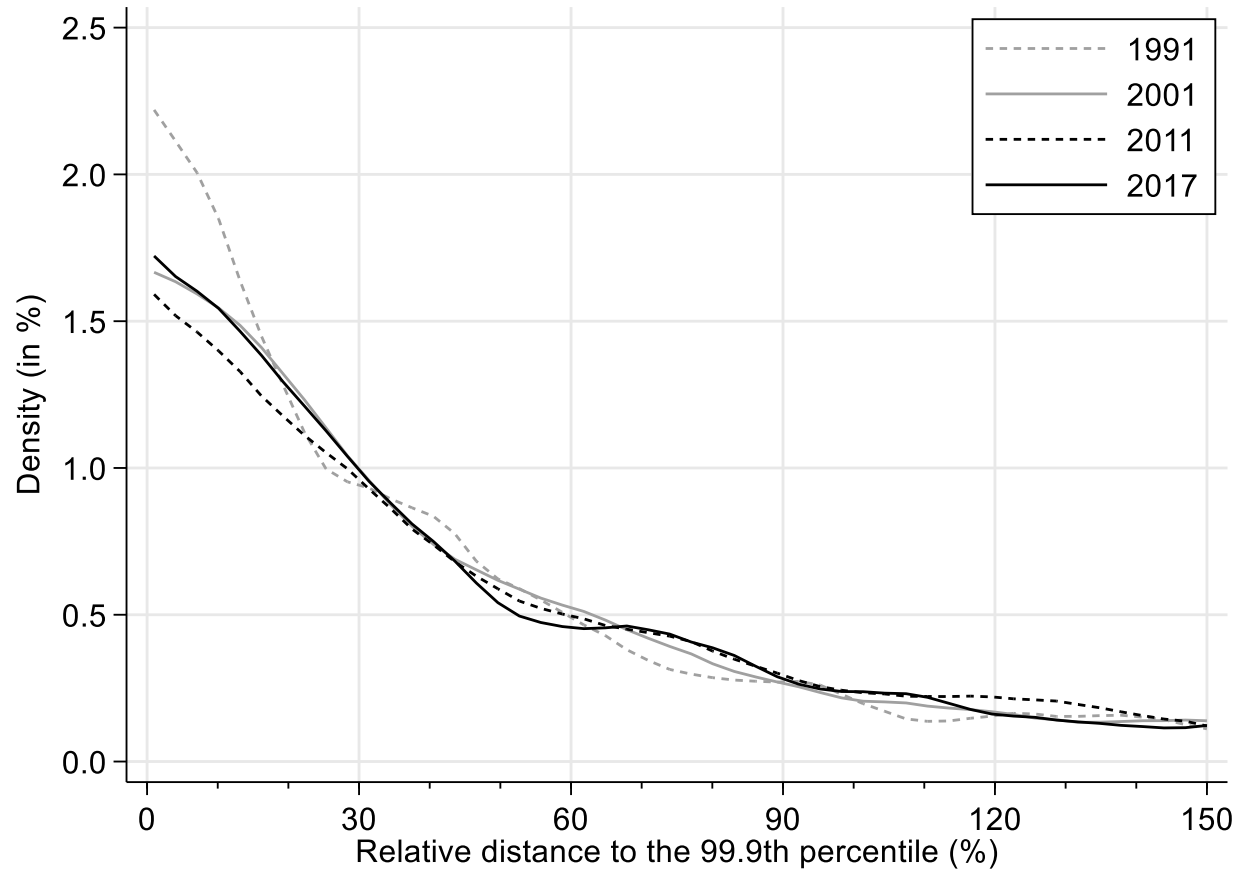

Notes: Kernel density estimates were calculated for the distribution of relative income distance to the $99.9^{\text {th }}$ income percentile, in per cent, using an Epanechnikov kernel and bandwidth of 1. The densities are truncated at incomes $150 \%$ above the $99.9^{\text {th }}$ percentile.

Stata figure discden_lpoly_top01_totinc_noKg 


\section{Appendix F. Top 10\% results}

\section{Figure F1. Top $10 \%$ income share}

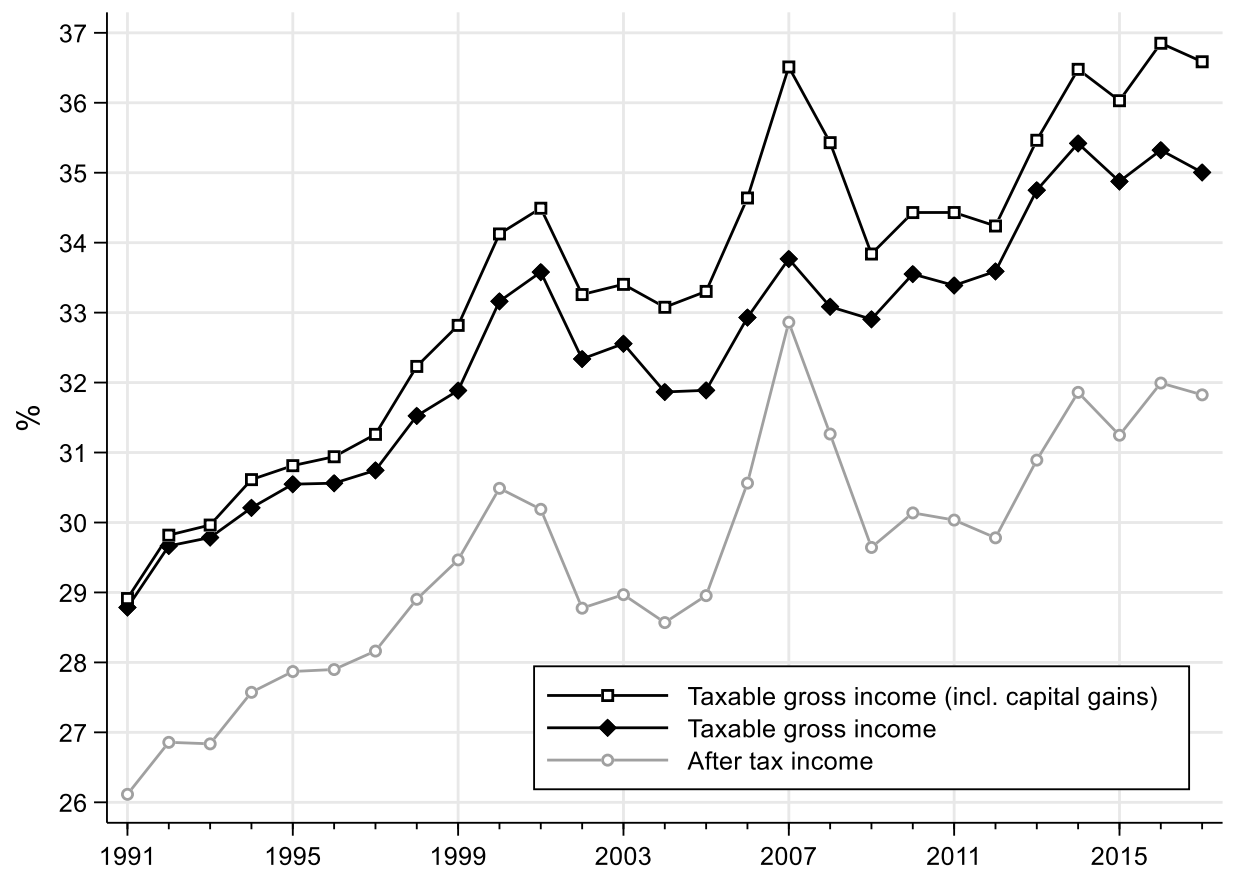

Notes: For after-tax income, the income control totals are reduced by the sum of all income tax collected according to ALife data. After-tax income includes realised capital gains, dividend imputation credits as well as other tax rebates and offsets. Source: Authors' calculations based on ALife data and ABS population estimates.

Stata figure top 10 shc

\section{Figure F2. Persistence rates in the top $10 \%$ income group}

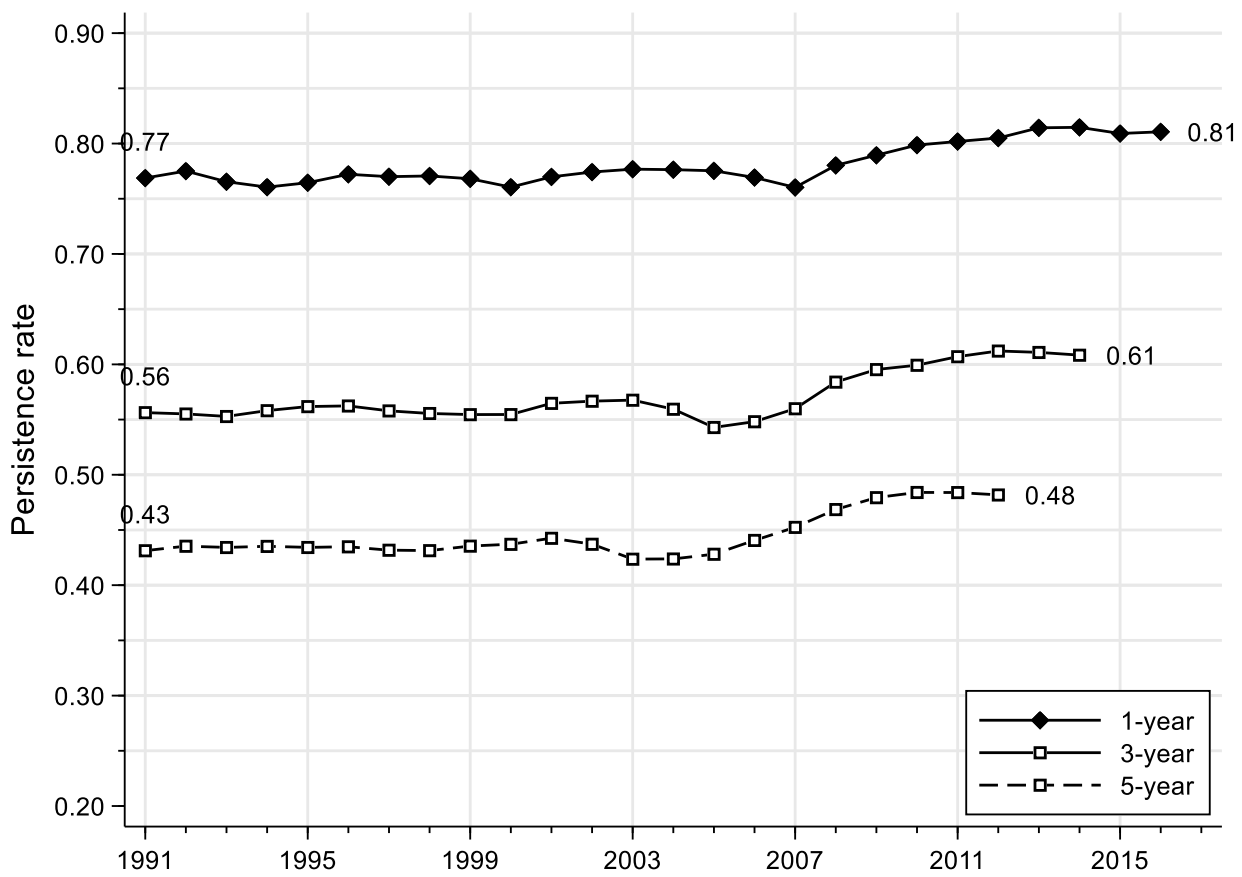

Notes: The persistence rate is the share of individuals in the top $10 \%$ in the base year who appear every year in top $10 \%$ between the base year and then in the subsequent 1,3 , and 5 years.

Stata figure persist5_Oto99_top10_totinc_noKg 
Figure F3. Probabilities of remaining in the top $10 \%$, by duration and top $10 \%$ entry cohort

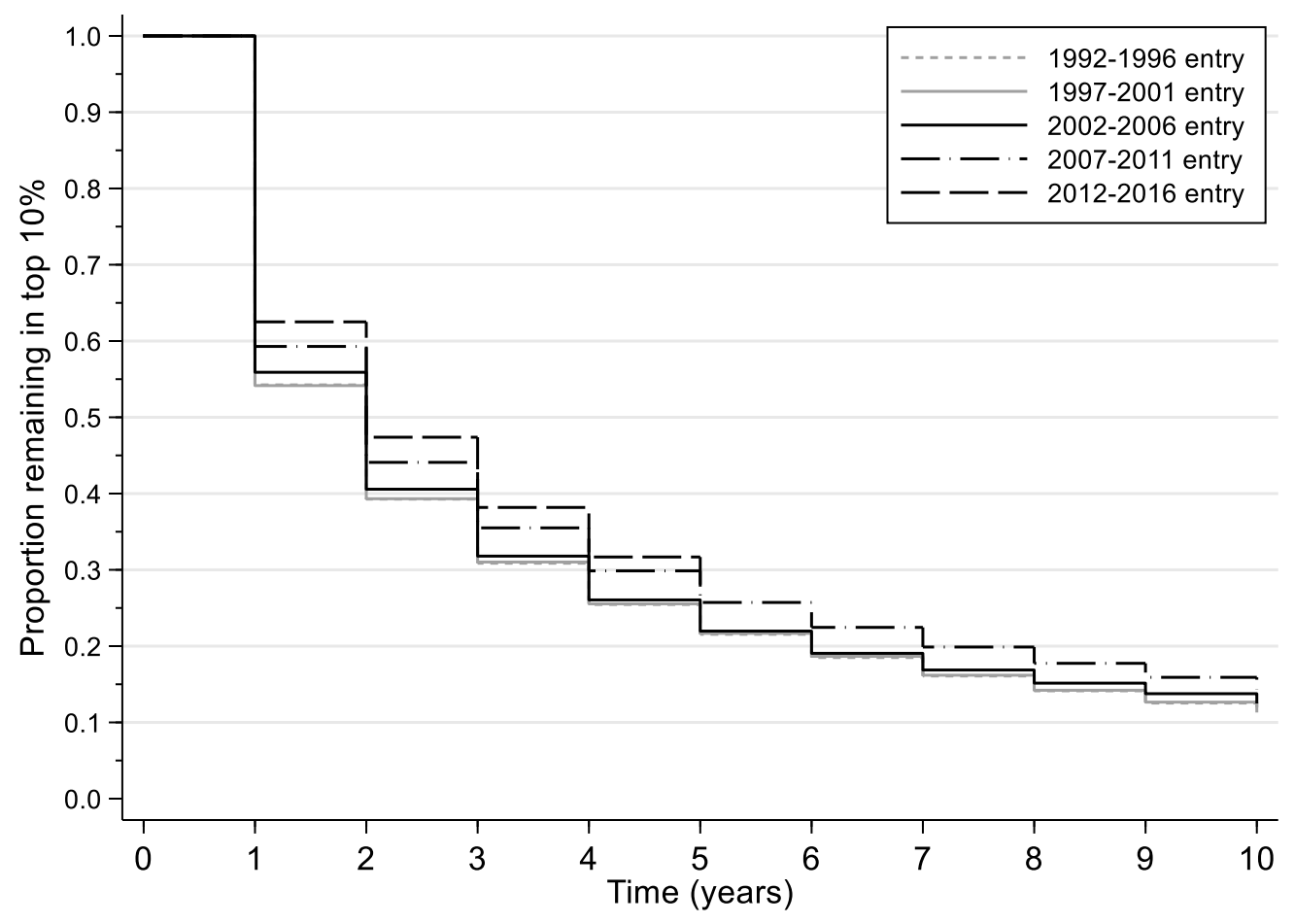

Stata figure Survival_byperiod_top10_totinc_noKg

Figure F4. Probabilities of remaining outside the top 1\%, by duration and top $10 \%$ exit cohort

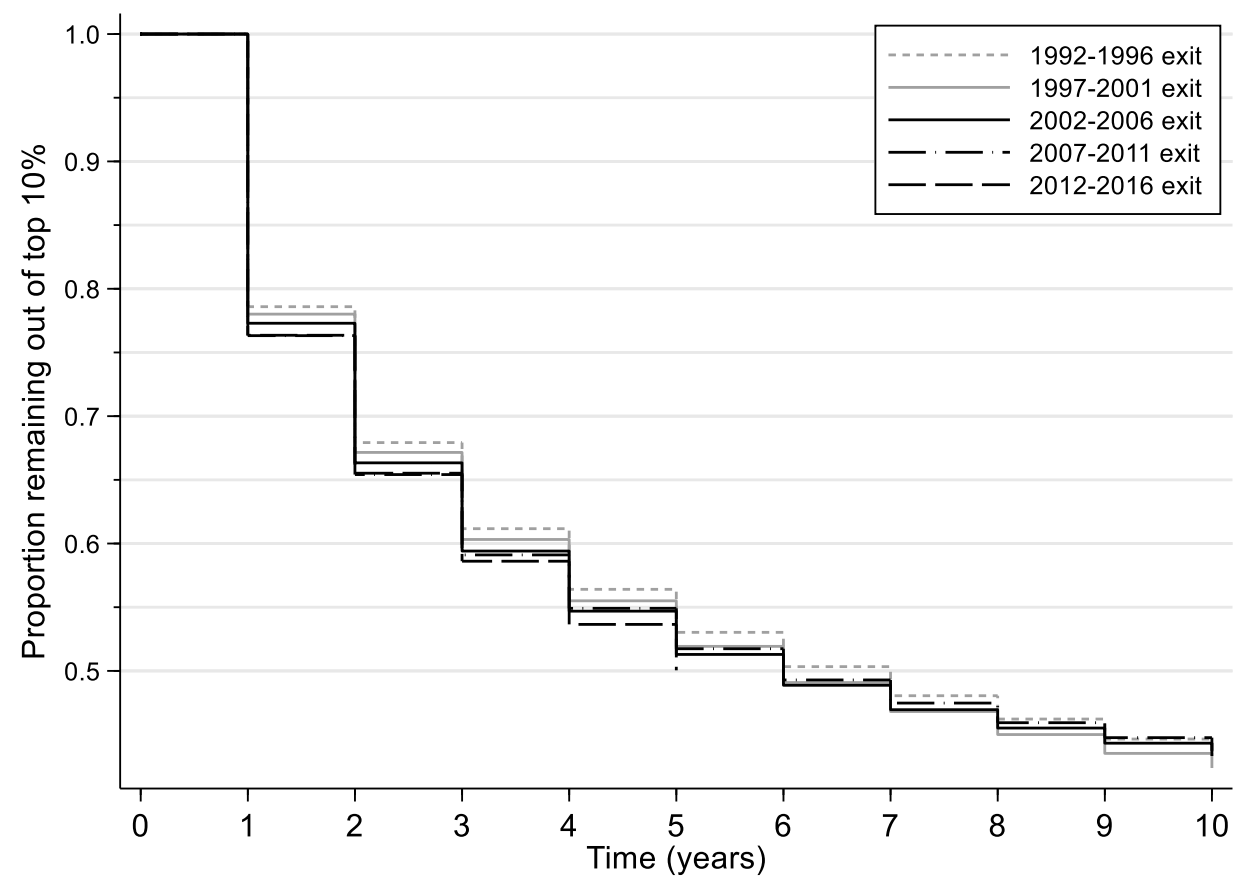

Statafigure Survival_reentry_byperiod_top10_totinc_noKg 
Figure F5. Three-year top $10 \%$ permanent and average yearly income shares

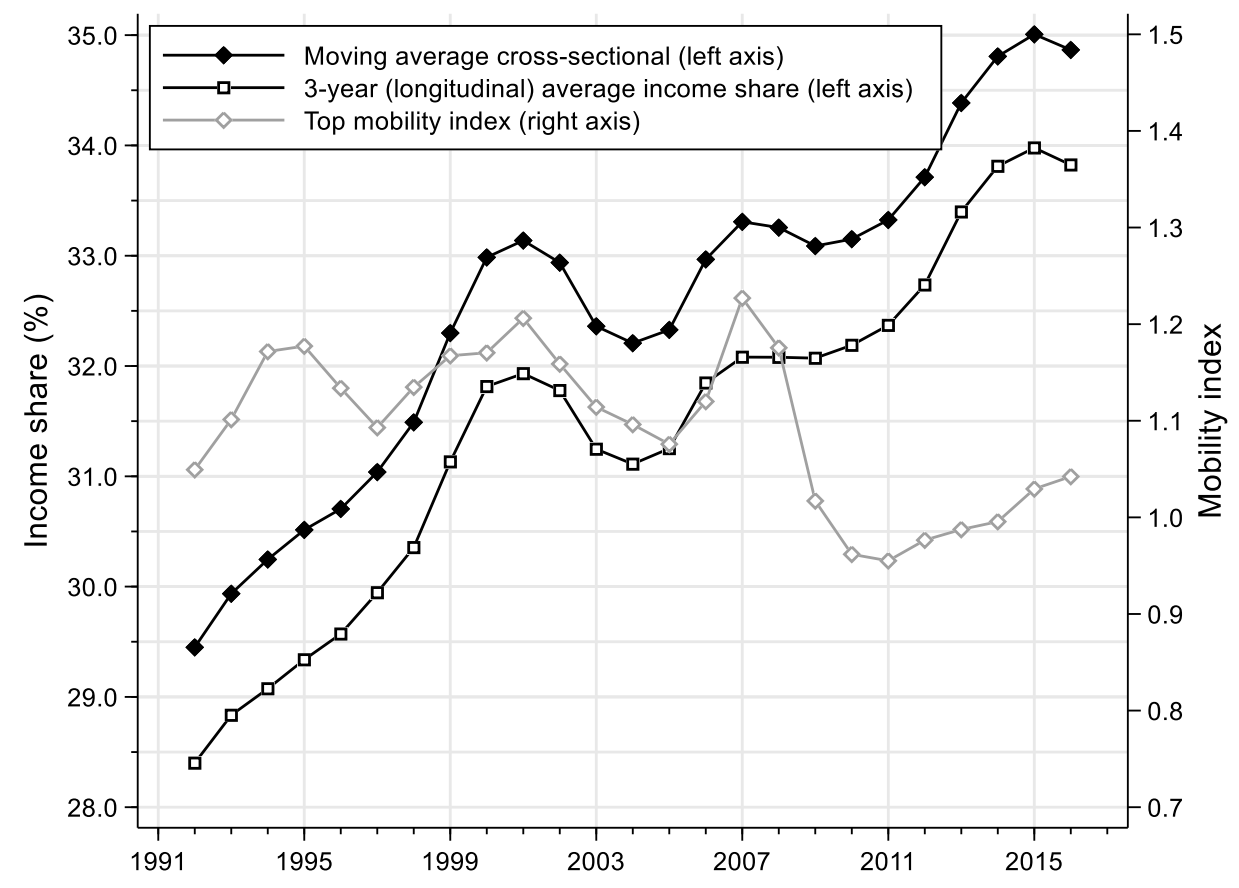

Notes: The $x$-axis labels refer to the middle year of the 3-year period.

Stata figure Perm_mov3top10sh_totinc_noKg

Figure F6. Five-year top $10 \%$ permanent and average yearly relative income shares

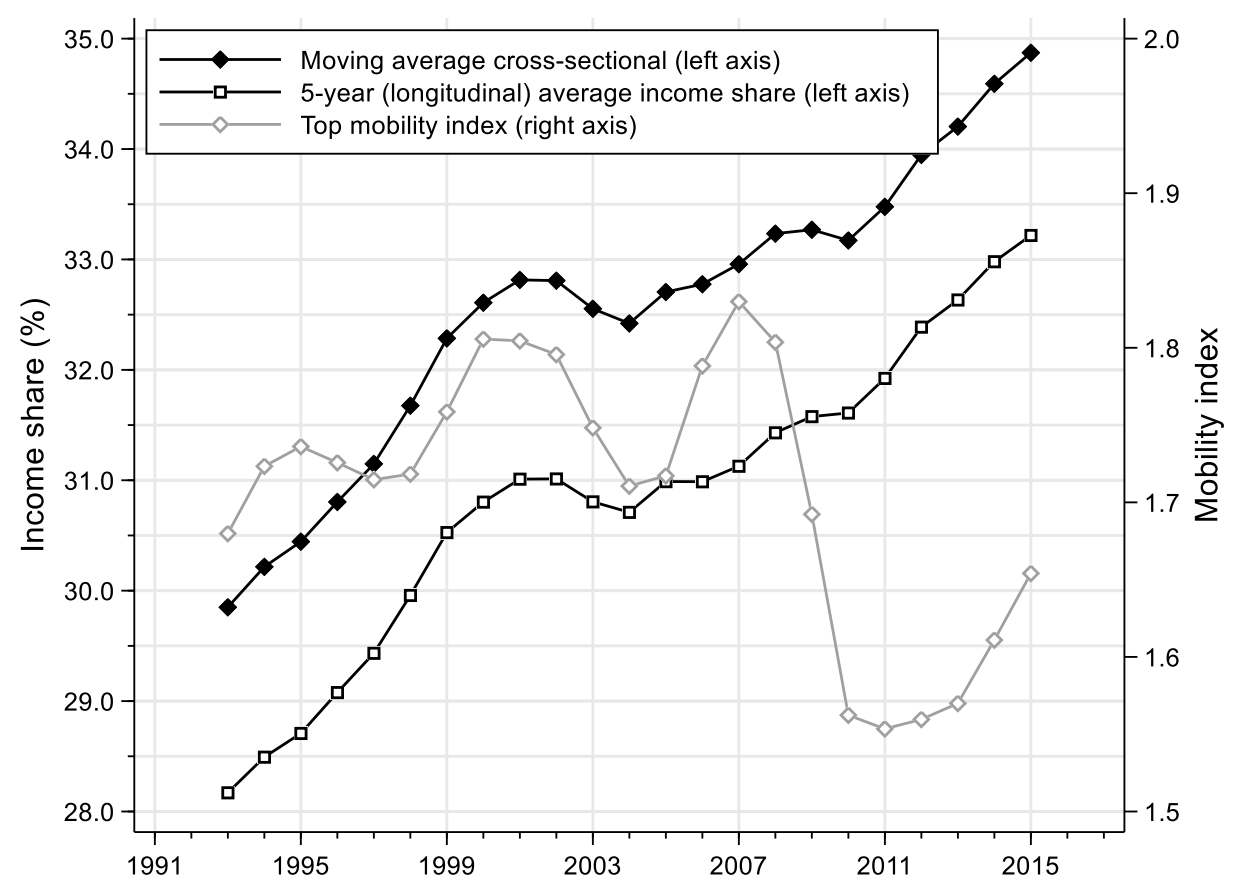

Notes: The $x$-axis labels refer to the middle year of the 5-year period.

Stata figure Perm_mov5top10sh_totinc_noKg 
Figure F7. Average yearly income changes for the top $10 \%$

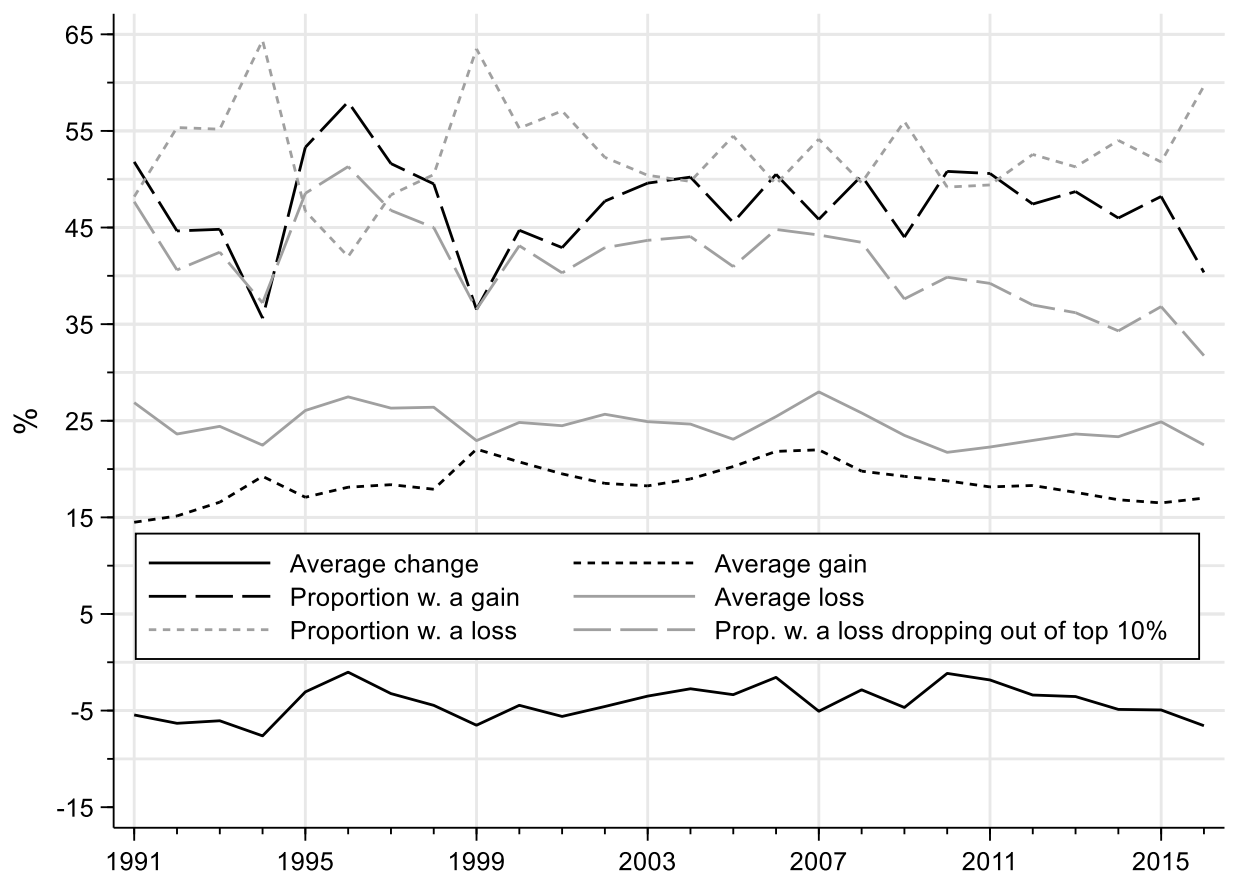

Stata figure avinc_changes_top10_totinc_noKg_b

Figure F8. Density estimates of the relative income distance to the $90^{\text {th }}$ income percentile for the top $10 \%$

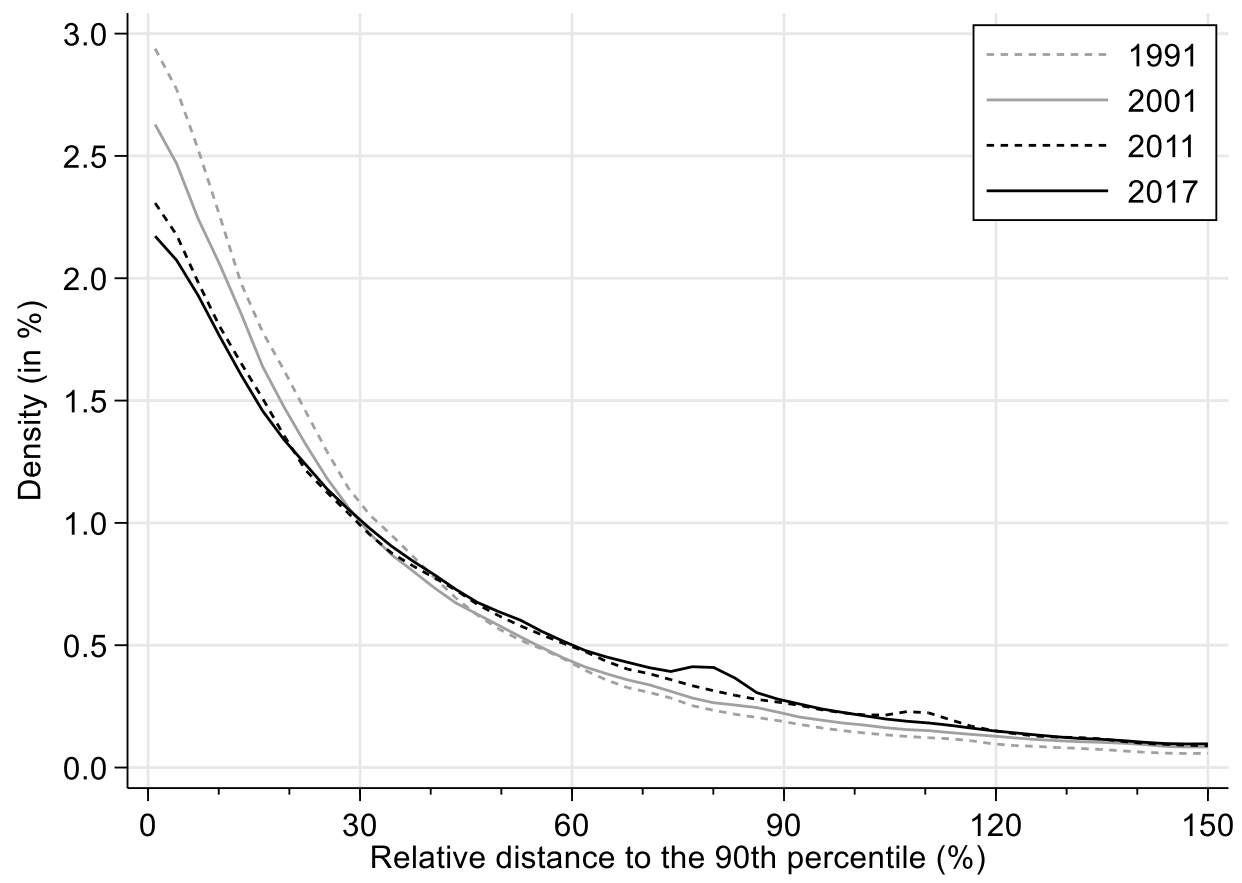

Notes: Kernel density estimates were calculated for the distribution of relative income distance to the $99.9^{\text {th }}$ income percentile, in per cent, using an Epanechnikov kernel and bandwidth of 1. The densities are truncated at incomes $150 \%$ above the $99.9^{\text {th }}$ percentile.

Stata figure discden_lpoly_top10_totinc_noKg 